\title{
Planeación estratágégica territorial urbana en el estado de Guanajuato
}

\section{MORA-ZIZUMBO, Martín BONALES-YALENCIA, Joel}

ORTÍz-PANIAGUA, Carlos Francisco 


\section{ECORFAN-México}

\section{Coordinador}

MORA-ZIZUMBO, Martín

BONALES-VALENCIA, Joel

ORTÍZ-PANIAGUA, Carlos Francisco

Editor en Jefe

VARGAS-DELGADO, Oscar. PhD

\section{Directora Ejecutiva}

RAMOS-ESCAMILLA, María. PhD

\section{Director Editorial}

PERALTA-CASTRO, Enrique. MsC

Diseñador Web

ESCAMILLA-BOUCHAN, Imelda. PhD

\section{Diagramador Web}

LUNA-SOTO, Vladimir. PhD

\section{Asistente Editorial}

TREJO-RAMOS, Iván. BsC

\section{Traductor}

DÍAZ-OCAMPO, Javier. BsC

\section{Filóloga}

RAMOS-ARANCIBIA, Alejandra. BsC
Planeación estratégica territorial urbana en el estado de Guanajuato

Ninguna parte de este escrito amparado por la Ley de Derechos de Autor, podrá ser reproducida, transmitida o utilizada en cualquier forma o medio, ya sea gráfico, electrónico o mecánico, incluyendo, pero sin limitarse a lo siguiente: Citas en artículos y comentarios bibliográficos, de compilación de datos periodísticos radiofónicos o electrónicos. Visite nuestro sitio WEB en: www.ecorfan.org

Primera edición ISBN: 978-607-8695-37-9

Sello Editorial ECORFAN: 607-8695

Número de Control B: 2020-04

Clasificación B (2020): 291020-0401

A los efectos de los artículos 13, 162, 163 fracción I, 164 fracción I, 168, 169,209, y otra fracción aplicable III de la Ley del Derecho de Autor. 


\section{Books}

\section{Definición de Books}

\section{Objetivos Científicos}

Apoyar a la Comunidad Científica Internacional en su producción escrita de Ciencia, Tecnología en Innovación en las Áreas de investigación CONACYT y PRODEP.

ECORFAN-Mexico S.C es una Empresa Científica y Tecnológica en aporte a la formación del Recurso Humano enfocado a la continuidad en el análisis crítico de Investigación Internacional y está adscrita al RENIECYT de CONACYT con número 1702902, su compromiso es difundir las investigaciones y aportaciones de la Comunidad Científica Internacional, de instituciones académicas, organismos y entidades de los sectores público y privado y contribuir a la vinculación de los investigadores que realizan actividades científicas, desarrollos tecnológicos y de formación de recursos humanos especializados con los gobiernos, empresas y organizaciones sociales.

Alentar la interlocución de la Comunidad Científica Internacional con otros centros de estudio de México y del exterior y promover una amplia incorporación de académicos, especialistas e investigadores a la publicación Seriada en Nichos de Ciencia de Universidades Autónomas Universidades Públicas Estatales - IES Federales - Universidades Politécnicas - Universidades Tecnológicas - Institutos Tecnológicos Federales - Escuelas Normales - Institutos Tecnológicos Descentralizados - Universidades Interculturales - Consejos de CyT - Centros de Investigación CONACYT.

\section{Alcances, Cobertura y Audiencia}

Books es un Producto editado por ECORFAN-Mexico S.C en su Holding con repositorio en México, es una publicación científica arbitrada e indizada. Admite una amplia gama de contenidos que son evaluados por pares académicos por el método de Doble-Ciego, en torno a temas relacionados con la teoría y práctica de las Área de investigación CONACYT y PRODEP respectivamente con enfoques y perspectivas diversos, que contribuyan a la difusión del desarrollo de la Ciencia la Tecnología e Innovación que permitan las argumentaciones relacionadas con la toma de decisiones e incidir en la formulación de las políticas internacionales en el Campo de las Ciencias. El horizonte editorial de ECORFAN-Mexico® se extiende más allá de la academia e integra otros segmentos de investigación y análisis ajenos a ese ámbito, siempre y cuando cumplan con los requisitos de rigor argumentativo y científico, además de abordar temas de interés general y actual de la Sociedad Científica Internacional. 


\section{Comité Editorial}

CAMPOS - QUIROGA, Peter. PhD

Universidad Real y Pontifica de San Francisco Xavier de Chuquisaca

NIÑO - GUTIÉRREZ, Naú Silverio. PhD

Universidad de Alicante

ARANCIBIA - VALVERDE, María Elena. PhD

Universidad San Francisco Xavier de Chuquisaca

TORRES - HERRERA, Moisés. PhD

Universidad Autónoma de Barcelona

FRANZONI - VELAZQUEZ, Ana Lidia. PhD

Institut National des Telécommunications

ROSILLO-MARTÍNEZ, Alejandro. PhD

Universidad Carlos III de Madrid

CHAPARRO, Germán Raúl. PhD

Universidad Nacional de Colombia

CUBÍAS-MEDINA, Ana Elizabeth. PhD

Universidad Carlos III de Madrid

POSADA - GÓMEZ, Rubén. PhD

Institut National Polytechnique de la Lorraine

RAMÍREZ - MARTÍNEZ, Ivonne Fabiana. PhD

Universidad Andina Simón Bolívar 


\section{Comité Arbitral}

MORENO - ELIZALDE, María Leticia. PhD

Instituto Universitario Anglo Español

SALAZAR - VÁZQUEZ - Fernando Adolfo. PhD

Instituto Universitario Internacional de Toluca

SÁNCHEZ - VÁZQUEZ, Elizabeth. PhD

Universidad Politécnica del Valle de México

SANTILLÁN - NÚÑEZ, María Aída. PhD

Escuela Normal de Sinaloa

SESENTO - GARCÍA, Leticia. PhD

Universidad Michoacana de San Nicolás de Hidalgo

TAVERA - CORTÉS, María Elena. PhD

Colegio de Postgraduados

TORRALBA - FLORES, Amado. PhD

Benemérita Universidad Autónoma de Puebla

TREJO - GARCÍA, José Carlos. PhD

Instituto Politécnico Nacional

VARGAS - SANCHEZ, Gustavo. PhD

Universidad Autónoma Metropolitana

VELASCO - CEPEDA, Raquel Ivonne. PhD

Instituto Tecnológico de Sonora

VELÁSQUEZ - SÁNCHEZ, Rosa María. PhD

Universidad Autónoma "Benito Juárez" de Oaxaca 


\section{Cesión de Derechos}

El envío de una Obra Científica a ECORFAN Books emana el compromiso del autor de no someterlo de manera simultánea a la consideración de otras publicaciones científicas para ello deberá complementar el Formato de Originalidad para su Obra Científica.

Los autores firman el Formato de Autorización para que su Obra Científica se difunda por los medios que ECORFAN-México, S.C. en su Holding México considere pertinentes para divulgación y difusión de su Obra Científica cediendo sus Derechos de Obra Científica.

\section{Declaración de Autoría}

Indicar el Nombre de 1 Autor y 3 Coautores como máximo en la participación de la Obra Científica y señalar en extenso la Afiliación Institucional indicando la Dependencia.

Identificar el Nombre de 1 Autor y 3 Coautores como máximo con el Número de CVU Becario-PNPC o SNI-CONACYT- Indicando el Nivel de Investigador y su Perfil de Google Scholar para verificar su nivel de Citación e índice $\mathrm{H}$.

Identificar el Nombre de 1 Autor y 3 Coautores como máximo en los Perfiles de Ciencia y Tecnología ampliamente aceptados por la Comunidad Científica Internacional ORC ID - Researcher ID Thomson arXiv Author ID - PubMed Author ID - Open ID respectivamente.

Indicar el contacto para correspondencia al Autor (Correo y Teléfono) e indicar al Investigador que contribuye como primer Autor de la Obra Científica.

\section{Detección de Plagio}

Todas las Obras Científicas serán testeadas por el software de plagio PLAGSCAN si se detecta un nivel de plagio Positivo no se mandará a arbitraje y se rescindirá de la recepción de la Obra Científica notificando a los Autores responsables, reivindicando que el plagio académico está tipificado como delito en el Código Penal.

\section{Proceso de Arbitraje}

Todas las Obras Científicas se evaluarán por pares académicos por el método de Doble Ciego, el arbitraje Aprobatorio es un requisito para que el Consejo Editorial tome una decisión final que será inapelable en todos los casos. MARVID® es una Marca de derivada de ECORFAN® especializada en proveer a los expertos evaluadores todos ellos con grado de Doctorado y distinción de Investigadores Internacionales en los respectivos Consejos de Ciencia y Tecnología el homólogo de CONACYT para los capítulos de América-Europa-Asia-África y Oceanía. La identificación de la autoría deberá aparecer únicamente en una primera página eliminable, con el objeto de asegurar que el proceso de Arbitraje sea anónimo y cubra las siguientes etapas: Identificación del ECORFAN Books con su tasa de ocupamiento autoral - Identificación del Autores y Coautores - Detección de Plagio PLAGSCAN Revisión de Formatos de Autorización y Originalidad - Asignación al Consejo Editorial - Asignación del par de Árbitros Expertos - Notificación de Dictamen - Declaratoria de Observaciones al Autor Cotejo de la Obra Científica Modificado para Edición - Publicación. 


\section{Planeación estratégica territorial urbana en el estado de Guanajuato}

\section{Urban territorial strategic planning in Guanajuato state}

MORA-ZIZUMBO, Martín, BONALES-VALENCIA, Joel, ORTÍZ-PANIAGUA, Carlos Francisco

Universidad Michoacana de San Nicolás de Hidalgo, México.

ID $1^{\text {er }}$ Autor: Martín, Mora-Zizumbo / ORC ID: 0000-0002-9583-9970, Researcher ID Thomson: AAX-5112-2020, SNI CONACYT ID: 746153

ID $1^{\text {er }}$ Coautor: Joel, Bonales-Valencia / ORC ID: 0000-0003-1492-9614, Researcher ID Thomson: Q-5336-2016, arXiv ID: jbonales, SNI CONACYT ID: 26054

ID $2^{\text {do }}$ Coautor: Carlos Francisco, Ortíz-Paniagua / ORC ID: 0000-0003-3645-1527, Researcher ID Thomson: Q-12352018, SNI CONACYT ID: 48497

DOI: $10.35429 /$ B.2020.4.1.98 


\section{Planeación estratégica territorial urbana en el estado de Guanajuato}

El Book ofrecerá contribuciones seleccionadas de investigadores que contribuyan a la actividad de difusión científica de la Universidad Michoacana de San Nicolás de Hidalgo para su área de investigación en la función de la Universidad ante los retos de las Sociedad de Conocimiento. Además de tener una evaluación total, en las manos de los directores de la Universidad Michoacana de San Nicolás de Hidalgo se colabora con calidad y puntualidad en sus capítulos, cada contribución individual fue arbitrada a estándares internacionales (RESEARCH GATE, MENDELEY, GOOGLE SCHOLAR y REDIB), el Book propone así a la comunidad académica, los informes recientes sobre los nuevos progresos en las áreas más interesantes y prometedoras de investigación en la función de la Universidad ante los retos de las Sociedad de Conocimiento. 


\section{Contenido}

$\begin{array}{ll}\text { Resumen } & 1\end{array}$

$\begin{array}{ll}\text { Abstract } & 1\end{array}$

Capítulo I Introducción metodológica a los estudios de planeación territorial 4

Capítulo II Marco teórico y conceptual de la planeación territorial 20

Capítulo III Planeación estratégica territorial en el estado de Guanajuato 46

Capítulo IV Diseño metodológico de la planeación territorial 62

Capítulo V Resultados de la investigación $\quad 79$

$\begin{array}{ll}\text { Conclusiones } & 84\end{array}$

$\begin{array}{ll}\text { Anexos } & 87\end{array}$

$\begin{array}{ll}\text { Referencias } & 96\end{array}$ 


\section{Resumen}

La presente investigación tiene como objetivo determinar los principales factores que influyen en la planeación estratégica y su desarrollo socioeconómico de la zona conurbada de Moroleón y Uriangato Guanajuato, México. Con este fin se investigó la literatura correspondiente, en relación con el Desarrollo Regional (DH) y otros temas concernientes, y se obtuvieron variables que fueron las que marcaron la ruta a seguir, se observa que la planeación estratégica territorial apenas va comenzando en la zona y que las autoridades municipales aún tienen que trabajar mucho sobre este tema, que es fundamental en estos tiempos.

Posteriormente con el Method for Employing Sampling Thecniques, se delimito el área de estudio, para después mediante una aplicación de encuestas realizadas en todos las áreas y regiones de la población se analizaron los resultados con el programa estadístico SPSS, para aplicar herramientas estadísticas que llevaron la investigación a obtener resultados. Se concluye que las políticas públicas (PP) es la variable independiente que más influye sobre la dependiente, por lo que la recomendación es mejorar este aspecto gubernamental del municipio e implementar planes estratégicos territoriales que coadyuven a mejorar el desarrollo urbano de ambos municipios.

\section{Territorio, Desarrollo, Urbanismo, Bienestar, Planificación}

\section{Abstract}

This research aims to determine the main factors that influence strategic planning and its socioeconomic development in the conurbation area of Moroleón and Uriangato Guanajuato, Mexico. To this end, the corresponding literature was investigated, in relation to Regional Development (DH) and other relevant topics, and variables were obtained that marked the route to follow, it is observed that territorial strategic planning is just beginning in the area and that the municipal authorities still have to work hard on this subject, which is fundamental in these times.

Subsequently with the Method to employ sampling techniques, delimit the study area, and then, through an application of surveys carried out in all sectors of the population, analyze the results with the statistical program SPSS, to apply statistical tools that investigate the research. Obtaining results. It is concluded that public policies (PP) is the independent variable that most influences dependence, so the recommendation is to improve this governmental aspect of the municipality and implement territorial strategic plans that improve the urban development of both municipalities.

\section{Territory, Development, Town Planning, Welfare, Planning}




\section{Introducción}

La definición de planificación estratégica como se conoce hoy en día nace en la década de los ochenta en la Escuela de Negocios de Harvard y fue aplicada por primera vez a la empresa privada, con la intención de que a partir de ella ésta lograra un máximo nivel de competitividad en el mercado, estando en presencia siempre de los movimientos de la competencia para alcanzar un solo propósito, el éxito empresarial. Hoy en día este instrumento se utiliza para elaborar planes de desarrollo regionales en que se usan métodos participativos, se trabaja en las fortalezas y debilidades de un territorio y se delinean las posibles vías o los llamados lineamientos transcendentales para que sean regiones altamente competitivas. Así, este instrumento se utiliza para rescatar algunas peculiaridades particulares de varias localidades y de sus fortalezas para que estas sienten las bases de un desarrollo local (Elizalde, 2003).

En México puede decirse que por mucho tiempo -propiamente por cinco décadas ininterrumpidas la racionabilidad económica que dejaba entrever el discurso gubernamental mexicano descansaba en el mandato constitucional de tomar bajo su responsabilidad directa la orientación y conducción del desarrollo social, político y económico (Navarro, Acevedo, Garcia, 2002).

Desde este particular punto de vista, los esfuerzos ejecutados en el núcleo de la estructura del poder político en favor de tal desarrollo tuvieron como referencia fundamental la legitimidad que la Constitución Política de los Estados Unidos Mexicanos (CPEUM), para la actividad de la economía del Estado; pero de manera fundamental, descansaron en el ánimo, en el interés, en la voluntad que mostraron los sucesivos gobiernos para enarbolar una política económica tendiente a instaurar de manera acelerada un método de relaciones socioeconómicas suficientemente amplio en lo social además de operativo y ágil en lo institucional, como para dotar de estabilidad y continuidad a largo plazo el vastísimo proceso nacional de integración y modernización e incluso del auténtico desarrollo (Navarro, Acevedo, Garcia, 2002).

Dentro de esa política económica jugó un papel primordial el proceso de programación y planeación por dos razones fundamentales: primera porque en los programas y planes que pudieron articularse y ponerse en vigor fueron señalados de la manera más explícita y directa posible las grandes metas macroeconómicas de México a largo, mediano y corto plazo dotando con ello a la población nacional de inusitada certidumbre acerca de su destino económico inmediato; y segunda porque a la vez se le proveyó de los mecanismos necesarios para corregir de la misma forma las posibles insuficiencias y excesos en que se incurrió de manera casi natural al hibridizar el mecanismo del libre mercado en el comando oficial del transcurso económico en cualesquiera de las actividades que coyuntural o estructuralmente se consideraron estratégicas o prioritarias y mediante las cuales se condicionó o al menos se indujo fuertemente el comportamiento de todas las áreas de la distribución y producción fronteras adentro (Navarro, Acevedo, Garcia,2002).

Guanajuato, al igual que las entidades federativas del país, ha buscado contribuir en que se consolide una sociedad en donde todas las personas, sin importar su edad, su condición socioeconómica, física o de origen étnico, vean una garantía para que se cumplan sus derechos sociales y que además pueda ser partícipe de un nivel de vida digno, a través de la elaboración y conducción de una política orientada al desarrollo social que haga frente a los desafíos como el cambio demográfico y social en la población, los cuales dependen en mayor medida de regular el crecimiento poblacional y ajustar la distribución territorial de forma que se pueda garantizar el potencial de desarrollo de los guanajuatenses, en un marco donde la generación de capacidades, un entorno e ingreso adecuado, así como la protección social y participación, que privilegie la atención a los sectores sociales más desprotegidos. De este modo, la manera en la que se interrelacionan los elementos que componen la dinámica demográfica: fecundidad, mortalidad y migración, así como la celeridad a la que ocurren los cambios en éstas, deben determinar el diseño de toda política pública mediante programas y estrategias en donde la población sea la parte fundamental del desarrollo de Guanajuato en los años por venir (PEDGTO2040, 2018).

En Moroleón y Uriangato, se desarrolló y fortaleció una cultura artesanal industrial que, junto al comercio, fueron las que llegaron a organizar y definir la vida económica local. La organización industrial se ha basado en la existencia de un gran número de talleres fundamentalmente familiares. Esta raigambre familiar ha fortalecido su crecimiento ya invertir en la empresa ha sido, al mismo tiempo invertir en el futuro de la familia (Vangstrum, 1995). 
Sin embargo, en los últimos años, ha decrecido el comercio con una baja de ventas, que se ve reflejada en la economía local, esto según entrevistas con la población local. Ante esta problemática, el presente trabajo es el resultado de una investigación que busca explicar y determinar cuáles han sido las variables de mayor influencia en la planeación estratégica territorial. La investigación es de carácter científico y su diseño es correlacional con el fin de determinar la relación funcional de las variables consideradas como explicativas del objeto de estudio.

En este contexto se inscribe la presente investigación, la cual se estructuró en cinco capítulos, siguiendo las pautas del método científico para la solución de problemas y para la generación de nuevos conocimientos; así como para dar cumplimiento a los objetivos planteados y respuesta a los cuestionamientos que dieron origen al trabajo de investigación. Siendo el campo de investigación la región sur del estado de Guanajuato, comprendida entre los municipios de Moroleón y Uriangato, donde se aplicaron 385 encuestas entre ambos municipios y aplicándolas a todos los sectores de ambas ciudades.

En el capítulo uno, se presentan los antecedentes y la problemática actual, de igual manera se plantean el objetivo e hipótesis que orientan el trabajo de investigación, así como la justificación y metodología empleada.

En el capítulo dos se presentan los resultados de la investigación documental, con base en el material bibliográfico y hemerográfico pertinente, sobre las teorías y conceptos que aluden y fundamentan el concepto, la aplicación, utilidad y vigencia de la planeación estratégica regional; asimismo se abordan otros conceptos que son importantes para el desarrollo regional y la planificación estratégica regional, así como algunos conceptos de urbanismo.

En el capítulo tres se describe la planeación estratégica territorial del estado de Guanajuato y se describe la zona de estudio de ambas ciudades, y se menciona una planeación estratégica de desarrollo de la zona, así como objetivos del plan de gobierno de Moroleón.

En el capítulo cuatro se analizan y presentan estrategias urbanas de crecimiento y sistemas urbanos y los factores que afectan al desarrollo urbano, también se aplicaron una serie de preguntas mediante un método para definir las variables de mayor influencia en la planeación estratégica las cuáles permitieron la construcción de un modelo de medición para la planeación estratégica territorial, después se procedió con la operacionalización de las variables y se diseñó el cuestionario a aplicar.

En el capítulo cinco se específica la medición de la validez y fiabilidad, y se obtienen resultados, primero de la prueba piloto, y después de las encuestas aplicadas para realizar el procesamiento de la información obtenida en el trabajo de campo y escritorio, destacando la medición de la escala, el diseño de los cuestionarios empleados, la obtención de datos y el procesamiento de los mismos, presentándose los principales estadísticos de cada indicador que conforman las variables definidas. 


\section{Capítulo I Introducción metodológica a los estudios de planeación territorial}

\section{Estudios regionales}

La mayor aportación de la Ciencia Regional a la política regional es la incorporación del concepto aespacial de polarización de Perroux (que se basa en la observación de que los diferentes tipos de industrias, que tienen diferentes niveles tecnológicos, tasas de innovación, elasticidades de demanda y efectos multiplicadores, presentan capacidades propulsivas diferentes) en el diseño de políticas de desarrollo para las regiones relativamente más atrasadas concentrando en un mismo espacio geográfico las industrias propulsoras y las empresas a ellas ligadas, de modo que los efectos externos puedan concentrarse en el hinterland ${ }^{1}$ objeto de la política de desarrollo.

La lectura de Keynes de la Ciencia Regional ha sido hecha desde la síntesis neoclásica que resalta las condiciones bajo los cuales el sistema tiende al equilibrio económico y al crecimiento regional, en vez de apuntar las limitaciones del mecanismo del mercado para garantizar un nivel de demanda efectiva que permitan un proceso de crecimiento libre de crisis para todas las regiones. Por otra parte, la aplicación de la teoría keynesiana a los estudios regionales entra en contradicción con la teoría en tanto que Keynes estudio economías cerradas y las regiones son economías abiertas, no pudiendo utilizarse, a nivel regional instrumentos monetarios o las tasas de cambio como mecanismos de regulación económica. De igual modo, la efectividad de las políticas fiscales está condicionada por el nivel de autonomía recaudatoria. En este contexto los autores de la inspiración keynesiana abogaran por el sector exportador de la economía regional (teoría de la base exportadora), o por una cuidadosa regionalización de la política de gastos (Modelos del tipo Harrod-Domard) a veces en el contexto de estrategia de polos de crecimiento.

Justificaciones para ambos argumentos se encuentran o en la idea de que las actividades exportadoras (los llamados sectores básicos) son un componente de la demanda, que además capta riqueza para la economía regional, o en la hipótesis de que los problemas regionales se derivan de la falta de inversiones, siendo necesarios por tanto incentivos e inversiones públicas para incrementar el atractivo de la región para el capital externo. A esta misma conclusión, pero desde posiciones metodológicas que se pueden identificar con el paradigma alternativo llegan algunos componentes de la teoría del desarrollo regional endógeno (Curbelo, 1989).

Con ser importantes las aportaciones teóricas de la ciencia regional y haber ejercido gran influencia en las políticas de desarrollo especialmente hasta mediados de los setenta, su trascendencia académica se debe en la actualidad a su preocupación por el desarrollo de métodos de análisis y sus intentos de formalización de los fenómenos económicos en el espacio (Curbelo,1989).

Ambos paradigmas están por otra parte lejos de ser cuerpos unificados de principios ideas y/o políticas siendo tan diversos internamente que la mayor parte del debate de la disciplina se produce en el interior de cada uno de los paradigmas y no entre estos. Asimismo, no se encuentra posible afirmar que uno de ellos es mejor o superior al otro o argumentar un tanto linealmente que la economía política regional añade un componente político o de cualquier otra dimensión a la ciencia regional, en tanto, que las diferencias entre ambos enfoques se dan no solo a nivel epistemológico (por ejemplo, positivismo idealista versus materialismo dialectico) sino también en su objetivo. Mientras la mayoría de los que trabajan en la economía política regional son críticos de las asignaciones del mercado e intentan ligar el análisis económico con una praxis, encaminada a cambiar las relaciones sociales de producción o al menos distribuir los frutos del proceso de producción, los científicos regionales no cuestionan la estructura de clases existente, sino que intentan dar soluciones para mejorar la eficiencia del mecanismo de mercado y corregir sus imperfecciones.

\footnotetext{
${ }^{1}$ Un hinterland es una zona de influencia que se localiza en el interior y detrás de un puerto. En este lugar es donde se recogen los productos que se van aexportar y se distribuyen las importaciones. En un sentido más amplio, un hinterland se refiere a una zona de influencia (cobertura comercial) alrededor de una ciudad o infraestructura logística.
} 
No obstante, debe tenerse en cuenta que la diferenciación por el fin perseguido no implica que los análisis en el marco de la economía política regional conduzcan a políticas económicas radicales (utilizando el calificativo en su acepción política anglosajona) como queda de manifiesto por la estrategia de enterprise zone ${ }^{2}$ o por las políticas de desarrollo regional endógeno (Curbelo, 1989).

¿Qué aspectos requiere la Ciencia Regional para alcanzar lo anterior? Algunas de sus herramientas fundamentales lo son los planes y los proyectos, ambos mutuamente relacionadas, pues la primera es la acción que trata de influir en el comportamiento futuro de la sociedad a través de la cual un sujeto o sujetos buscan cómo desenvolverse sobre determinadas circunstancias o problemas de la región, para cambiarla o llevar de acuerdo con ciertos propósitos, bajo el supuesto de que estos objetivos no serán alcanzados al menos que se introduzca la acción intencionada alcanzada. Desde esta perspectiva, la planificación regional es aquella acción encaminada a proyectar un futuro deseado y la forma efectiva de realizarlo, algunos de cuyos resultados es el "plan regional" y los "proyectos" (Miguel, 2011).

Algunos estudiosos proponen sustituir el concepto de política regional por el de política económica territorial (Cuervo, 1999). Mientras la primera se preocupa por la regulación de las brechas de desarrollo subnacional, teniendo al Estado central como actor principal, la segunda conjuga lo primero con la política de desarrollo local, surgida desde abajo y construida a partir de las regiones y localidades con base en sus propios recursos. La propia Organización de Cooperación para el Desarrollo OCDE (1998), señala para el caso de México, que sus problemas no son regionales, sino básicamente económicos y sociales pues afectan a todo el país por igual. Se afirma que no existe una política regional, sino políticas sectoriales con marcadas dimensiones regionales con una estrategia territorial implícita y reforzada por grandes reformas estructurales, como son los fundamentos macroeconómicos, la privatización, la descentralización y la política social. Las políticas sectoriales con una orientación territorial, tienen efectos diferenciados según la zona, así las políticas de combate a la pobreza tienen mayor importancia en la zona sur, mientras que las políticas de integración económica tienen mayores efectos en los sistemas de producción modernos (Merchand, 2007).

\section{Bienestar y felicidad}

Cuando se aborda el tema del bienestar se piensa en algo relativo con la felicidad o el placer, en estrecha correspondencia con las aspiraciones de cada persona, es decir, con sus intereses, y con un contenido de carácter material o aceptablemente de tipo espiritual o cultural, cerca de objetivable, que es un bien para quien lo busca. Precisamente por la liga entre el bienestar y todos los demás términos resulta a veces complicado distinguirlos y en varias ocasiones se confunden. Cuando se dirige la mirada al Estado del Bienestar, se observa la misma ambigüedad a la hora de detallar el bienestar: trabajo, salud, comodidad, seguros, un sueldo mínimo o máximo, etc. Entran en juego muchos otros conceptos que son brindados por el Estado (Gómez, 2001).

Este trabajo es poner de manifiesto esta ambigüedad y tratar de captar lo que se entiende o puede ser comprendido por bienestar. Para una primera aproximación se consultará al Diccionario de la Lengua Española de la Real Academia. La definición de ‘bienestar' tiene estos tres accesos:

1. Lo necesario de las cosas indispensables para vivir bien.

2. Vida holgada o bien abastecida de lo que conduce a pasarla bien y con tranquilidad.

3. Estado de la persona, en el que se le hace sensitivo el buen ejercicio de su actividad somática.

\footnotetext{
${ }^{2}$ Una zona de enterprise zone (zona de empresa urbana) es un área en la que se implementan políticas para fomentar el crecimiento económico y el desarrollo. Las políticas de zonas empresariales urbanas generalmente ofrecen concesiones fiscales, incentivas de infraestructura y regulaciones reducidas para atraer inversiones y empresas privadas a las zonas.
} 
Las tres se refieren a algo valorado positivamente, empero, se observa que se soslaya el uso de la palabra felicidad. Mientras las primeras identifican el bienestar con cosas materiales que hacen posible el estar bien, la segunda alude a la vida misma, representada por una holgura o abastecimiento de lo señalado en la primera definición más un tinte de tranquilidad, y la tercera a un estado sensible de la persona, esto es, a una manera de estar (bien estar) en la que todo va bien, tanto el plano físico como el psíquico. Son tres interpretaciones diferentes que reflejan ya la variedad de concepciones que se han dado (Gomez, 2001).

\section{Bienestarismo y pobreza}

Desaparecida en la práctica (aunque sus ritos formales continúen) la concepción religiosa judeo cristiana en la que el pobre tenía una función, una misión que cumplir, en la actualidad se abre paso la creencia social de que el pobre, el marginado, debe desaparecer, pero no resolviendo su situación de necesidad sino escondiéndolo debajo de la alfombra, porque su visión resulta intolerable (Aranzadi, 2014).

El bienestarismo podría definirse también como un estado colectivo de ensimismamiento individual. El bienestarismo rechaza la existencia de todo elemento que perturbe su concepción del hombre y la vida. Como está en una sociedad basada fundamentalmente en la producción y consumo masivos, para él, el que no produce, y no se diga ya el que no consume, es rechazado y su existencia ignorada. Los pobres y demás desheredados de la fortuna lo único que consumen son recursos de la beneficencia (asumida ahora en gran parte por la Administración Pública), y la beneficencia, por ahora, no es un mercado rentable. Es decir, los pobres consumen recursos comunes de la sociedad bienestarista, pero no ofrecen nada a cambio para su desarrollo (pues carecen de potencial productivo consumidor). Eso es algo que una sociedad empeñada en el crecimiento económico a ultranza no puede tolerar. Por tanto, los pobres son considerados un lastre para el desarrollo económico, que es condición indispensable para que el bienestarismo, concepción radicalmente materialista, pueda desarrollarse. En lógica consecuencia, los pobres deben ser abandonados a su suerte ya que después de todo, en este mundo de oportunidades, los únicos culpables de su situación son ellos mismos (Aranzadi, 2014).

\section{Índice de bienestar para realizar comparaciones entre países}

En Sen (1976b), se usa nuevamente el método axiomático para proporcionar los fundamentos de un índice que considere al concepto de ingreso nacional, y permita realizar comparaciones relevantes entre diferentes países. La medición propuesta es (l-G) y, donde $\mathrm{G}$ es el índice de desigualdad de Gini y el ingreso per cápita en el país. Las bases para la evaluación del bienestar social se ven fortalecidas con el trabajo de Sen, quien introduce el concepto de "bien personalizado", en donde se señala la cantidad de bien i que se asigna al individuo;. Con este lenguaje se pueden asignar pesos relativos que consideran el precio de mercado del bien; y el rango relativo del ingreso del individuo, mientras más pobre es una persona, mayores son los pesos sobre los bienes que se le asignan. Los pesos distribucionales son relevantes para establecer juicios intermedios que incorporan rasgos utilitaristas y rawlsianos al mismo tiempo.

\section{Funcionamiento, capacidad y valores}

En otros contextos, que incluyen problemas más generales del desarrollo económico, la lista puede ser mucho más larga y diversa. Es preciso hacer elecciones al delinear los funcionamientos importantes. El formato siempre permite que se definan e incluyan logros adicionales, Muchos funcionamientos carecen de interés para la persona (por ejemplo, utilizar un determinado detergente que se parece a mucho a otros detergentes) (Sen, 1979). El enfoque bienestarista reduce el bienestar a los aspectos económicos. Su visión es monista ${ }^{3} \mathrm{y}$, por tanto, la única información disponible para ser tenida en cuenta es la utilidad. La pregunta central de Sen no es si la utilidad es la fuente de información para el bienestar de las personas, sino si es la única (Sen, 1979):

\footnotetext{
${ }^{3}$ El monismo describe el modo de pensar de los filósofos que admiten que hay una sola substancia, o una sola especie de substancia. Un monista puede admitir que solamente hay materia o que solamente hay espíritu, pero también se considera monismo cuando se acepta que hay una pluralidad de individuos que son de la misma substancia.
} 
"Dos críticas se pueden hacer al bienestar basado en la utilidad y, en concreto, a la consideración de que la utilidad es la única fuente de valor. En primer lugar, la utilidad es, en el mejor de los casos, un reflejo del bienestar de una persona, pero el éxito de ésta no se puede evaluar en términos de su bienestar. (...) En segundo lugar, se puede discutir que el bienestar personal deba considerarse en términos de utilidad en vez de en otros términos" (Sen 1987).

Sen desarrolla la primera crítica partiendo de la distinción entre el rol del agente y el del bienestar. La segunda la fábrica a partir de asimilar la utilidad como satisfacción del deseo, como felicidad o como decisión. De este modo, Sen muestra que la única motivación de las personas no es maximizar su propio bienestar. Rechaza la ética utilitarista y el razonamiento moral fundamentado en el bienestar. Considera que esta aproximación bienestarista limita la información necesaria para valorar la situación de las personas. Sólo si se acepta que las personas son egoístas en todas sus acciones, se puede justificar la idea de que su única motivación es la búsqueda del propio bienestar. Por ejemplo, la maximización bienestarista de la utilidad no deja espacio para cuestionar la legitimidad de los derechos liberales. La utilidad es insuficiente para determinar la motivación y el estado en que se encuentran los individuos. Las personas tienen creencias y deberes que los comprometen frente a su comunidad. Y al obrar en consecuencia no necesariamente implica un mejoramiento del bienestar propio (Gamboa, 1991).

\section{Antecedentes del desarrollo}

En los inicios del Tercer Milenio la sociedad humana ha obtenido una conciencia mayor que si desea conservar su supervivencia, su reproducción económica y demográfica esta debe ser acorde a la renovación de los recursos naturales y de un buen manejo de estos, de las regiones y ciudades donde se asienta, esto es, debe prever su sustentabilidad, la preservación de la variedad biológica, social y cultural que tienen las regiones, así como aspirar a un desarrollo equilibrado y armonioso, todo esto acompañado por una progresiva participación social, con acciones cada vez más certeras y trascendentes, lo cual puede ser proporcionado por la planificación y la planeación. Debe entenderse que pieza vital de éstas lo son la explicación y entendimiento de los fenómenos económicos, sociales, culturales, espaciales y ambientales que la circunscriben (Miguel, 2011).

Se entiende por desarrollo urbano-regional el proceso de progreso del bienestar y la calidad de vida que favorece a determinadas partes de un país, las cuales reciben el nombre de "regiones" y "ciudades". Según la Organización de las Naciones Unidas (ONU), es el proceso de desarrollo nacional en escala regional que abarca las características económicas, sociales y físicas del cambio en una zona durante un periodo de tiempo más extenso. Los participantes de un proceso de desarrollo regional (gobierno, empresas, instituciones, hogares y personas) se intervienen mutuamente al efectuar múltiples actividades económicas, sociales y culturales. Por lo tanto, el DR se considera como un proceso amplio, que abarca actividades sociales económicas, políticas, culturales, y ambientales (Miguel, 2011).

Desde el punto de vista social, se ha reconocido que el desarrollo es el proceso que favorece la creación de capital económico y de todo tipo, y transformar ésta en bienestar social. En la práctica, los expertos consideran que el "desarrollo" evalúa el proceso de mejoría de las condiciones económicas y de bienestar de la población de las ciudades y regiones. El "bienestar" se refiere al nivel conseguido en la satisfacción de las necesidades básicas más importantes de la sociedad, que se expresan en los niveles de salud, educación, alimentación, seguridad social, vivienda, desarrollo urbano y medio ambiente (SHCP, 2001).

\section{La pobreza}

La pobreza, es una forma de vida que surge cuando las personas no tienen los recursos necesarios para satisfacer sus necesidades básicas. Este estado se caracteriza por una mala alimentación, por la falta de acceso a la asistencia sanitaria y a la educación, y por no tener una vivienda que reúna los requisitos primordiales para desarrollarse correctamente (Pérez Porto \& Gardey, 2009). 
Existen diversos contextos involuntarios que pueden acarrear a una persona a la pobreza; el desempleo, los salarios escasos y las catástrofes naturales son algunas de las más habituales. Asimismo, una enfermedad cuya recuperación exija gastos desmesurados suele ser la lamentable ruta hacia la quiebra de muchas familias. Por otro lado, es preciso señalar que el manejo inconsciente del dinero puede terminar con grandes fortunas (Perez Porto \& Gardey, 2009).

Se suele considerar a menudo que una familia se hunde por debajo de la línea de pobreza cuando sus ingresos no le permiten obtener a la canasta básica de alimentos. Cuando dicha situación desesperada se alarga en el tiempo, se entiende por pauperización (Pérez Porto \& Gardey, 2009).

Pero mucha gente consigue superar estas etapas gracias a pensar distinto, a actuar como nunca lo habían hecho; no se dejan caer ante la imposibilidad de caminar el camino convencional, sino que se enfocan en la posibilidad de esas decisiones que, tal vez, los llevarán a las mejores oportunidades. Esa fuerza de voluntad, esa lucidez en los momentos críticos es su verdadera bendición (Perez Porto \& Gardey, 2009).

La medición de la pobreza ha sido desarrollada, mayoritariamente y tradicional desde una vertiente unidimensional, en la cual se utiliza al ingreso como un acercamiento del bienestar económico de la población. A pesar de la indudable utilidad, así como de su vasta aceptación en el orden mundial, las medidas unidimensionales de pobreza han sido sujetas a exhaustivas revisiones (CONEVAL, 2017).

Se argumenta que una de sus principales restricciones reside en que el concepto de la pobreza comprende diferentes componentes o dimensiones, es decir, se trata de un fenómeno de naturaleza multidimensional que no debe ser considerado, única y exclusivamente, por los bienes y servicios que se pueden adquirir en el mercado. Conforme a lo dispuesto en el Artículo 36 de la Ley General de Desarrollo Social, el Consejo Nacional de Evaluación para la Política de Desarrollo Social (CONEVAL) debe instaurar la normatividad y los criterios para realizar la definición, la identificación la medición de la pobreza en México, tomando en cuenta al menos los siguientes indicadores:

- Ingreso corriente per cápita.

- Rezago educativo promedio en el hogar.

- Acceso a los servicios de salud.

- Acceso a la seguridad social.

- Calidad y espacios de la vivienda.

- Acceso a los servicios básicos en la vivienda.

- Acceso a la alimentación.

- Grado de cohesión social.

La información que deberá emplear el CONEVAL para la medición de la pobreza en México será la que genere el Instituto Nacional de Estadística y Geografía (INEGI), con una periodicidad al menos de dos años para información estatal y de cinco años para la desagregación municipal. La normatividad y los criterios generales para la definición, la identificación y la medición de la pobreza en México fueron publicados en el Diario Oficial de la Federación (DOF) el 16 de junio de 2010 (CONEVAL, 2017).

La pobreza en su acepción más vasta está asociada a entornos de vida que transgreden la dignidad de las personas, restringen sus derecho y libertades básicas, impiden la satisfacción de sus necesidades básica e imposibilitan su plena integración social (Guzman, 2012). 
Aun cuando existe una enorme cantidad de aproximaciones teóricas para identificar qué hace pobre a una persona, hay un consenso cada vez más grande sobre la naturaleza multidimensional de este concepto, el cual reconoce que los componentes que toda persona necesita decidir de manera libre, informada y con igualdad de oportunidades sobre sus opciones transcendentales, no pueden ser reducidos a una sola de las características o dimensiones de su existencia (Feres, 2009).

La medición de la pobreza en el país ha sido desarrollada, tradicional y mayoritariamente, desde una perspectiva unidimensional, en la que es utilizado el ingreso como una aproximación del bienestar económico de la localidad. Desde esta perspectiva, suele definirse un umbral o línea de pobreza que representa ingreso mínimo preciso para adquirir una canasta básica de bienes considerados indispensables. Tal umbral es comparado con el ingreso de los hogares para establecer aquellos que son pobres. Esta aproximación permite identificar a la población que no tiene las condiciones indispensables para satisfacer sus necesidades elementales, siempre y cuando se puedan adquirir por medio de los mercados de bienes y servicios.

A pesar de la indiscutible utilidad, así como de su gran aceptación en el orden mundial, las medidas unidimensionales de requisito han sido sujetas a exhaustivas revisiones y críticas. Se argumenta que una de sus trascendentes limitaciones es en que el concepto de pobreza comprende varios componentes o dimensiones, lo que quiere decir, se trata de un fenómeno de naturaleza multidimensional que no puede ser aprehendido, solo y exclusivamente, por los bienes y productos que pueden adquirirse en el mercado.

La pobreza está asociada también a la imposibilidad de disfrutar diversos satisfactores esenciales, muchos de los cuales son provistos por el Estado (como el acceso a servicios de saneamiento o la seguridad pública), o que son considerados fundamentales por formar parte de los derechos humanos, económicos, sociales y culturales.

En consonancia con la discusión académica y el debate internacional, la Ley General de Desarrollo Social (LGDS, 9 en su artículo 36, establece que para la medición de la pobreza en México deben considerarse los derechos sociales y el bienestar económico.

De esta forma, bienestar social y derechos, asociados ambos al principio universal e inalienable de libertad individual, muestran el espíritu de una ley que supone un vínculo social contractual (que no es solamente político, sino normativo a partir de los criterios determinados en la propia LGDS) entre el Estado, la comunidad y los individuos, con el propósito primordial de garantizar el acceso de toda la población al desarrollo social y humano que toda la sociedad es capaz de generar CONEVAL,2014).

El camino que va hacia una sociedad más incluyente e igualitaria está en función, en gran medida, del cumplimiento de este pacto entre representantes del Estado y de la sociedad civil, y de que dicho pacto, al mismo tiempo, se exprese en reciprocidad de derechos y deberes para toda la población en general (CEPAL, 2006).

De esta forma, el logro del bienestar y el ejercicio de los derechos humanos ya no son meras aspiraciones o "normas programáticas" para cambiar a deberes y responsabilidades legítimamente instituidas (Jahan, 2002; Kurczyn y Gutiérrez, 2009).

Si bien la discusión académica y la normatividad legal presionan hacia una aproximación multidimensional de la pobreza, por supuesto que no es una tarea sencilla. Hay diversos retos conceptuales que deben solucionarse como, por ejemplo, la definición de las dimensiones relevantes, las interacciones entre estas dimensiones o las limitaciones de las fuentes de información. Estos retos han creado una amplia discusión y debates académicos, en los cuales, si bien se suele dar la razón a la necesidad de adoptar un enfoque multidimensional para el estudio de la pobreza, también se puede reconocer que existen problemas para hacer operativa una medición de esta índole (Alkire y Foster, 2007; Bourguignon y Chakravarty, 2003; Kakwani y Silber, 2008).

De tal forma, una medición multidimensional de la pobreza tiene que tener en cuenta criterios que permitan, de una forma transparente, imparcial y sistemática, y con rigor técnico, solucionar estos retos conceptuales y empíricos (CONEVAL, 2010). 
Tabla 1 Los más altos índices de pobreza por estado en 2016

\begin{tabular}{|c|c|c|}
\hline Estado & \multicolumn{2}{|c|}{ Porcentaje } \\
\hline Chiapas & & $77.10 \%$ \\
\hline Oaxaca & & $70.40 \%$ \\
\hline Guerrero & & $64.40 \%$ \\
\hline Veracruz & & $62.20 \%$ \\
\hline Puebla & & $59.40 \%$ \\
\hline \multirow{2}{*}{ Estados donde aumento la pobreza del 2014 al 2016} & \multicolumn{2}{|c|}{ Porcentaje } \\
\hline & 2014 & 2016 \\
\hline Veracruz & $58.00 \%$ & $62.20 \%$ \\
\hline Oaxaca & $66.80 \%$ & $70.40 \%$ \\
\hline Tabasco & $49.60 \%$ & $50.90 \%$ \\
\hline Chiapas & $76.72 \%$ & $77.70 \%$ \\
\hline Campeche & $43.60 \%$ & $43.80 \%$ \\
\hline Estados con menor índice de pobreza & \multicolumn{2}{|c|}{ Porcentaje } \\
\hline Nuevo Leon & & $14.30 \%$ \\
\hline Baja California Sur & & $22.10 \%$ \\
\hline Baja California Norte & & $22.20 \%$ \\
\hline Coahuila & & $24.80 \%$ \\
\hline Estado de Mexico & & $27.60 \%$ \\
\hline
\end{tabular}

Fuente: Aguilar, (2016)

Durante el 2014 y el 2016 disminuyo la pobreza si se toma en cuenta que desde el 2012, los seis últimos años, la pobreza incrementa en 600,000 personas, según el CONEVAL. En estos años, no se ha podido revertir el número de la población que habita en pobreza (Aguilar, 2015).

La población indígena del país en los últimos 17 años se mantiene aún con los mismos niveles de pobreza. En el 2010 estaba en esta realidad $79.5 \%$ de la población, en el 2014 era de $78.4 \%$ y en el 2016 fue 77.6 por ciento. Todas las políticas públicas para reducir la pobreza en este sector tan vasto de la población no han tenido éxito (Aguilar, 2017).

En el 2014, 46.3\% de la población de mujeres estaba en situación de pobreza y en el 2016 fue de 44.0 por ciento. En ese mismo periodo de tiempo los hombres bajaron de $46.0 \%$ a 43.0 por ciento. La diferencia fue de solamente un punto porcentual. Hombres y mujeres se encuentran en la misma condición. Los niveles de pobreza extrema han disminuido, 3 millones 500,000 en 17 años, pero no los de pobreza que se conservan más o menos igual en este mismo tiempo. Hay consenso entre los especialistas que la única forma de superar este problema es subir los niveles de empleo e ingreso. No existiendo otro camino.

\section{La desigualdad económica}

Ha sido un tema recurrente en la historia de la humanidad, la distribución del ingreso que se genera anualmente por el uso de los factores productivos en la generación del producto interno bruto de un país (PIB). En un mundo ideal, algunas personas promueven la igualdad absoluta, donde cada porcentaje de la población económicamente activa debe recibir la misma proporción del ingreso. Gráficamente a esa línea de 45 grados se le nombra curva de equidad. A la manera más común de medir la desigualdad o concentración de la distribución del ingreso es conocida como el coeficiente de Gini, que es un cociente que se calcula como el área entre la curva de Lorenz y la línea de Igualdad Absoluta respecto al área total abajo de la línea de igualdad. Al ser un cociente, su valor varía en una escala de 0 a 1 . En el caso extremo, cuando el Coeficiente de Gini es cero, es debido a que la curva de Lorenz se asemeja totalmente a la línea de distribución perfecta o equitativa y si, por el contrario, es 1 en el caso extremo donde un solo individuo recibe todos los ingresos que es una desigualdad. Entre más cerca este el cociente a 0 , mejor o más equitativa es la distribución del ingreso y, por el contrario, entre más se acerque a 1 , mayor desigualdad. 
México es el segundo país con una mayor desigualdad en los ingresos de los individuos dentro de los integrantes de la OCDE. México, Chile, Turquía y los Estados Unidos (EE.UU.) fueron las naciones con las mayores desigualdades entre ricos y pobres, en contraste Dinamarca, Eslovenia, Finlandia y la República Checa fueron las naciones más equitativas, señaló la OCDE en su actualización de datos acerca de desigualdad y pobreza. México tuvo un resultado de 0.47 en el coeficiente de GINI, el cual es quien mide la inequidad de los ingresos y donde 'cero' tiene el significado que todos tienen ingresos similares y 'uno' si una sola persona tuviera el total de todos los ingresos. El resultado del coeficiente OCDE de esta zona en total fue de 0.32. En pobreza relativa, que se está refiriendo al porcentaje de la población que recibe un ingreso menor del 50\% respecto a la media nacional, sólo Israel sobresale por arriba de México con un 20.9\% de la población en 2011, contra el 20.4\% nacional en $20.4 \%$ en 2010 (Forbes, 2014).

Tabla 2 La pobreza en el estado de Guanajuato según el CONEVAL 2016

\begin{tabular}{|c|c|c|c|c|c|c|c|c|c|c|c|c|}
\hline Año & 2010 & 2012 & 2014 & 2016 & 2010 & 2012 & 2014 & 2016 & 2010 & 2012 & 2014 & 2016 \\
\hline $\begin{array}{l}\text { Población en } \\
\text { situación de pobreza }\end{array}$ & 48.50 & 44.50 & 46.60 & 42.40 & 2703.7 & 2525.8 & 2683.3 & 2489.7 & 2.4 & 2.2 & 2.0 & 1.9 \\
\hline $\begin{array}{l}\text { Población en } \\
\text { situación de pobreza } \\
\text { moderada }\end{array}$ & 40.1 & 37.6 & 41.0 & 38.0 & 2234.2 & 2134.0 & 2365.7 & 2231.1 & 2.1 & 2.0 & 1.8 & 1.7 \\
\hline $\begin{array}{l}\text { Población en } \\
\text { situación de pobreza } \\
\text { extrema }\end{array}$ & 8.4 & 6.9 & 5.5 & 4.4 & 469.5 & 391.9 & 317.6 & 257.6 & 3.5 & 3.5 & 3.6 & 3.4 \\
\hline $\begin{array}{l}\text { Población vulnerable } \\
\text { por carencias sociales }\end{array}$ & 28.9 & 32.6 & 27.7 & 30.0 & 1611.2 & 1851.3 & 1594.8 & 1760.7 & 1.8 & 1.8 & 1.7 & 1.7 \\
\hline $\begin{array}{l}\text { Población vulnerable } \\
\text { por ingresos }\end{array}$ & 5.7 & 4.9 & 8.6 & 8.2 & 315.17 & 276.6 & 494.5 & 482.1 & 0.0 & 0.0 & 0.0 & 0.0 \\
\hline $\begin{array}{l}\text { Población no pobre y } \\
\text { no vulnerable }\end{array}$ & 16.9 & 18.1 & 17.2 & 19.5 & 942.7 & 1026.5 & 991.1 & 1145.1 & 0.0 & 0.0 & 0.0 & 0.0 \\
\hline \multicolumn{13}{|c|}{ Privación social } \\
\hline Año & 2010 & 2012 & 2014 & 2016 & 2010 & 2012 & 2014 & 2016 & 2010 & 2012 & 2014 & 2016 \\
\hline $\begin{array}{l}\text { Población con al } \\
\text { menos una carencia } \\
\text { social }\end{array}$ & 77.4 & 77.1 & 74.2 & 72.3 & 4319.9 & 4372.2 & 4278.1 & 4250.4 & 2.1 & 2.1 & 1.9 & 1.8 \\
\hline $\begin{array}{l}\text { Población con al } \\
\text { menos tres carencias } \\
\text { sociales }\end{array}$ & 24.7 & 22.2 & 17.7 & 13.9 & 1376.3 & 1262.2 & 1022.8 & 819.1 & 3.4 & 3.4 & 3.4 & 3.3 \\
\hline \multicolumn{13}{|c|}{ Indicadores de carencia social } \\
\hline Año & 2010 & 2012 & 2014 & 2016 & 2010 & 2012 & 2014 & 2016 & 2010 & 2012 & 2014 & 2016 \\
\hline Rezago educativo & 23.6 & 23.9 & 21.0 & 20.01 & 1315.1 & 1359.3 & 1207.8 & 1181.9 & 2.7 & 2.6 & 2.6 & 2.3 \\
\hline $\begin{array}{l}\text { carencia por acceso a } \\
\text { los servicios de salud }\end{array}$ & 25.3 & 19.0 & 15.4 & 13.4 & 1408.6 & 1081.8 & 888.6 & 790.3 & 2.7 & 2.7 & 2.7 & 2.6 \\
\hline $\begin{array}{l}\text { Carencia por acceso a } \\
\text { la seguridad social }\end{array}$ & 65.7 & 62.1 & 57.9 & 54.5 & 3663.3 & 3257.0 & 3345.5 & 3203.2 & 2.3 & 2.2 & 2.1 & 2.0 \\
\hline $\begin{array}{l}\text { Carencia por calidad } \\
\text { y espacios en la } \\
\text { vivienda }\end{array}$ & 9.6 & 9.8 & 9.8 & 7.7 & 532.7 & 554.0 & 563.2 & 454.6 & 3.4 & 3.1 & 2.9 & 2.8 \\
\hline $\begin{array}{l}\text { Carencia por acceso a } \\
\text { los servicios básicos } \\
\text { en la vivienda }\end{array}$ & 18.0 & 15.3 & 14.9 & 13.5 & 1001.3 & 871.4 & 859.7 & 792.3 & 3.0 & 3.1 & 2.9 & 2.7 \\
\hline $\begin{array}{l}\text { Carencia por acceso a } \\
\text { la alimentación }\end{array}$ & 23.7 & 28.5 & 22.9 & 19.8 & 1323.3 & 1617.1 & 1322.3 & 1162.1 & 2.9 & 2.6 & 2.6 & 2.3 \\
\hline \multicolumn{13}{|c|}{ Bienestar } \\
\hline Año & 2010 & 2012 & 2014 & 2016 & 2010 & 2012 & 2014 & 2016 & 2010 & 2012 & 2014 & 2016 \\
\hline $\begin{array}{l}\text { Población con ingreso } \\
\text { inferior a la línea de } \\
\text { bienestar mínimo }\end{array}$ & 16.5 & 16.9 & 17.9 & 15.6 & 917.4 & 958.2 & 1032.5 & 916.5 & 2.6 & 2.4 & 2.0 & 1.9 \\
\hline $\begin{array}{l}\text { Población con ingreso } \\
\text { inferior a la línea de } \\
\text { bienestar }\end{array}$ & 54.2 & 49.3 & 55.1 & 50.6 & 3019.5 & 2802.5 & 3177.8 & 2971.8 & 2.1 & 2.0 & 1.7 & 1.6 \\
\hline
\end{tabular}

Fuente: Estimaciones del CONEVAL con base en MCS-ENIGH 2010, 2012 y el MEC 2016 del MCS-ENIGH. 
Tabla 3 Porcentaje de población en situación de pobreza en Guanajuato 2010

\begin{tabular}{|c|c|c|c|c|}
\hline Municipio & Población & Pobreza \% & Pobreza extrema $\%$ & Pobreza moderada \% \\
\hline Abasolo & 84116 & 69.20 & 15.40 & 53.70 \\
\hline Acámbaro & 95114 & 55.20 & 8.70 & 46.50 \\
\hline San Miguel de Allende & 139634 & 66.70 & 21.30 & 42.40 \\
\hline Apaseo el Alto & 58084 & 57.80 & 10.50 & 47.30 \\
\hline Atarjea & 4475 & 56.00 & 9.30 & 46.70 \\
\hline Celaya & 513403 & 77.90 & 26.90 & 50.00 \\
\hline Manuel Doblado & 33015 & 65.70 & 19.10 & 46.60 \\
\hline Comonfort & 67135 & 62.00 & 15.70 & 46.30 \\
\hline Coroneo & 11865 & 62.50 & 10.30 & 52.20 \\
\hline Cortazar & 93257 & 59.30 & 6.90 & 44.50 \\
\hline Cueramaro & 26018 & 62.50 & 10.80 & 51.80 \\
\hline Doctor Mora & 17184 & 68.40 & 17.00 & 51.40 \\
\hline Dolores Hidalgo & 136176 & 64.10 & 15.60 & 48.50 \\
\hline Guanajuato & 187929 & 38.30 & 5.10 & 33.30 \\
\hline Huanímaro & 19180 & 65.90 & 11.80 & 54.20 \\
\hline Irapuato & 558600 & 43.60 & 6.50 & 37.10 \\
\hline Jaral del Progreso & 31054 & 58.30 & 7.40 & 50.80 \\
\hline Jerécuaro & 38793 & 67.70 & 18.70 & 48.90 \\
\hline León & 1588458 & 37.80 & 4.20 & 33.60 \\
\hline Moroleón & 41875 & 54.60 & 6.00 & 48.60 \\
\hline Ocampo & 18503 & 74.90 & 21.80 & 53.10 \\
\hline Pénjamo & 126318 & 67.50 & 19.70 & 47.90 \\
\hline Pueblo Nuevo & 11117 & 58.80 & 9.00 & 49.80 \\
\hline Purísima del Rincón & 66928 & 55.20 & 8.30 & 47.00 \\
\hline Romita & 49883 & 65.60 & 14.30 & 51.30 \\
\hline Salamanca & 285087 & 41.10 & 5.00 & 36.10 \\
\hline Salvatierra & 78663 & 59.70 & 10.10 & 49.70 \\
\hline San Diego de la Unión & 26078 & 72.80 & 20.70 & 52.10 \\
\hline San Felipe & 96645 & 68.10 & 18.80 & 49.20 \\
\hline San Francisco del Rincón & 110895 & 50.90 & 6.80 & 44.20 \\
\hline San José Iturbide & 83383 & 44.50 & 5.00 & 39.50 \\
\hline San Luis de la Paz & 109610 & 62.90 & 13.60 & 49.30 \\
\hline Santa Catarina & 3210 & 74.70 & 23.70 & 51.00 \\
\hline $\begin{array}{l}\text { Santa Cruz de Juventino } \\
\text { Rosas }\end{array}$ & 66462 & 68.20 & 20.00 & 48.20 \\
\hline Santiago Maravatío & 5463 & 61.50 & 8.30 & 53.30 \\
\hline Silao & 161512 & 57.00 & 12.80 & 44.20 \\
\hline Tarandacuao & 8939 & 62.10 & 10.20 & 51.90 \\
\hline Tarimoro & 32075 & 58.20 & 9.40 & 48.80 \\
\hline Tierra Blanca & 12425 & 70.40 & 28.10 & 42.20 \\
\hline Uriangato & 53598 & 61.60 & 8.70 & 52.90 \\
\hline Valle de Santiago & 124232 & 64.00 & 12.30 & 51.60 \\
\hline Victoria & 13824 & 74.30 & 28.20 & 46.20 \\
\hline Villagrán & 59831 & 48.50 & 5.40 & 43.10 \\
\hline Xichú & 7370 & 77.60 & 29.20 & 48.40 \\
\hline Yuriria & 70573 & 58.10 & 8.70 & 49.40 \\
\hline
\end{tabular}

Fuente: Estimaciones del CONEVAL en base en la muestra del Censo de Población y Vivienda 2010 y el MCS-ENIGH 2010 
Tabla 4 Desigualdad en Guanajuato

\begin{tabular}{|c|c|c|c|}
\hline Municipio & Coeficiente de Gini & Razón de ingreso ${ }^{4}$ & Grado de cohesión social $^{5}$ \\
\hline Abasolo & 0.412 & 0.09 & Alta cohesión social \\
\hline Acámbaro & 0.426 & 0.09 & Alta cohesión social \\
\hline Apaseo el Alto & 0.420 & 0.11 & Baja cohesión social \\
\hline Apaseo el Grande & 0.380 & 0.15 & Alta cohesión social \\
\hline Atarjea & 0.417 & 0.11 & Baja cohesión social \\
\hline Celaya & 0.477 & 0.12 & Alta cohesión social \\
\hline Comonfort & 0.424 & 0.11 & Alta cohesión social \\
\hline Coroneo & 0.414 & 0.08 & Alta cohesión social \\
\hline Cortázar & 0.384 & 0.17 & Alta cohesión social \\
\hline Cuerámaro & 0.442 & 0.11 & Baja cohesión social \\
\hline Doctor Mora & 0.464 & 0.09 & Alta cohesión social \\
\hline Dolores Hidalgo & 0.411 & 0.11 & Baja cohesión social \\
\hline Guanajuato & 0.483 & 0.11 & Alta cohesión social \\
\hline Huanímaro & 0.372 & 0.14 & Alta cohesión social \\
\hline Irapuato & 0.460 & 0.11 & Alta cohesión social \\
\hline Jaral del Progreso & 0.421 & 0.12 & Alta cohesión social \\
\hline Jerécuaro & 0.421 & 0.10 & Baja cohesión social \\
\hline Juventino Rosas & 0.424 & 0.12 & Alta cohesión social \\
\hline León & 0.443 & 0.12 & Alta cohesión social \\
\hline Manuel Doblado & 0.417 & 0.09 & Baja cohesión social \\
\hline Moroleón & 0.410 & 0.12 & Alta cohesión social \\
\hline Ocampo & 0.429 & 0.10 & Alta cohesión social \\
\hline Pénjamo & 0.457 & 0.09 & Alta cohesión social \\
\hline Pueblo Nuevo & 0.399 & 0.13 & Alta cohesión social \\
\hline Purísima del Rincón & 0.366 & 0.16 & Alta cohesión social \\
\hline Romita & 0.399 & 0.14 & Alta cohesión social \\
\hline Salamanca & 0.441 & 0.12 & Alta cohesión social \\
\hline Salvatierra & 0.404 & 0.14 & Alta cohesión social \\
\hline San Diego de la Unión & 0.436 & 0.09 & Baja cohesión social \\
\hline San Felipe & 0.411 & 0.12 & Alta cohesión social \\
\hline San Francisco del Rincón & 0.410 & 0.13 & Alta cohesión social \\
\hline San José Iturbide & 0.386 & 0.17 & Alta cohesión social \\
\hline San Luis de la Paz & 0.438 & 0.10 & Baja cohesión social \\
\hline San Miguel de Allende & 0.502 & 0.07 & Baja cohesión social \\
\hline Santa Catarina & 0.438 & 0.09 & Alta cohesión social \\
\hline Santiago Maravatio & 0.398 & 0.12 & Alta cohesión social \\
\hline Silao & 0.443 & 0.11 & Alta cohesión social \\
\hline Tarandacuao & 0.431 & 0.10 & Alta cohesión social \\
\hline Tarimoro & 0.370 & 0.17 & Alta cohesión social \\
\hline Tierra Blanca & 0.443 & 0.10 & Baja cohesión social \\
\hline Uriangato & 0.375 & 0.13 & Alta cohesión social \\
\hline Valle de Santiago & 0.409 & 0.11 & Baja cohesión social \\
\hline Victoria & 0.460 & 0.08 & Baja cohesión social \\
\hline Villagrán & 0.364 & 0.17 & Alta cohesión social \\
\hline Xichú & 0.439 & 0.10 & Baja cohesión social \\
\hline Yuriria & 0.423 & 0.10 & Baja cohesión social \\
\hline
\end{tabular}

Fuente: Estimaciones del CONEVAL con base en el MCS-ENIGH 2010 y la muestra del Censo de Población y Vivienda 2010

\section{Identificación del problema}

El estado de Guanajuato se instala de nueva cuenta como una referencia nacional, al atender los intereses y necesidades de la población guanajuatense, por medio de la planeación estratégica y ordenada del territorio que promueve la conservación del medio ambiente y el aprovechamiento de las potencialidades y cualidades de Guanajuato (PROTS9, 2014).

\footnotetext{
${ }^{4}$ Se determina como el coeficiente del promedio corriente per cápita de la población en situación de pobreza extrema respecto al promedio del ingreso corriente per cápita de la población no pobre y vulnerable.

${ }^{5} \mathrm{Se}$ considera de alta cohesión social a los estados con polo derecho (de baja marginación social) o sin polo o de baja cohesión social a los estados polarizados o con polo izquierdo (de alta marginación).
} 
Para promover un entorno tal cual debe ser, para el desarrollo de una vida más digna, se debe mudar hacia un Modelo de Desarrollo Urbano Sustentable que permita consolidar ciudades productivas compactas, incluyentes, competitivas y sustentables que faciliten la movilidad y eleven la calidad de vida de sus pobladores, salvaguardando a los habitantes, a sus bienes y a su entorno ante una catástrofe de origen natural o humano. Debido al interés para lograr este Modelo de Desarrollo Urbano Sustentable, el Programa Estatal de Desarrollo Urbano y de Ordenamiento Ecológico Territorial ha definido cuatro regiones, que juntas integran 10 subregiónes, para la planeación y gestión transcendental del territorio, con el objetivo de precisar su vocación y lograr el óptimo aprovechamiento del mismo. Es a partir de esta subdivisión regional cuando se delimita el territorio para el cual está elaborado el presente Programa Regional de Ordenamiento Territorial para la Subregión 9, denominada Lacustre, conformada por los municipios de Moroleón, Salvatierra, Santiago Maravatío, Uriangato, Valle de Santiago y Yuriria (PROTS9,2014).

Según el Censo Económico 2005, la región de estudio Moroleón y Uriangato cuenta con 1,544 empresas y emplea a 7,911 trabajadores, absorbiendo el $2.17 \%$ de la población económicamente activa de la región; representando aproximadamente el $9 \%$ del personal ocupado en el sector secundario de la región (INEGI, 2005).

Por otra parte, la región se ha convertido en un importante centro comercial textil, en la que se encuentran localizadas más de 5 mil establecimientos comerciales, formales e informales, que emplean a más de 15 mil personas, constituyéndose para algunos municipios de esta región, como la actividad más importante de su economía. Si bien la región, presentó un importante crecimiento de la industria textil durante las décadas de los 80 's y 90's, logrando una expansión y alcanzando una fuerte presencia en el mercado, regional y nacional, el nuevo siglo ha traído innumerables retos que han impactado de manera negativa en su participación de mercado (Lara, 2009).

Las tasas de crecimiento en Moroleón durante los siguientes periodos fueron como sigue de 1960 a 1970 de $3.58 \%$, de 1970 a 1990 de $2.4 \%$, de 1990 a $1995-0.26 \%$ de 1995 a $2000-0.05 \%$ de 2000 a $20050.68 \%$ de 2005 a $20100.61 \%$ de 2010 a $20140.63 \%$ (Fuente Population City, 2015). Y en Uriangato fueron para el periodo 1980-1990 su Tc fue de 4.42\% (la mayor en los cuatro periodos analizados). La Tc para el periodo 1990-2000 fue de 1.26\%, mientras que para el periodo 2000-2010 fue de 1.4\% misma que se mantiene en el periodo 2010-2015 (Periódico Oficial del Estado de Guanajuato, 2018).

Estos incrementos trajeron como consecuencia un crecimiento desordenado, debido a la demanda de vivienda, la razón es que por el incremento en el empleo de la zona mucha gente se vino de otros lugares y se estableció aquí. Al tener la región el régimen de tenencia de la tierra de pequeña propiedad y una gran parte de ejido, dio lugar a una serie de desarrollos urbanos sin control, fraccionamientos irregulares se fueron creando en lugares donde era originalmente un área de cultivo, trayendo innumerables problemas de servicios de infraestructura, calles tapadas, calles angostas, problemas de derechos de vía, invasión de cauces federales de arroyos, etc. A nivel mundial este problema no es de ninguna manera ignorado ya que durante del siglo XX la población ha crecido más de cuatro veces. Y a pesar de que se ha producido una baja en la tasa de crecimiento de la población, sin embargo, esta sigue aumentando en unos ochenta millones por año, por lo que puede duplicarse de nuevo en unas décadas más. La Comisión Mundial del Medio Ambiente y del Desarrollo (1988) señaló hace tiempo las consecuencias: "En varias partes del mundo, la población continúa creciendo según tasas que los recursos naturales disponibles no pueden sostener, tasas que están por arriba de todas las expectativas razonables de mejora en materia de vivienda, seguridad alimentaria atención médica, o suministro de energía" (Programa de acción global, 2015).

De esta manera los ayuntamientos de ambos municipios, en conjunto con gobierno del estado, han venido planteando diferentes acciones de apoyo a la planificación estratégica, a fin de incrementar su utilización, sin lograr los resultados esperados y llevando a la actividad económica a una crisis que se ha venido agravando; por tal motivo, la presente investigación se plantea con la idea de identificar los principales los factores que a nivel regional contribuyan a incrementar el nivel de planificación estrategia de la región y del comercio local, como una posibilidad de afrontar la situación actual que experimentan. 
Ante esta problemática, surge la interrogante, que da sentido a este trabajo de investigación. La zona comercial del objeto de estudio no cuenta con los servicios mínimos indispensables para atender la afluencia de personas en sus distintas modalidades como peatonal, transporte ligero y pesado. Con el propósito de ofrecer seguridad a los clientes, así como acceso a los servicios bancarios, estacionamiento y gastronómico. Con este panorama surge la pregunta de investigación.

\section{Pregunta de investigación}

¿Cuáles han sido las variables que han influido en la planeación estratégica territorial en los municipios de Moroleón y Uriangato ambos ubicados en la región sur del estado de Guanajuato, en los últimos años?

\section{Objetivo general de la investigación}

Determinar cuáles han sido las variables que han influido en mayor medida, en la baja planeación estratégica territorial de Moroleón y Uriangato, ambos ubicados en la región Sur del estado de Guanajuato.

\section{Objetivos particulares principales}

- Identificar y establecer las variables que integran la planeación estratégica territorial, así como determinar un modelo que permita cuantificarlas.

- Definir la relación funcional de las variables que conforman el nivel de planificación estratégica territorial de la región y su influencia en las actividades de la población en los últimos años.

\section{Hipótesis}

La infraestructura, el crecimiento urbano, las PP y utilización del agua, son las variables que influyen en la planeación estratégica territorial, en los municipios Moroleón y Uriangato ubicados en el sur de Guanajuato, México.

\section{Hipótesis de trabajo}

$\mathrm{H}_{1}$ : La infraestructura influye de manera directa en el nivel de planificación estratégica territorial en la zona conurbada Moroleón-Uriangato ubicada en el sur del estado de Guanajuato.

$\mathrm{H}_{2}$ : El crecimiento urbano influye de manera directa en el nivel de planificación estratégica territorial en la zona conurbada Moroleón-Uriangato ubicada en el sur del estado de Guanajuato.

$\mathrm{H}_{3}$ : Las políticas públicas influyen de manera directa en el nivel de planificación estratégica territorial en la zona conurbada Moroleón-Uriangato ubicada en el sur del estado de Guanajuato.

$\mathrm{H}_{4}$ : La utilización del agua influye de manera directa en el nivel de planificación estratégica territorial en la zona conurbada Moroleón-Uriangato ubicada en el sur del estado de Guanajuato

\section{Variables}

Las variables por estudiar son:

- Variables independientes: infraestructura, crecimiento urbano, políticas públicas y utilización del agua.

- Variable dependiente: planificación estratégica territorial. 


\section{Justificación}

La planificación regional solía ser a veces una réplica de la nacional, que no consentía que los líderes locales dispusieran de autonomía en la destinación de fondos públicos. Hoy ya existe una pequeña pero gradual descentralización, que es necesario acelerar ya que propicia que algunas disposiciones se tomen en el ámbito local. En las últimas décadas se implantó el concepto de planificación estratégica para definir normatividades y metas, con el objetivo de lograr el desarrollo territorial. Gracias a este instrumento se incorporaron a la planificación elementos de colaboración de los actores locales, lo que se manifiesta en los planes de desarrollo regional de muchos países.

Conveniencia: la planificación estratégica territorial, es conveniente aplicarla, sobre todo en el diseño de nuevos desarrollos urbanos, en las ciudades, es preciso hacer una planeación para que el uso del suelo sea el adecuado, para no revolver zonas habitacionales con zonas destinadas para usos industriales y/o de otro tipo, por citar un ejemplo.

Relevancia social: la conformación de afluencias industriales tiene su cimiento en los aspectos culturales de las zonas donde se instalan. De esa forma es transcendental generar tejido social y empresarial para que se consolide el desarrollo de un determinado territorio. Implicaciones prácticas: investigar el problema, definir las variables de la problemática, establecer una metodología, a fin de encontrar estrategias para, plantear soluciones en base a resultados, y establecer conclusiones y recomendaciones.

Propósito de la investigación: proponer una planificación estratégica en la zona conurbada Moroleón - Uriangato, para darle al uso del suelo el adecuado destino y no revolver actividades muy distintas unas de las otras, mediante una planeación adecuada y considerada a largo plazo.

Importancia: el orden es por encima de todas las cosas una disciplina que se debe de aplicar en todas las actividades del ser humano, con orden sale mejor cualquier tipo de actividad y el ordenamiento territorial no debe de ser la excepción. En la zona conurbada se observa un desorden territorial inusitado, que incide en el desarrollo local.

Trascendencia: promover y conducir el desarrollo urbano de la zona conurbada Moroleón Uriangato optimizando el uso racional de los recursos en beneficio de la comunidad en general, brindando oportunidades de igualdad en el crecimiento de ambas ciudades.

\section{Tipo de investigación}

Para la construcción científica los investigadores ponen en marcha procesos para conocer la realidad, usando el método científico como una herramienta. Es la metodología o instrumento de la ciencia conveniente para lograr esa expresión de las cosas gracias al cual se puede combinar, manejar, y utilizar esas mismas cosas, además, permite demostrar si una hipótesis dada consigue el rango de Ley, lo que hace que el razonamiento científico es, primeramente, el método de observación, el experimento y el análisis y después, la construcción de hipótesis y la subsiguiente comprobación de éstas.

Este procedimiento no solamente es válido para las ciencias físicas, también es perfectamente aplicable a todas las áreas del saber. A través de la historia, el hombre se ha enfrentado a un sinnúmero de obstáculos y problemas para desenmarañar los secretos de la naturaleza, tanto para vivir de ella como con ella. Para superar esos problemas ha usado muy diferentes estrategias, quienes dieron paso a la formalización de procedimientos, no son sino el propio método científico. 
Figura 1 Diagrama de variables

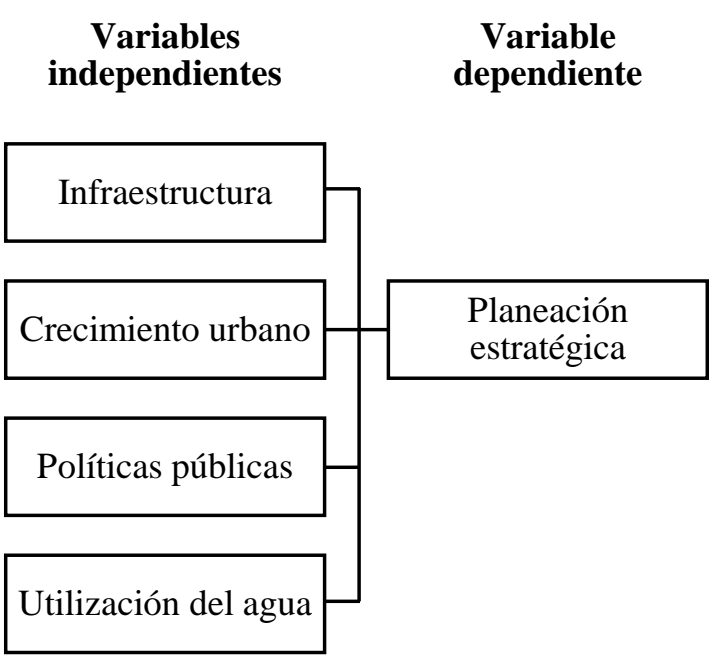

Fuente: Elaboración propia con base en el marco teórico

La figura anterior muestra el diagrama de variables que habrán de desarrollarse conceptualmente, derivadas de las hipótesis de trabajo.

\section{Metodología}

En la construcción científica, los investigadores ponen en marcha procesos para explorar la realidad, los cuáles resultan en un proceso social, empleando el método científico para resolver diversos tipos de problema, por lo que, en la búsqueda de conocimientos este método es el más usado. Por otra parte, la metodología se refiere a las reglas del juego refrendadas para generar conocimientos y cuyo cumplimiento demostrado es requisito para avalarlo y aceptarlo por parte de la comunidad científica; así el método científico establece las reglas para producir de manera rigurosa el conocimiento (Lara, 2009).

El método científico sigue el camino de la duda sistemática no duda de todas las cosas pues esto es imposible, pero sí de todo aquello que carece del apoyo de elementos de juicio adecuados. La ciencia no se contenta con la certidumbre psicológica pues la intensidad con la cual se abriga una creencia no es garantía alguna de su verdad. La ciencia exige y busca fundamentos lógicamente apropiados para sus proposiciones. La epistemología y la ciencia ponen de manifiesto el método científico, hasta que no se pueda dialogar de investigación sin tener que hablar de método científico. Se puede afirmar que entre la investigación científica y el conocimiento científico sé halla el método científico, que es el que asegura el primero y el segundo. El método científico es un procedimiento para descubrir las condiciones en que se presentan sucesos específicos, que se caracterizan generalmente por ser tentativo, verificable, de razonamiento riguroso y observación empírica (Tamayo, 2003).

Por ende, el método científico es un conjunto de procedimientos mediante los cuales se plantean los problemas científicos y se colocan a prueba las hipótesis y los instrumentos de trabajo investigativo.

Pardinas menciona: Método de trabajo científico es el proceso que se le debe dar para descubrir otros nuevos conocimientos o, en otros términos, para comprobar o desaprobar hipótesis que implican o predican conductas de fenómenos, no conocidos hasta el momento (Citados por Tamayo, 2003).

Esta sucesión de pasos como menciona Pardinas; aseguran la adecuada selección y formulación de un problema, a la toma de decisiones técnico-metodológicas sobre como observarlo en la realidad y a la adecuada interpretación de los resultados.

Según Ruth Vieytes (Bonilla, Hurtado y Jaramillo, 2009), el método científico se puede expresar en los siguientes momentos: 
- El momento epistémico, donde se plantea el objeto de la investigación y sus objetivos, en este momento se plantea el problema de investigación; el marco teórico, que establece la teoría del objeto; y se plantean las hipótesis que responden a las conjeturas que hace el investigador respecto a las posibles soluciones a la problemática planteada.

- El momento técnico-metodológico, que permite definir la manera en cómo se habrá de investigar; estableciendo la operacionalización de los conceptos y la definición de los indicadores; asimismo, se realiza la elección y diseño de los instrumentos, la determinación de la unidad de análisis y la muestra que habrán de utilizarse para observar al objeto de estudio; para proceder a la recolección de la información.

- El momento teórico, que establece el cómo construir y analizar los datos, se refiere a la validación, limpieza, construcción, análisis e interpretación de los datos; asimismo es en este momento donde se contrastan las hipótesis deduciendo las posibles soluciones al problema de la investigación.

Para la realización de este trabajo, se utilizó la metodología de R. Hernández Sampieri, Pilar Baptista Lucio y Carlos Fernández Collado (1995) donde el proceso de investigación está compuesto por ocho pasos que se siguieron para la realización de la presente investigación:

1. Planteamiento del problema: plantear el problema no es sino afinar y darle mayor estructura formalmente a la idea de investigación. El paso de la idea al planteamiento del problema puede ser a menudo inmediato, casi automático, o bien llevar una suma cantidad de tiempo considerable; lo que depende de qué tan familiarizado esté el investigador con el tema a resolver, la complejidad propia de la idea, la existencia de estudios previos, el empeño del investigador y las habilidades particulares de éste. De acuerdo con Kerlinger (1975), los criterios para plantear debidamente el problema de investigación son:

a. El problema tiene que expresar una relación entre dos o más variables.

b. El problema debe estar formulado visiblemente y sin ambigüedad como pregunta.

c. El planteamiento involucra la posibilidad de prueba empírica.

2. Elaboración del marco teórico: esto es analizar y exponer aquellas teorías, enfoques teóricos, investigaciones y antecedentes en general que se supongan válidos para el correcto encuadre del estudio (Rojas, 1981). La elaboración del marco teórico comprende dos fases:

a. La revisión de la literatura correspondiente que consiste en obtener, detectar y consultar la bibliografía y demás materiales que pueden ser útiles para los objetivos del estudio, así como en extraer y reunir la información más relevante y necesaria que atañe a el problema de investigación.

b. La adopción de una teoría o desarrollo de una perspectiva teórica, que consienta construir el marco de referencia.

3. Definición del tipo de investigación a realizar: Dankhe (1986), clasifica los trabajos de investigación de la siguiente manera en que se dividen en: explicativos, descriptivos, exploratorios, y correlaciónales. Esta clasificación es muy trascendente, debido a que según el tipo de estudio de que se refiera varía la estrategia de investigación, los datos que se recolectan, el diseño y la manera de obtenerlos, así como el muestreo y otros componentes del proceso de investigación.

4. Formulación de Hipótesis: el siguiente paso reside en establecer guías precisas orientadas hacia el problema de investigación o fenómeno se está estudiando. Estas guías son las hipótesis, las cuales indican lo que se está investigando o tratando de probar y pueden definirse como explicaciones tentativas del fenómeno investigado, formuladas a modo de proposiciones. 
5. Selección del diseño de la investigación: el término "diseño" es referido al plan o estrategia creada para responder a las preguntas de investigación (Christensen, 1980). El diseño señala al investigador lo que se debe hacer para conseguir sus objetivos de estudio, contestar las preguntas que se ha planteado y analizar la veracidad de las hipótesis formuladas en un contexto en particular. La elección sobre qué tipo de investigación y diseño específico se ha de seleccionar, depende de los objetivos que se hayan trazado, el tipo de estudio a realizar, (exploratorio, descriptivo, correlacional o explicativo), las preguntas planteadas y las hipótesis formuladas. Debiendo precisar si el diseño será experimental, cuasi experimental o no experimental.

6. Selección de las unidades de estudio: se refiere a la selección de la población o universo que se habrá de estudiar, el tamaño de la muestra, la representatividad de la misma y el procedimiento de selección. La selección de las unidades de estudio, está en función de igual manera del planteamiento inicial de la investigación.

7. Recolección de los datos: ya una vez seleccionado el diseño de investigación adecuado y la muestra apropiada que vaya de acuerdo con el problema de estudio e hipótesis, la siguiente etapa consistirá en recolectar los datos adecuados sobre las variables implicadas en la investigación. Recolectar los datos implica tres actividades estrechamente vinculadas entre sí:

a. Seleccionar un instrumento de medición. El instrumento debe ser válido y confiable, de lo contrario no se podrá basar en sus resultados.

b. Aplicar el instrumento de medición. Es decir, alcanzar las observaciones y mediciones de las variables que son de interés para este estudio (medir variables).

c. Preparar las mediciones obtenidas para que se puedan analizar correctamente (a esta actividad también se le denomina codificación de los datos).

8. Análisis de la información: por lo regular el investigador busca, en primer término, describir sus datos y posteriormente realizar análisis estadísticos para relacionar sus variables. Esto es, realiza análisis de estadística descriptiva para sus variables y luego describe la relación que existe entre éstas. Los tipos o métodos de análisis son múltiples. Pero cabe señalar que el análisis no es indiscriminado, cada método por sí mismo tiene su razón de ser y un propósito específico, no se deberán hacer más análisis de los necesarios. Siendo la estadística una herramienta matemática para analizar los datos.

La investigación se nutrió de materiales documentales y de procesamiento de los datos obtenidos durante el trabajo de campo. Los documentales permitieron fundamentar teórica y metodológicamente el tema de investigación, siendo de carácter general y especializado. Se consultaron libros, artículos de divulgación científica, revistas y periódicos, así como documentos históricos, archivos y documentos oficiales de gobierno y de la iniciativa privada.

En cuanto a los materiales derivados del procesamiento de datos, éstos fueron el resultado encuestas sociales dirigidas a todos los sectores de ambos municipios durante el año 2018 y 2019, donde se entrevistó a empresarios, funcionarios públicos, comerciantes, fabricantes de ropa, personal operativo y público en general quienes respondieron al cuestionario diseñado para recabar información pertinente para el logro del objetivo de la investigación; quienes aportaron información importante para el diseño de los cuestionarios aplicados. 


\section{Capítulo II Marco teórico y conceptual de la planeación territorial}

Este capítulo presenta los aspectos teóricos que permiten fundamentar el problema y dar soporte a las hipótesis planteadas. Se analizan los conceptos de región, de planeación, de desarrollo en las diferentes modalidades regional, local, y endógeno para establecer una relación entre la dimensión territorial de la explicación de los fenómenos sociales y económicos. Dentro del análisis presentado en el capítulo, se analizan las políticas de ordenamiento territorial de México, su situación actual y resultados de estas políticas, también se analiza la planeación territorial del país y se abordan conceptos de planificación.

\section{La región o territorio}

El territorio es un concepto que forma y ha formado parte del corpus teórico en las distintas vertientes del pensamiento geográfico, ya sea como parte de la geografía física, de la llamada teoría del análisis regional o bien de la geografía crítica, solo por mencionar algunas de las corrientes del conocimiento que han nacido en esta disciplina. Desde su origen, en la geografía, como en otras artes y disciplinas, el pensamiento crítico no se ha determinado por su unicidad, sino por la múltiple diversidad en sus maneras de pensar y de interpretar, sobre todo en los tiempos modernos, en los cuales la trascendencia de los acontecimientos es más volátil, de tal forma que en el pensamiento geográfico se puede hallar que "no ha existido una sola geografía sino una constelación de saberes geográficos, o sea una pluralidad y diversidad de pensamientos".

El territorio como concepto se refiere a elementos presentes en la realidad; o sea, describe los elementos empíricos que están contenidos en el objeto de estudio y hace más fácil la generación de nuevo conocimiento. El territorio puede formar parte de una teoría o estar implícito en varias teorías; pero éstas, al ser inconmensurables entre sí, (Kuhn, 1993), van a incurrir en el significado del concepto, éste no representa el equivalente contenido cuando se inscribe en teorías distintas y más aún cuando forma parte de una perspectiva más extensa como es el asunto de la constitución de un paradigma. Las relaciones sociales cambian y por ende los conceptos y las teorías también están en constante crítica. En la geografía, como en cualquiera otra disciplina, el territorio tiene un diálogo distinto con el investigador cuando forma parte de paradigmas diferentes; $v$. $g r$ : en los inicios de la época moderna el territorio tenía una clara autoridad de la cartografía, se constituirá en el sustentáculo fisiográfico de los emergentes Estados Nacionales y describirá los límites y fronteras que éstos poseen. A través de este concepto se podrá establecer el recuento de las montañas, mares, rios, desiertos, bosques, minerales, animales, flora; es decir la riqueza natural de los Estados Nacionales. Este concepto va a permanecer sin grandes cambios epistemológicos y será por medio de él que se describirán las características que guarda la superficie terrestre enla que descansa la acción de los seres humanos (Llanos, 2000).

\section{Territorio, organización y ordenación}

La preocupación por ordenar el territorio se acentúa en la mayor parte de los países desarrollados, a partir de la década de 1950 y se irá sistematizando en el último cuarto del siglo XX. En este último periodo también se refuerzan las teorías orientadas a lograr un desarrollo socioeconómico y territorial armónico, teorías que hoy se formulan en términos de desarrollo sostenible. Sin embargo, la necesidad de ordenar el territorio no es algo nuevo ni exclusivo de nuestro tiempo, a lo largo de la historia las diversas sociedades siempre se han apoyado en una determinada estructura territorial.

Algunos autores consideran que la organización y la ordenación del espacio son términos modernos que designan los trabajos orientados a modelar el espacio heredado para introducir en él nuevas estructuras técnicas, jurídicas y administrativas con la finalidad de sistematizar su utilización en función de objetivos fijados previamente, en mayor o menor medida. En realidad, la organización del espacio empieza con el dibujo del primer campo, la construcción de la primera muralla o el trazado del primer camino. La diferencia esencial con las intervenciones complejas, orientadas a ordenar la vida económica y social en las sociedades modernas, sería un problema de escala y de estructura (Salinas, 2008). 


\section{Planificación estratégica}

El concepto de planificación estratégica como es conocido hoy en día surge en los años ochenta en la Escuela de Negocios de Harvard y fue en primera instancia aplicado a la empresa privada, con el objetivo de alcanzar un mayor grado de competitividad en el mercado. Actualmente, esta herramienta funciona para elaborar planes de desarrollo regionales en que se usan métodos participativos, se trabajan las fortalezas y debilidades de un territorio y se trazan los posibles caminos o los también llamados lineamientos estratégicos para que sean regiones competitivas. Se destina para rescatar ciertas características muy especiales de algunas localidades y sus fortalezas para que sean ellas la base de un desarrollo local.

La planificación estratégica territorial y las propuestas del desarrollo territorial rural son justificadas por los autores, revelando que la centralidad que ha prevalecido en las propuestas de desarrollo rural (DL) ha sido muy poco incluyente en algunos países de América Latina con debilidades en la planificación regional. Y también, se expone como argumento principal la necesidad de fortificar el desarrollo local ${ }^{6}$ para actuar desde el territorio en el contexto de globalización (Reyna, 2015).

\section{Conceptualización de la estrategia}

De acuerdo con Koontz y Weihrich (2001), la estrategia radica en la determinación de los objetivos fundamentales a largo plazo de una empresa y la adopción de los cursos de acción y la asignación de los recursos indispensables para su cumplimiento. Para Garrido (2006), la estrategia es un componente en una estructura de cuatro partes. Primero están los fines a alcanzar; en segundo lugar, están los caminos en donde los recursos serán utilizados; en tercer lugar, las tácticas, las maneras en que los recursos que han sido usados han sido realmente empleados y, por último, en cuarto sitio, están los recursos como tales, los medios a la disposición. Para este autor el éxito de una estrategia estará en función de múltiples factores entre otros (Cruz, 2013).

- Lo apropiado del análisis de recursos, fortalezas, amenazas capacidades, debilidades, y oportunidades.

- La evaluación que se haya podido realizar de los competidores.

- La evolución del entorno y su consonancia con las previsiones, planes y cálculos.

- Las acciones de la competencia.

Castañeda (2009), cree que estrategia es un plan que le permite a la empresa alcanzar una ventaja importante sobre sus demás competidores. En este tenor, Porter (2008), considera que las estrategias admiten a las organizaciones lograr una ventaja competitiva por tres vías: el liderazgo en costos, la diferenciación y enfoque. Según Porter la estrategia competitiva tiene que ser fruto de una perfecta competitividad de la estructura del sector y sus variaciones tanto en el ámbito nacional como en el internacional y complementa que para poder competir se debe cuidar el manejo de cinco fuerzas a saber (Cruz, 2013):

1. La amenaza de nuevos competidores.

2. La amenaza de productos o servicios sustitutos.

3. El poder de negociación con los proveedores.

4. El poder de negociación con la competencia.

5. La rivalidad entre las empresas.

\footnotetext{
${ }^{6}$ Desarrollo local: Se basa en la identificación y aprovechamiento de los recursos y potencialidades endógenas de una comunidad barrio o ciudad. Se consideran potencialidades endógenas de cada territorio a factores económicos y no económicos, entre estos últimos: los recursos sociales, culturales, históricos, institucionales, paisajísticos, etc. Todos factores también decisivos en el proceso de desarrollo económico local (Ecured, 2018).
} 
Es razonable evitar las imposiciones desde diseños centrales de una determinada planificación estratégica del territorio, siendo muy probable que un enfoque de este tipo fracase. No obstante, ello no impide al menos dos tipos de enfoques. El primero refiere a que la planificación desde el territorio pueda ser promovida por el ámbito central nacional, aunque el contenido surja desde el propio territorio, por el elemento ya mencionado de que son los gobiernos y sociedades locales los que deben otorgar validez y reconocimiento. El segundo refiere a que debe existir determinada compatibilidad entre la planificación para el territorio y los desafíos y objetivos planteados a nivel nacional, no porque este último sea la simple suma de los territorios, sino por cierta coherencia y sinergia que debe existir para la sostenibilidad del desarrollo (Uruguay integra, 2011).

La idea de progreso es una de las cuestiones complejas del pensamiento social occidental moderno y contemporáneo. Este concepto sigue siendo utilizado de forma frecuente bajo alguno de los preceptos anteriores, lo que conlleva conclusiones erróneas, pues los puntos descritos por Cambra, aunque reflejan generalmente la realidad, no se cumplen en todas las ocasiones. De ahí que el mal entendido progreso no haya conducido siempre a la mejora en todos los ámbitos humanos ni de todos los territorios. Algunos han quedado al margen de las iniciativas de mejora, por eso ciertos autores hablan del desarrollo como "consecuencia de unos efectivos procesos de comunicación interna entre los diferentes actores de un espacio local" para poder hablar de un proceso global (Llobera, 2001). En este punto, lo local entra a formar parte del desarrollo (Juarez, 2013).

\section{Inicios de la Planeación Estratégica}

Aníbal Barca quien fue un general cartaginés que pertenecía a la dinastía Bárcida, se destacó por sus campañas en contra de los romanos. Es considerado como uno de los líderes militares más importantes de la historia por sus extraordinarias habilidades en la táctica y la estrategia en el campo de batalla. Cuando él ya planeaba conquistar Roma inició con la definición de la misión de su reino, luego diseñó las estrategias, analizó los factores del medio ambiente y los comparó y combinó con sus propios medios para establecer las tácticas, proyectos y pasos a seguir. Esto es lo que representa el proceso de planificación estratégica que se aplica aun hoy en día en cualquier empresa (Cuero et al, 2007).

La planeación estratégica formal con sus particularidades modernas fue introducida por vez primera en algunas empresas comerciales a la mitad del año 1950. En aquel tiempo, las empresas más importantes fueron especialmente las que desarrollaron métodos de planeación estratégica formal, nombrados sistemas de planeación a largo plazo. Desde ese tiempo, la planeación estratégica formal ha ido perfeccionándose de tal manera que en la actualidad todas las empresas importantes en el mundo tienen algún tipo de este sistema, y un número cada vez más elevado de empresas pequeñas que están siguiendo este ejemplo (Cuero et al, 2007).

La planeación estratégica es el proceso de crear y mantener una congruencia factible entre las habilidades, objetivos, y recursos dentro de un mundo que cambia constantemente. La planificación estratégica se puede definir como un enfoque objetivo y sistemático que permite tomar decisiones (David, 1998). En este sentido, supone un instrumento que les permite a las instituciones, unidades y/o territorios prepararse para afrontar las situaciones que se presentan en el futuro, ayudando con ello a orientar sus esfuerzos hacia metas reales de desempeño.

Cuando todos los elementos que forman un sistema avanzan juntos como un equipo que sabe lo que pretende lograr. Por medio del establecimiento y la comunicación de objetivos bien definidos los que forman parte de los subsistemas sociales, económicos y ambientales trabajan juntos hacia los resultados pretendidos, creando ventajas para sus contextos territoriales concretos (Perez, 2014).

El método diseñado para la elaboración/renovación de la estrategia tiene que garantizar la capacidad para articular la responsabilidad de los actores, quienes tienen el poder efectivo para promover (o impedir) los proyectos estratégicos que se vayan identificando de una forma rigurosa, con el hecho de que la estrategia de la ciudad responda de una manera positiva a las necesidades y retos del conjunto de los ciudadanos. El liderazgo político democrático es importante para que la planificación estratégica sea una herramienta para desarrollar aspectos relacionales (Perez, 2014). 
La Carta de Leipzig (2007), hace referencia explícita a un "enfoque integrado del desarrollo urbano" (Ministros responsables del Desarrollo Urbano de los Estados miembros de la UE, 2007), inspirado en un "acervo urbano común" (Atkinson y Rossignolo, 2009; González, 2011), acumulado en el ámbito de la regeneración urbana —especialmente en el marco de las iniciativas URBAN- (Blanco et al., 2011). Los pilares de este enfoque son: a) una perspectiva transectorial; b) la inclusión de nuevos instrumentos de gobernanza y gestión urbana; c) la selección de ciudades y zonas elegibles, al objeto de concentrar la financiación; y d) la creación de redes, la evaluación y el intercambio de conocimientos y experiencias (Comisión Europea, 2009 CE). Los excelentes resultados de esta metodología llevan a aseverar que "la mejor forma para alcanzar un desarrollo urbano sostenible es por medio de planes de desarrollo urbano integrado que se formen en torno a visiones a largo plazo para ciudades y barrios en su contexto regional" (Comisión Europea, 2009: 45).

Con la reforma de los fondos estructurales para el periodo 2007-2013 se produce la incorporación de la dimensión urbana a la política de cohesión, y se insiste en los procesos orientados a la transformación del territorio se convierten en un aspecto clave de las políticas urbanas (Healey, 2003), entre los que destaca la planificación estratégica: "las ciudades que han tenido una mayor transformación económica y social han dispuesto de un Plan Estratégico" (Pascual, Tarragona, 2009).

En este sentido, cabe señalar que, si tradicionalmente el principal instrumento transformador de un territorio había sido el plan urbanístico, la progresiva asunción de una visión relacional del territorio impone un estilo de planificación que permita abordar la cuestión del desarrollo urbano de acuerdo con un enfoque integrado (Martín y Merinero, 2010).

La importancia de adoptar un enfoque integrado con relación a la planificación urbana; y propone que todo apoyo gubernamental al desarrollo urbano deberá tener que basarse en planes de desarrollo urbano integrado; pide que el enfoque integrado pase a ser una condición vinculante cuanto antes, y a más tardar durante el siguiente periodo de programación, ese enfoque integrado debe ser una de las condiciones más trascendentales para conceder y ejecutar créditos de los Fondos Estructurales y para obtener créditos del Banco Europeo de Inversiones.

Progresivamente, la "perspectiva de proceso" se va reforzando en el marco de la nueva Política de Cohesión, especialmente desde la entrada en vigor del Tratado de Lisboa (2009), en virtud del que la "cohesión territorial" se convierte en una competencia compartida entre la UE y los Estados miembros. En este sentido, la Agenda Territorial 2020 (Ministros responsables de Ordenación del Territorio y Desarrollo Territorial UE, 2011) señala a los Estados miembros que para agregar los principios de "cohesión territorial" las regiones y ciudades tienen que desarrollar y adoptar estrategias integradas y planes espaciales adecuados para aumentar la eficiencia de todas las intervenciones que tengan que realizarse en un territorio.

De este modo, la Agenda Territorial se convierte en un "marco de política pública orientado a la acción" (action oriented policy framework) que constriñe a los ministros responsables de planificación territorial y desarrollo de los Estados miembros a identificar "vías prometedoras para la coordinación entre diferentes sectores, y realizar sugerencias para mejorar la cooperación entre los territorios y los portadores de intereses, haciendo énfasis en la necesidad de mejorar la gobernanza territorial multinivel" (Schmitt, 2011).

La reactivación del interés por la planificación estratégica de las ciudades debe ser entendida en este contexto (Le Galès, 2006). Por un lado, se ha visto cómo "el enfoque estratégico va calando progresivamente en los departamentos técnicos de la Comisión Europea y comienza a perfilarse como un posible requisito para la concesión de ciertas ayudas a ciudades y territorios" (Fernández, 2007: 633). Por otro, su consideración como instrumento de gobernanza convierte a los planes estratégicos en una "solución institucional ligera" para la consolidación de prácticas de cooperación en ámbitos geográficos complejos como las áreas metropolitanas y las regiones urbanas (Dente, 1990; Dente y Melloni, 2005; Perulli, 2007). 


\section{El concepto de desarrollo}

Una primera aproximación a la idea de desarrollo indica que está asociado y tiene su origen en la idea y concepto de progreso, la cual sostiene que la humanidad ha avanzado en el pasado a partir de una situación inicial en el primitivismo, barbarie o incluso nulidad, y que sigue y seguirá avanzando en el futuro (Garcia, 2014).

Es decir que el desarrollo humano es producto de un proceso lineal y unidireccional por el cual las sociedades avanzan desde estadios cultural, económica y socialmente poco evolucionados en dirección a estadios cultural, económica y socialmente superiores y en cuyo cenit se encuentra la sociedad y cultura occidentales.

Desde esta perspectiva, el desarrollo es entendido como un mero desarrollo material. Se trata de un concepto cuantitativo de desarrollo propio de los países occidentales, donde se concede una fuerte valoración a la opulencia en mercancías, por lo que la concepción del subdesarrollo desde esta perspectiva es entendida como carencia de bienes (Melchor, 2014).

Por otro lado, Tuñón plantea que es un error considerar al "desarrollo" como una simple categoría económica, sino que más bien éste debe ser considerado como una idea compleja, donde figuran también las ideas de progreso y globalización (Tuñon, 2000).

\section{Ciencia regional}

La Ciencia Regional tiene como objetivo final propiciar la felicidad y elevar el nivel y la calidad de vida humana conservando la armonía y la diversidad social y natural de las regiones; dicho de otra manera, su finalidad es el bienestar de la humanidad, mediante el logro de la relación armoniosa con lo natural y social de las regiones que la abrigan. Abarca aspectos prácticos, pero también teóricos. ¿Qué aspectos incluye la Ciencia Regional para poder lograr lo anterior? Algunas de sus herramientas fundamentales lo son los planes y los proyectos, ambas están mutuamente relacionadas, pues la primera es la actividad que trata de influir en el comportamiento futuro de la sociedad a través de la cual un sujeto o sujetos buscan como actuar sobre determinadas escenarios o problemas de la región, para cambiarla o guiarla de acuerdo con ciertos objetivos, bajo el supuesto de que estos propósitos no serán alcanzados al menos que se introduzca la acción intencionada lograda. Desde esta perspectiva la planificación regional es aquella actividad orientada a proyectar un futuro deseado y la forma efectiva de elaborarlo, algunos de cuyos resultados es el "plan regional" y los "proyectos" (Andrés, Torres, Maldonado, 2011).

La gobernanza presupone que el buen gobierno no puede estar solamente garantizado por los actores públicos, sino también por el funcionamiento eficaz de redes más o menos institucionalizadas de actores estratégicos que disponen de su agenda estratégica y de su propia autonomía (Ligov, 2002). Mas, sin embargo, esto ha llevado a defender en algunas ocasiones que la gobernanza significa un debilitamiento del gobierno; pero más bien parece que esto no es lo que sucede, sino que lo que se manifiesta es un cambio en la manera en que el gobierno ejerce su capacidad para controlar, de forma que los actores públicos que participan en las redes de políticas juegan un papel específico y privilegiado, puesto que tienen medios importantes de intervención (Mayntz, 2001). Se trata, por lo tanto, de un cambio en la naturaleza del gobierno, donde predomina la resolución en conjunto de los problemas en un área determinada del PP (Martin, Merinero, 2009).

Desde esta perspectiva, se puede afirmar que el gobierno es un propio reflejo del mundo (Winograd, 2002), lo que permite mantener que la gobernanza es propiamente de los escenarios complejos modernos (Marsh, 1998); la nueva manera que adopta la PP basada en el prototipo de las redes de actores públicos y privados, que se elabora como respuesta a las transformaciones del contexto social, de tal manera que es el contexto el que tiende a favorecer que el nuevo modelo de gobierno no sea jerárquico, sino que más bien esté basado en las dependencias y en las relaciones (Kooiman, 1993). El nuevo contexto al que responde la gobernanza como una manera de gobierno es caracterizado por lo siguiente: 
- En la sociedad actualmente no existe un conocimiento que sea único y duradero que sea válido para actuar, no hay un monopolio de los conocimientos de parte de ningún actor social, ni claro por parte del gobierno y, por lo tanto, no existe una respuesta de validez universal para solucionar los problemas. Para que se pueda actuar sobre éstos es más que indispensable contar con conocimientos especializados, lo que implanta la obligación de contar con los diversos actores en cuyas manos se encuentran esos conocimientos heterogéneos y específicos.

- Existe hoy en día en la sociedad actual una importante diferencia social asociada a una sectorialización y especialización de tareas, que está resistida sobre una diversificación de estructuras sociales, valores y pautas culturales. Esta diferenciación, está en relación con el tejido social, desagrega la capacidad efectiva de poder solucionar un problema social determinado por parte de un actor único.

- La sociedad civil ha experimentado una muy importante transformación, gracias a que los ciudadanos ahora disponen de una más grande cantidad y calidad de los conocimientos, lo que les ha conducido a reclamar mayores derechos ciudadanos, y que, por lo tanto, se produzca un ascendente papel político de la sociedad civil, que se concreta en la existencia de un más grande número de actores sociales colectivos y ciudadanos que ejercen una demanda mayor de participar en las decisiones que afectan a los problemas que tienen en común.

Los nuevos problemas sociales a los que hay que dar respuesta son otro de los puntos importantes en los que se concreta la complejidad del contexto. Estos nuevos temas son de una naturaleza muy variada y dinámica que introduce un componente bastante importante de incertidumbre. Así, los nuevos temas a los que tienen que dar respuesta la sociedad y, especialmente, las PP, tales como el medio ambiente, el desarrollo económico local, la cultura, la inmigración, la discriminación social, etc., introducen nuevos desafíos para los actores sociales y la necesidad de nuevos instrumentos para intentar atenderlos, lo que hace que las competencias necesarias para resolverlos sean más complejas.

Ya en lo estrictamente político, la complejidad se especifica en la transformación del interés y el esfuerzo político en los derechos universales, en un mayor esmero a los derechos ciudadanos relacionados a la extensión de los servicios públicos inmersos en el Estado del Bienestar, donde el mayor interés se centraliza sobre la validez y la eficacia del gobierno la acción de brindar los servicios públicos. Esto hace que los derechos de los usuarios, la satisfacción de la demanda y la calidad de los servicios sea la base sobre la que se articula la acción del gobierno (Prior, 1996). En este marco, la crisis fiscal de los gobiernos a finales del siglo XX y principios del actual y la dispersión del resto de recursos no económicos establece una acelerada dependencia de la eficacia de los servicios en la necesidad de coordinación y cooperación de actores políticos y sociales para atender a los problemas de un área de política pública cualesquiera que esta sea.

Otro de los elementos de la diversificación existente que procede de lo político se encuentra en el quebrantamiento de las estructuras administrativas a nivel territorial, que tienen que ver con el proceso de descentralización administrativa mediante el traspaso de competencias del gobierno central hacia otros niveles territoriales. Principalmente debido a la extraordinaria complejidad de los asuntos que hay que solucionar, la mayoría de las veces es necesaria la intervención conjunta de los distintos órdenes de gobierno, produciéndose, así, el desarrollo de lo que se ha llamado gestión multinivel de asuntos de política pública (Martin, Merinero, 2009).

\section{El desarrollo regional}

El DR es un proceso localizado de cambio social sostenido que tiene como objetivo último el progreso permanente de la región, la localidad el territorio, la comunidad y de cada individuo que resida en ella. Además de estar ligado estrechamente a un proceso de crecimiento económico (U. Gto., 2017).

La industrialización acelerada de Europa Occidental y de los EE.UU. Desde la segunda mitad del siglo XIX hasta los primeros años del siglo xx provocó un crecimiento económico en algunas áreas donde las actividades nuevas económicas iban tomando un papel fundamental en el proceso de desarrollo. 
Como un resultado de ello, las ciudades crecieron concentrando riqueza, servicios y población mientras que muchas otras áreas se quedaban olvidadas de ese proceso de rápida evolución. Estaba claro que la economía estaba orientada al crecimiento y los gobiernos no tuvieron mucha necesidad de intervenir directamente en ese proceso, sino solo proveer las condiciones ideales para las necesidades de los empresarios. Fue hasta los primeros años del siglo XX cuando nuevos teóricos (tales como Weber, Mumford, Odum, Veblen y otros) empezaron a darse cuenta de las implicaciones sociales y espaciales de tal crecimiento económico desequilibrado, así como del potencial de aquellas sociedades para desarrollar regiones enteras como parte del proceso de desarrollo global. Sin embargo, parece ser que todos ellos no pudieron cambiar las iniciativas de parte de aquellos Estados implicados en tal proceso (Bustamante, 1986).

Teoría es un organismo de ideas que se basa en procedimientos específicos otorgados por la observación de una serie de fenómenos en la realidad. Estos fenómenos son estudiados, en el asunto del desarrollo regional, por las diversas ciencias sociales y ambientales, las que nutren tal «concepto definido de desarrollo» (Friedmann y Weaver, 1979).

La práctica (sobre todo en la planeación regional) generalmente envuelve una iniciativa de parte del Estado. Aunque esta puede tomar multivariadas formas, siempre habrá un método específico de instrucciones y un concepto definido de desarrollo que lo ayude.

\section{El concepto de desarrollo regional endógeno o desarrollo local}

El desarrollo económico local o desarrollo regional se puede definir como un proceso de crecimiento y cambio estructural que, por medio de la utilización del potencial de desarrollo existente en el territorio, traslada a elevar el bienestar de la población de una localidad o región. Si la comunidad local es capaz de liderar el proceso de un cambio estructural, se encuentra entonces ante un proceso DL endógeno (Vázquez Barquero, 2000).

La hipótesis de partida de este concepto es que las localidades y territorios ambas tienen un conjunto de recursos (culturales, económicos, institucionales y humanos,) y de economías de escala que no han sido explotadas y que instituyen su potencial para el desarrollo. Bajo esta hipótesis, cada territorio o localidad se caracteriza, por ejemplo, por una determinada estructura productiva, una capacidad empresarial y tecnológica, un mercado de trabajo, un sistema social y político una dotación de recursos naturales e infraestructuras, una tradición y cultura, sobre los cuales se articulan los procesos de desarrollo (Diez, 2004).

Como se puede observar, este concepto de desarrollo reúne un conjunto de características y rasgos que le dan una configuración específica. Esta configuración es fruto de la evolución de, por un lado, el concepto tradicional de crecimiento económico y a su vez, de la concepción geográfica de región (Diez, 2004).

Olivera (1959), presentó una clasificación precisa no sólo de los conceptos de desarrollo y crecimiento, sino abarcando además las nociones de evolución y progreso.

Olivera entendía la noción de crecimiento económico como la expansión del producto social como función del tiempo, mientras que según su visión el desarrollo económico debía entenderse como el incremento de la razón del producto social real al producto social potencial, ambos en función del tiempo. Por progreso económico entendía el aumento en el grado de satisfacción de las necesidades sociales y por evolución económica a un proceso de cambio cualitativo en la organización económica de la sociedad o "cambio de estructura" (Diez, 2004).

Esta clasificación permite estudiar una gran variedad de situaciones, en lo concerniente a la relación entre crecimiento y desarrollo: casos en los que un país o región se desarrolla sin crecer o viceversa, países o regiones en los que el crecimiento es negativo pero el desarrollo positivo, etc. (Diez, 2004). 
En el año 1967, Furtado elaboraba una definición de desarrollo marcando su diferencia con el concepto de crecimiento económico:

"El concepto de desarrollo, abarca la idea de crecimiento, superándola. En efecto: se refiere al crecimiento de una estructura compleja. Esta complejidad estructural no es una cuestión de nivel tecnológico. En verdad ella expresa la diversidad de las formas sociales y económicas engendradas por la división social del trabajo"

\section{Modelos de desarrollo regional en América Latina}

Como se ha escrito en numerosas oportunidades, la experiencia en materia de PP de DR en América Latina puede ser rastreada con mucha exactitud en sus principios, circa 1947, momento en el cual se crean en México las Comisiones de Cuencas Hidrográficas (Papaloapan y Tepalcatepec las primeras) como organismos de DR enmarcados en el modelo de la TVA (Higgins y Savoie, 1995; y Barker y King, 1970, son referencias obligatorias para la historia de la Autoridad del Valle de Tennessee (TVA) en el primer caso y para la historia de la experiencia mexicana en el segundo), un año antes de que en Brasil se creara la CODEVASF (Comisión para el Desenvolvimento do Vale do Rio São Francisco). Se enfatiza políticas que ya tienen cincuenta años de vida, período más que suficiente para aprender lecciones y conclusiones de él (Boisier, 1998).

Amplias síntesis de las multivariadas experiencias latinoamericanas en materia de PP sobre desarrollo territorial se encuentran en Stöhr (1972), en de Mattos (1986) y en Boisier (1996a), estos dos últimos casos refiriendo más al corpus teórico de citadas experiencias. Los estudios recién citados son referencias muy generales a todo el subcontinente; algunos de los países más grandes tendrían, por decirlo así, secciones especializadas en cualquier biblioteca sobre DR. La experiencia de Argentina se puede revisar a través de diversos trabajos de Rofman, Rocattagliata, Coraggio, Gatto y otros; Brasil por sí solo requeriría enormes citaciones sobre la base de trabajos de Haddad, Rocha Magalhaes, Monteiro da Costa, Guimaraes Neto, Cavalcanti, Tolosa y tantos otros y para el caso de México, Garza, Hiernaux, Wong, Unikel son citas obligadas (Boisier, 1998).

Los modelos de DR, o territorial en un sentido más vasto, se han construido sobre la base de tres procesos: 1) la regionalización de los países; 2) la descentralización de los sistemas decisionales privados y públicos (y de las instituciones correspondientes) en ámbitos territoriales, y 3) el desarrollo mismo de las regiones, aparentemente descentralizado por pura definición. Del primero de estos procesos se puede dialogar como de un fracaso casi total; del segundo se puede opinar que aún no termina por configurarse y que la cultura centralista todavía domina la vida en América Latina, y del tercero cabe resaltar su rareza y escasez (Boisier, 1998).

Según un reciente trabajo del Programa de las Naciones Unidas para el Desarrollo, PNUD (1997), un último examen del contexto de la regionalización en América Latina (como institucionalización de una nueva distribución territorial, o sea, como una nueva división políticoadministrativa) arroja un panorama decepcionante. En efecto, a fines de siglo, sólo Chile, Nicaragua, Perú y República Dominicana muestran sistemas regionales establecidos y con rango institucional, de orden constitucional o simplemente legal. De estos casos, el de que tiene mayor real interés hoy es el de Chile, ya que la Constitución peruana de 1993 deja a las regiones como asuntos secundarios. Hay varios otros países en los cuales la regionalización es solamente de carácter administrativo, más bien como artificio planificador, como Brasil y Colombia, por ejemplo, tema que no deja de ser importante de todas maneras.

Se está aún muy lejos de haber triunfado, de haber vuelto realidad la premisa, tan empapada de las ideas de modernización social de los sesenta, de ser la regionalización una herramienta indispensable de la modernización, particularmente en tanto la idea de "modernización" era muy asociada con la disminución de las desigualdades (sociales y territoriales). Una nueva partición territorial ayudaría más al proceso de integración nacional (económica, física y sociopolítica), que es crucial para superar necesariamente la falta de integración interna, diagnosticada, no sin razón, como un serio escollo al desarrollo (Boisier, 1998). 
Posiblemente no era así, tal vez se redificó la región como concepto y como instrumento; el síndrome de Pigmalión ${ }^{7}$ no les fue ajeno a los antiguos planificadores regionales y a su importante creación. Posiblemente lo cierto era y es que el territorio es importante para la modernización, pero entendido de una forma flexible y compleja simultáneamente, en un abanico en el cual "región" pasa a ser un elemento o una configuración más entre muchas más (Boisier, 1998).

\section{Desarrollo regional y descentralización}

La relación DR, planificación regional y descentralización ha ingresado, en los últimos años, a un complejo proceso de revisión, ya sea en sus concepciones teóricas como en lo relativo a las experiencias que a partir de ellas se han realizado en América Latina en las décadas precedentes. La inclusión en el análisis de los procesos de diferenciación funcional y globalización está consintiendo replantear cuestiones que parecían tener ciertos niveles de confianzas en períodos pasados, a pesar de existir perspectivismos algunas veces encontrados. De hecho, estos replanteamientos han impactado desde las definiciones elementales de región hasta en sentido y plausibilidad que hoy tendría una planificación del desarrollo regional de corte centralista en estos nuevos escenarios. Críticas que, definitivamente, apuntan a configurar nuevos marcos explicativos para el DR y la descentralización bajo los nuevos parámetros de construcción de lo social. En un primer término, se dirá que el concepto de región ha sido analizado y determinado a partir de varios paradigmas, los que en suma se pueden identificar en dos grandes grupos. Uno que contiene todas las formulaciones que hacen abstracción de toda consideración histórica - social y así postulan conceptos que proyectan sean universales, por citar un ejemplo, la Escuela francesa de los espacios abstractos (Perroux y Boudebille), la escuela alemana de la región económica (Christaller y Lösch), y la región productiva (Teoría de la base económica). El segundo, agrupa a aquellas elaboraciones cuyo punto de partida es la afirmación de la vigencia de un sistema social históricamente definitivo, el cual da origen a toda concepción regional en la medida que sustenta que la ocupación de un territorio está restringida por el tipo de relaciones sociales que prevalecen entre los grupos humanos que se asientan en determinadas partes del continuo geográfico. Entre estas concepciones, están la de región espacial (Coraggio), la región integral (Rofman), la región histórica (Moreno y Florescano).

\section{Consideraciones histórico-conceptuales sobre el desarrollo local}

El tema de discusión sobre DL se inicia en el contexto de la crisis que tuvieron que sufrir los países industrializados en la década de los setenta. Desde de la cual se hace indispensable imaginar otras maneras de desarrollo que superaran cualitativamente las formas anteriores. La crisis y declive de las tradicionales palancas de progresión y clivajes ${ }^{8}$ de los modos de acumulación, así como la coexistencia de regiones hiperindustrializadas con otras en franca retroceso, exigían reflexionar acerca de "los modos de desarrollo" cuestionando la pertinencia de los mayores aparatos industriales concentrados. Por lo tanto, se revaloriza "la pequeña dimensión" como la respuesta más adecuada a la dinámica rápida del cambio tecnológico, sustituyendo la creencia en las macrodinámicas, los polos industriales y grandes proyectos por "lo pequeño y lo local". Reflexión inscrita dentro del Paradigma Económico Neoliberal, en boga para ese momento (Cárdenas, 2002).

Entonces e comienza hablar de "desarrollo de iniciativas locales" o DL como una alternativa ante la crisis, que va orientada a movilizar el potencial humano mediante acciones locales en diferentes campos, como la introducción de nuevas fuentes de energía, nuevas tecnologías, renovación de actividades tradicionales, la revitalización de la pequeña empresa innovación en la comercialización y en la prestación de servicios, etc. y ligado a ellos como instrumento fundamental para movilizar los recursos humanos: la capacitación y formación profesional. Estos son procesos que expresan la revalorización actual de la iniciativa tanto individual como colectiva que emerge en el contexto de la gran crisis, con efectos multivariados sobre las sociedades de dinamización efectiva de los tejidos sociales y económicos locales, así como la entrada en escena de nuevos actores (Cárdenas, 2002).

\footnotetext{
${ }^{7}$ El efecto Pigmalion puede manifestarse de distintas maneras. Un docente puede tener ciertas expectativas respecto de sus estudiantes, determinando finalmente el rendimiento de sus alumnos mediante sus previsiones. El efecto Pigmalion puede también puede aparecer cuando una persona logra concretar sus expectativas a partir de su convencimiento de poder hacerlo. (Pérez, Gardey, 2013).

${ }^{8}$ El termino clivaje no forma parte del diccionario de la Real Academia Española (RAE). Se trata de un anglicismo: un giro del inglés que se utiliza en nuestra lengua con referencia a una segmentación un quiebre o una disociación (Pérez, Gardey, 2018).
} 
De esta manera, la resignificación de lo local en los países mayormente industrializados, por una parte, tiene un clivaje de orden cultural, bajo el que cobra un sentido particular en el reconocimiento de tradiciones fuertemente arraigadas, en normas y valores que forman sólidas identidades que le conceden plena validez. Por otra parte, clivajes de orden político en la crisis de gobernabilidad y de las maneras de acción colectiva generadas por el Estado de Bienestar ${ }^{9}$ (Cárdenas, 2002).

\section{La planificación estratégica territorial}

En este inicio de siglo, América Latina tiene que plantearse en cómo volver a tomar el crecimiento, aprovechando los avances que se han originado en la gestión macroeconómica, especialmente en lo que se refiere al control de la inflación. Mas, sin embargo, estos avances no han bastado para promover el desarrollo, sobre todo en el ámbito local; de tal forma que es preciso encontrar un nuevo enfoque, que recobre la identidad local con sus rasgos culturales propios. Simultáneamente, habrá que modernizar los mecanismos de fomento y financiamiento que hagan más fácil la conformación de redes empresariales y le den fuerza al tejido social en el plano territorial (Helizalde, 2003).

Como parte de este proceso, se destaca el fomento de las aglomeraciones industriales como maneras de organizar la producción en un determinado territorio, en particular en los distritos industriales, que, con sus rasgos de acción colectiva, dan posibilidades a una mayor flexibilidad de la industria de cara al fenómeno de la globalización.

En América Latina, las circunstancias culturales y espaciales tal vez no sean las más idóneas para concretar aglomeraciones industriales del modelo distritos, al estilo europeo. Sin embargo, aún existe la posibilidad de inducir estos procesos, para lo que se requiere la formulación del PP predestinadas a la formación de redes empresariales y al fortalecimiento de las alianzas estratégicas entre los sectores público y el privado. Sólo de esta manera será posible posicionarse en los mercados de un mundo formado por bloques comerciales (Elizalde, 2003).

En todos los casos analizados en este estudio se puede observar que la ubicación de las aglomeraciones industriales y sus particularidades obedecen a tres factores: el apoyo de centros tecnológicos o universidades con una fuerte relación de investigación y desarrollo con las empresas situadas en el territorio; la presencia de empresarios innovadores (los llamados pioneros); y la mano de obra barata, principalmente en las aglomeraciones asiáticas y en la migración industrial hacia el nordeste de Brasil.

Al imponerse la convicción de la no viabilidad de cualquier forma de ingeniería social holística y cobrar impulso una indiscutible revolución anti keynesiana, en cuyo eje predominaron las ideas del pensamiento neoclásico sobre el rol central del mercado en la regulación económica, comenzó a hacerse realidad un cambio radical en los criterios básicos que debían conducir el diseño del PP.

De esta forma, ante el hundimiento de los experimentos voluntaristas de la mitad del Siglo XX, se disolvió la confianza en una concepción iluminada y strictu sensuautoritaria acerca de la gestión de las prácticas y de los sistemas sociales. En el nuevo escenario acabaron por imponerse las políticas de liberalización económica, en donde el mercado recuperó velozmente su papel de mecanismo básico para regular la actividad económica y el capital privado tomó su papel de protagonista primordial de los procesos de acumulación y crecimiento (Chaparro,2000).

En ese ámbito, predominó la convicción de que era inevitable descartar la posibilidad de un óptimo social, en tanto la gestión pública se debe imbricar forzadamente en procesos sociales modulados por una variedad de actores, que actúan y deciden motivados por valores, intereses y demandas diversas, acudiendo a estrategias que frecuentemente son contradictorias entre sí.

\footnotetext{
${ }^{9} \mathrm{El}$ estado de Bienestar es un concepto político que tiene que ver con la forma de gobierno en la cual, que no les falte nada, que puedan satisfacer sus necesidades básicas, proveyéndoles en este caso aquello que no puedan conseguir por sus propios medios y entonces se hace cargo de los servicios y derechos de una gran parte de la población considerada humilde o empobrecida vía definición ABC 2017.
} 


\section{Planificación estratégica urbana}

El objetivo principal de cualquier proceso de planificación estratégica urbana es el de influenciar el futuro de la ciudad mediante el consenso y la coordinación de las acciones que van a llevar a cabo los actores económicos y sociales. El término "Estratégico", es definido como una acción ejecutada que influirá en otras poblaciones-territorio y ocasionará la reacción de los mismos, pero, en este caso, las mutuas reacciones serán positivas y generarán sinergias. A esas mutuas reacciones es que se conoce como Interacción Complementaria. "La planificación estratégica" es una combinación de arte y conocimiento, a diferencia de las disciplinas económicas que apelan más al conocimiento (Blaccut, 2013).

La planificación estratégica es reciente aparición, pues su origen data sólo de finales del siglo pasado. Los expertos mencionan que la ciudad de San Francisco, California (en los EE. UU) fue la primera en crear y ejecutar un proceso de planificación estratégica urbana con el objetivo de tomar acciones coordinadas para afrontar con mayores posibilidades de éxitos circunstancias tales como los problemas emergentes de la acumulación de basura, el congestionamiento ocasionado por el tráfico vehicular y otros típicos de una ciudad grande. En el presente, la planificación estratégica urbana cambia en su óptica y en vez de establecer un conjunto de acciones para solucionar algún problema, más bien adelanta actividades para tratar de evitarlos (Blaccut, 2013).

La práctica de la planificación para la promoción tanto de creación de la riqueza, así como del bienestar de las ciudades y regiones se fundamentó como un ejercicio propio de la investigación científica en el Siglo XX. En la gran mayoría de los países occidentales en donde se ha ejercido, finalmente se aceptó que la planificación, y en particular la planeación, son herramientas útiles para la utilización racional de los recursos de toda índole, y que bien orientadas, no solo no suprimen la iniciativa ni la libertad de las organizaciones ni de los individuos, sino que inclusive pueden ampliarlas. La utilidad de estas herramientas fue promovida originalmente como técnicas meramente administrativas, pero paulatinamente han recuperado su papel de instrumentos que son promotores del cambio bien guiado y ordenado.

En medio del contexto de luchas ideológicas, económicas, y de poder para el manejo de las ciudades y regiones que se sucedieron durante este periodo, los ingenieros, arquitectos, urbanistas y los planificadores del desarrollo, han desplegado una tradición permanente en la ciencia y el arte de planificar las ciudades y regiones mediante sus "planes maestros" y de todo tipo (Andrés, Torres, Maldonado, 2011).

En los inicios del Siglo XXI, las personas, regiones y ciudades afrontan nuevos retos, que requieren intervenciones fundadas en una metodología establecida en la Ciencia que permitan adelantarse y controlar los hechos, ya que los desafíos que estos plantean son bastantes y muy poderosos para permitir que ocurran al azar. Las desigualdades regionales no solo no han desaparecido, al contrario, han aumentado. La escasez de recursos naturales básicos como el agua amenaza en convertirse en una indudable catástrofe tanto para las regiones ricas como también para las pobres (Andrés, Torres, Maldonado, 2011).

En regiones tradicionalmente atrasadas y con nula producción agrícola e industrial, todavía se requiere combatir la pobreza, asegurar su acceso al mercado, y por lo general, mejorar la calidad de vida a la par de las regiones más desarrolladas. Pero también es necesario mantener adecuadamente las regiones y ciudades afrontando el cambio climático, para impedir la destrucción del ambiente y la perdida de la diversidad biológica y cultural de las mismas.

Durante los inicios del Tercer Milenio la sociedad humana ha obtenido una mayor conciencia que si desea conservar su supervivencia, su reproducción económica y demográfica tiene que ser acorde a la renovación de los recursos naturales de las regiones y ciudades donde se establece, es decir, debe prever su sustentabilidad, la conservación de la diversidad biológica, social y cultural que tienen las regiones, así como aspirar a un desarrollo equitativo y armonioso, todo esto seguido por una creciente participación social, con acciones que son cada vez más efectivas y trascendentes, lo cual puede ser proporcionado por la planificación y la planeación. 
La planificación y la planeación resultan en este panorama herramientas indispensables para poder lograr la sustentabilidad del desarrollo de las regiones y ciudades actuales y futuras; así como asegurar la equidad y la colaboración de la sociedad regional. Se da por supuesto que ello se conseguirá mediante la puesta en práctica de formas acreditadas por la ciencia para abordar los cambios. Muy a pesar de las dudas que se le han impuesto, incluso a la planificación se la ha tratado de cambiar su nombre por el de "gestión", estas herramientas han desarrollado, fundamentalmente de herramientas rutinarias -caso de la planeación normativa institucional y empresarial-, a una planificación indicativa, participativa, y estratégica (Andrés, Torres, Maldonado, 2011).

\section{El soporte del crecimiento}

En los últimos años, diversos estudios demostraron que la inversión en infraestructura es la herramienta con mayor impacto para promover el desarrollo de un país. Esto tiene que ver con el efecto multiplicador que tiene la disponibilidad de infraestructura de mejor calidad que permite el aumento de la competitividad de las economías regionales, así como la puesta en producción de nuevas áreas. Incluso, según un informe del Banco Mundial (BM), estas inversiones podrían agregar per se una suba de alrededor del 1,7\% el PBI por año por un aumento de la competitividad a través del aumento de la calidad y disponibilidad de la infraestructura. Además, la inversión en infraestructura no sólo trae un aumento generalizado del ingreso, sino que ayuda a reducir la desigualdad, al dar mayores oportunidades al conjunto de la población, verificándose una correlación entre la inversión y la reducción del coeficiente de Gini (medida de la desigualdad). El debate acerca de la inversión en infraestructura y especialmente la forma de financiarla es un tema de discusión a nivel global. The Economist publicó en marzo de 2014 que se estima que el déficit mundial en infraestructura es del orden de 1 trillón de dólares estadounidenses (usd) al año (es decir un millón de millones (usd)), por lo que las inversiones requeridas previstas por ejemplo en transporte entre 2013 y 2030 serían superiores a los 22 trillones de dólares. Dentro de este debate, existen claramente matices y situaciones diferentes en cada caso. En los EE. UU el debate actual está centrado en cómo financiar y ejecutar el mantenimiento de su extensa red de transporte existente, mientras que en países en desarrollo como el nuestro, el hincapié está en analizar formas de desarrollar nueva infraestructura que permita el crecimiento sostenido a largo plazo, además de garantizar el correcto mantenimiento (Agosta, 2015).

\section{Planificación a largo plazo}

Una vez identificado que la inversión en infraestructura es la herramienta clave para el desarrollo sostenible y para lograr competitividad en términos logísticos, debemos destacar la importancia de planificar estas inversiones en forma sistemática. Cuando se piensa en desembolsos de centenares de miles de millones de dólares (usd), es evidente que el uso racional y la optimización de esos recursos son crítico para lograr resultados. Tal como hace una empresa privada al evaluar sus inversiones estratégicas (Agosta, 2015).

\section{Importancia de la Planeación}

Ante la decisión de la promoción de acciones de mejora o crecimiento en una comunidad, municipio o ciudad, y atender de esta forma las necesidades particulares de diverso orden (de salud, educativas, de convivencia de alimentación, de producción y generación de bienes y servicios, o de seguridad); tanto las autoridades como los diferentes grupos de interés que forman la sociedad organizada, se enfrentan a la tarea de realizar, articular, y coordinar una serie de acciones que una vez estructuradas y puestas en marcha hacen más fácil la obtención de resultados específicos. Bajo esta perspectiva, al diseño, producción y articulación de las acciones y recursos necesarios para la puesta en marcha de planes y propuestas de trabajo específicas que guíen a la obtención de resultados particulares en un periodo de tiempo determinado, se le ha nombrado proceso de planeación (SHCP, 2007).

La planeación vista como un proceso, constituye una técnica de análisis e intervención institucional, cuyos fundamentos están establecidos en el conocimiento de los estudios de organización, su aplicación ayuda a estructurar y coordinar el conjunto de trabajos y recursos que se mueven para la consecución de ciertos propósitos particulares que conforman su punto de partida (generación de un bien o servicio), los cuales se verifican por medio de la obtención de resultados específicos que vienen a satisfacer las necesidades diseñadas en dichos objetivos (SHCP, 2007). 
Esta nueva realidad, plantea la búsqueda de la planeación estratégica territorial, pero también nos lleva a preguntarnos ¿Cómo se conforma ésta?, ¿Cuáles son las variables que la integran?

La planificación territorial es interpretada como el análisis y evaluación permanente de las dinámicas y dimensiones que acontecen en determinados ámbitos espaciales del país, para identificar estrategias y quehaceres que promuevan cambios encaminados a perfeccionar las condiciones de vida de la población, mediante ejercicios participativos de construcción de acuerdos, para la identificación de iniciativas de inversión que orientan el desarrollo y que se reflejan en el Plan de Desarrollo (SEGEPLAN).

Así pues, y como resultado del análisis a los modelos de medición e índices de planificación estratégica, que se presentaron anteriormente; se analizan a continuación, las diferentes variables que integran la planificación estratégica regional y permiten medir el nivel de esta, en la región bajo estudio, tratando de responder a la pregunta que dio origen de la presente investigación.

\section{Variables de la investigación}

A continuación, se describirán las variables de la presente investigación, tanto las independientes como las dependientes.

\section{Infraestructura}

Se le llama infraestructura urbana (etimología: Infra=debajo) a aquella obra humana diseñada y dirigida por profesionales de Arquitectura, Ingeniería Civil, Urbanistas, etc., que actúan de soporte para el desarrollo de otras actividades y su funcionamiento, necesario en la organización estructural de las ciudades y empresas (Monroy, 2018).

El término, utilizado habitualmente como equivalente de obra pública por haber sido el Estado el encargado de su construcción y mantenimiento, debido a la utilidad pública y de los costos de construcción, generalmente elevados, comprende:

Las infraestructuras energéticas.

- Redes de energía eléctrica: alta, media y baja tensión, distribución transformación, y alumbrado público.

- Redes de combustibles: gasoductos, oleoductos, concentradoras, distribución.

Otras fuentes de energía: presas, energías eólicas, energías térmicas, energías nucleares, etc. (Monroy, 2018).

Las infraestructuras hidráulicas.

- Redes de agua potable: como son embalses, depósitos, tratamiento y distribución.

- Redes de desagüe: Alcantarillado o saneamiento y plantas tratadoras.

- Redes de reciclaje: Recogida de residuos de metal, plástico y demás, vertederos, incineradoras.

- Las infraestructuras de telecomunicaciones.

Redes de telefonía, internet y telefonía fija (Monroy, 2018) .

- Redes de televisión de señal cerrada o circuito cerrado.

- Fibra óptica.

- Celdas de telefonía móvil o celular. 
- Internet inalámbrico, conexiones Wi Fi, roaming, voz y datos.

\section{El conocimiento de la infraestructura}

El conocimiento de la infraestructura es definido como no solamente los recursos humanos que participan en los sistemas de infraestructura (en el diseño, la planificación, construcción y operación de infraestructura), sino también el conocimiento dentro de las instituciones que proveen un entorno favorable para los sistemas de infraestructura por medio de la prestación de los marcos legales y regulatorios. Esto incluye todos los de la política, la legislación planificación, reglamentos y códigos, el plan de desarrollo estratégico general para el país o región que proporciona la toma de decisiones y priorizar orientación acerca de qué invertir dónde y cuándo (Habitat, 2016).

Las instituciones relacionadas con la infraestructura y los servicios de la calidad de los servicios proporcionados por la infraestructura urbana están directamente relacionadas con la capacidad de los marcos institucionales. Marcos institucionales son importante para garantizar la viabilidad financiera y la planificación, regulación efectiva, la gestión y operación de la infraestructura urbana.

\section{Interdependencia Infraestructura}

Las redes de infraestructuras: Redes que representan las interdependencias que existen entre los activos (sistemas) de la infraestructura; estas interdependencias a veces pueden ser tanto físicos como sutil y no físico en la naturaleza. La interdependencia de la red puede ser más fácilmente de entender que la salida de una parte de la infraestructura de convertirse en la entrada a otra pieza de la infraestructura, por este medio asegurando nuevamente la función general y la cohesión. En términos de la interdependencia física más indiscutible que esto podría ser la dependencia del sistema de salud de la infraestructura que necesita el agua como un insumo vital para asegurar la función eficaz. En términos de la interdependencia sutil no física esto se ve ejemplificado por el conocimiento indispensable como insumo para la regulación de la infraestructura dentro de las instituciones.

\section{Resiliencia y enlace a la infraestructura urbana}

La progresiva necesidad de las ciudades del siglo 21 para gestionar y adaptarse a los efectos del cambio climático y la creciente urbanización enseña los conceptos explicados anteriormente. No es un requisito que se movilice la atención de un ser reactivo, se concentra en la respuesta a desastres efectiva a uno proactivo, por medio del cual se desarrolla una comprensión de qué, cuándo y dónde la infraestructura necesita que la pongan en su lugar y la forma de abordar la infraestructura urbana para impedir o minimizar los efectos de un fenómeno natural.

Sólo a través de la comprensión de por qué el costo de los desastres está aumentando gradualmente se puede empezar a abordar las causas. Cuando, por ejemplo, el clima interactúa con el entorno construido que puede causar daños que resultan de la pérdida financiera o pérdida de vidas ¿por qué pasa esto? ¿Fue la infraestructura construida mal (problema de activos)? ¿Fue la infraestructura mal cuidada por lo que no podía realizar tal como fue diseñado (problema de capacidad)? ¿Fue la respuesta al evento ineficaz? (Conocimiento y el problema de la institución), fue la escala del evento mayor de lo previsto? (Problema del conocimiento), fueron los códigos de construcción no muestra los cambios en el medio ambiente o las nuevas tecnologías (problema del conocimiento), o eran los códigos adecuados, pero no regulados de manera segura e implementado (problema de la institución) (Habitat,2016).

La infraestructura urbana se conoce, a veces, como Obra Pública, ya que era el estado quien preservaba y construía dichas obras puesto que la calidad de estas es elevada y al final son de utilidad pública, no obstante, en ocasiones son de tal impacto ambiental que pueden poner en peligro la salud de los habitantes.

Infraestructura procede de la palabra debajo, por lo que uno de sus significados tiende a significar: Parte de una construcción que está debajo del nivel del suelo.

En otras ocasiones son elementos o servicios que se perfilan de primera necesidad para la creación y funcionamiento de una organización (Arqhis, 2016). 


\section{Crecimiento urbano}

Según la ONU la mitad de la humanidad, 3500 millones de personas, vive ahora en ciudades; para 2030 casi el $60 \%$ de la población mundial se mudarán y vivirán en zonas urbanas. La acelerada urbanización, sin planificación e insostenible, está determinando que las ciudades de los países en vías de desarrollo sean el foco de problemas sociales y económicos (INFDM, 2017).

Ese crecimiento excesivo va de la mano con la proliferación de barrios pobres, con personas en condiciones de vida antihigiénica, hacinada, en zonas de riesgo, sin seguridad de tenencia de sus viviendas y de la tierra, así como con mayores desigualdades, disparidades, y discriminación.

El cúmulo de problemas que presentan actualmente las ciudades es posible aminorarse con una planeación y organización que genere mejores condiciones vida para sus pobladores (INFDM, 2017).

Para conseguir que las ciudades y sus asentamientos humanos sean seguros, inclusivos, resilientes y sustentables, se hace necesario que los gobiernos de sus municipios se comprometan y adopten modelos de urbanización sostenible.

\section{Las megaciudades}

Estas ciudades representan núcleos de población mayores a 10 millones de habitantes y actualmente hay 43 en el mundo. La primera, de ellas es la ciudad de Tokio, la urbe más poblada con 37 millones de personas, y, enseguida de ella, Nueva Delhi con 29 millones (ONU, 2018).

En este sentido, se pueden observar distintas dinámicas. En el caso de Tokio, se espera que la población se comience a reducir a partir de 2020, mientras que Nueva Delhi va a continuar creciendo hasta llegar a convertirse en la ciudad más poblada en 2028. Sin embargo, las megaciudades no serán quienes dirijan el crecimiento demográfico urbano, sino que esto lo harán las urbes con menos de un millón de habitantes, principalmente en Asia y África, serán las que liderarán la tendencia. Mientras que en las primeras vive una de cada ocho personas, las últimas acogen a cerca de la mitad de la población urbana mundial (ONU, 2018).

\section{Una urbanización sostenible}

El informe pone de manifiesto que entender cómo se desarrollará el proceso de urbanización en los años próximos resulta fundamental para cumplir los Objetivos de Desarrollo Sostenible (DS).

"La urbanización es un proceso que está en relación con los tres pilares del desarrollo sostenible: el ambiental, el social y el económico. De tal manera que, este informe es una herramienta muy eficaz para los planificadores de políticas urbanas o de desarrollo en general"

El crecimiento de la población urbana -principalmente en los países de ingresos bajos y medios, que son los que lideran la tendencia- involucra prestar atención a aspectos como el transporte, el alojamiento, la energía, los servicios educativos y sanitarios o el trabajo para poder satisfacer las necesidades de los ciudadanos. "No se puede generalizar en cuanto a los efectos de la urbanización", advierte Lina (ONU, 2018).

Por ello, los gobiernos deben emprender PP que eleven la calidad de vida tanto de los habitantes de las zonas rurales y rurales, simultáneamente que fortalezcan los vínculos entre ellas. Se trata de que los beneficios de la urbanización sean inclusivos, garantizando que todo el mundo, independientemente de su lugar de residencia, tenga acceso a un empleo decente, formación cuidados de salud, y un medio ambiente seguro.

"Un evento al cual este informe puede ser eficaz es la implementación de la nueva Agenda Urbana, que es legítimamente sobre los desafíos y las oportunidades que brinda el crecimiento urbano en el contexto del desarrollo sostenible" 


\section{La expansión desordenada y el modelo de desarrollo de las ciudades}

El crecimiento de las ciudades mexicanas se origina a finales de la década de los cincuentas. A partir de ese momento el estrecho vínculo entre el desarrollo económico y el incremento urbano comienza a reflejarse en el crecimiento acelerado de la migración del medio rural hacia el medio urbano (PNDU, 2014-2018).

En la década de los ochentas, México se convirtió en un país preferentemente urbano. Los datos muestran que es a partir de esa década y hasta nuestros, días que más de la mitad de la población mexicana ha habitado en las ciudades (PNDU, 2014-2018).

Mientras que, en 1900, el país contaba con 33 ciudades de poco más de 15 mil habitantes, en donde residían 1.4 millones de personas (10.4\% de la población total), para la década de los ochentas, 36.7 millones de personas, que representaban más de la mitad de la población, vivia en localidades urbanas. En el 2000 existían 343 ciudades, mayores a 15 mil habitantes, las cuales albergaban a 66.6 millones de personas que representaban $63.3 \%$ de la población nacional; y finalmente, para el año 2010 la cifra de ciudades aumentó a 384, alojando $71.6 \%$ de la población total del país. Las tendencias muestran que el proceso de urbanización continuará, aunque no con la misma velocidad que en las décadas anteriores, de tal forma que entre 2010 y 2030, la población urbana en México pasará de $71.6 \%$ a $83.2 \% .2$ (PNDU, 2014-2018).

El proceso de urbanización tuvo severas consecuencias sobre la configuración de los asentamientos humanos tanto urbanos como rurales en el país. Por un lado y esto se debió a que las ciudades no estaban competentes para recibir tales cantidades de población, el proceso migratorio no fue asimilado de forma sistemática. En las ciudades no existía una oferta suficiente de suelo apto y accesible por lo que millones de mexicanos se asentaron de manera irregular, sin verificar el uso de suelo (PNDU, 2014-2018).

Aún en tiempos recientes la inexistencia de suelo idóneo al interior de las ciudades y posible para los sectores más desfavorecidos de la población, sigue siendo un elemento que promueve el asentamiento de dicha población en zonas de alto riesgo. A nivel nacional, $11 \%$ de las viviendas en localidades urbanas se encuentran cerca o sobre el cauce de un río; $9 \%$ sobre barrancas y $2.3 \%$ se encuentra sobre rellenos sanitarios, cuevas o minas.

Las expresiones más dramáticas de la presencia de población en zonas de alto y muy alto riesgo se reflejan en fenómenos como el hundimiento del terreno en calles y viviendas, reportado como un hecho frecuente en $4 \%$ de las viviendas urbanas, cuarteaduras de muros por reblandecimiento al estar edificadas sobre terrenos arcillosos reportado por 5\% de las viviendas y deslaves y derrumbes de cerros por lluvias reportado por 4\% 4 (PNDU, 2014-2018).

Una segunda consecuencia del proceso de urbanización en México es el crecimiento desproporcionado de la mancha urbana. En las ciudades mexicanas el incremento del territorio urbano no siempre ha respondido a la tendencia de la expansión poblacional. Así, mientras la población urbana se multiplicó pos dos durante los últimos treinta años, la superficie urbana se multiplicó por seis.

Otra cara del proceso de urbanización en México es el efecto de la dinámica de migración actual. El patrón de migración ha ocasionado el despoblamiento de muchas localidades y ciudades, al mismo tiempo que genera flujos trascedentes hacia los centros de población más dinámicos. Este fenómeno se ha vuelto muy evidente y ha impactado, tanto a los ámbitos rurales, así como al urbano, incluyendo a las mayores zonas metropolitanas que décadas más atrás fueron polos de atracción para la población (PNDU, 2014-2018).

\section{Políticas públicas}

Idealmente, las políticas públicas deberían sentar las bases para una convivencia pacífica con igualdad de oportunidades de desarrollo, sin embargo, es claro que existen deficiencias en el marco institucional para estas acciones (Ceey, 2018). 
Las políticas públicas deben buscar el máximo beneficio posible para la sociedad. Deben ser capaces de proteger los intereses de la comunidad a través de un compromiso entre el Estado, las instituciones y la ciudadanía. Aquellos problemas o situaciones que la sociedad no puede resolver por sí misma requieren de la atención por parte de los responsables de elaborar e implementar las políticas públicas en México.

Las investigaciones y estudios realizados por el CEEY permiten presentar propuestas para políticas públicas viables, fundamentadas en información confiable y apoyadas por las mejores herramientas de análisis para obtener de esta manera diagnósticos acertados, con la movilidad social como eje rector (Ceey,2 018).

Uno de los factores de mayor relevancia al elaborar políticas públicas es la comprensión de la conducta humana. Los hacedores de políticas deben conocer a fondo los posibles efectos y el impacto que éstas tendrían en la sociedad al ser implementadas y tomar en cuenta la reacción pública. Para esto, la OCDE ha publicado un reporte, Behavioural Insights and Public Policy: Lessons From Around the World (Comprensión de la conducta: lecciones de todo el mundo), en el que se presentan ejemplos de los beneficios de aplicar el conocimiento conjunto acerca del comportamiento de los individuos en situaciones prácticas llevadas a la elaboración del PP.

Las políticas públicas son una respuesta a las exigencias y necesidades de la sociedad y como tal, requieren de ser dinámicas y flexibles, capaces de adaptarse y a la vez generar cambios en la dirección apropiada. Las recomendaciones del CEEY en la materia son un excelente punto de partida para que los creadores de políticas públicas tengan a la mano los elementos que requieren para realizar su labor con calidad y eficiencia (Ceey, 2018).

El campo de las políticas públicas urbanas es muy vasto, pues incluye todas aquellas acciones que llevan a cabo los distintos poderes del estado (ejecutivo, legislativo, judicial militar) en diferentes campos de la actividad económica, social, política, cultural, etc., que tienen efectos directos o indirectos, temporales o durables sobre las estructuras y el funcionamiento de las ciudades. Su existencia se remonta muy atrás en la historia: al surgimiento del estado y a las concentraciones llamadas ciudades. En América Latina se tendría que remontar a las políticas de fundación de ciudades indígenas o las de destrucción y fundación de las españolas o a las leyes de indias a mediados del siglo XVI (Pradilla).

Pero su mayor desarrollo ocurre con el surgimiento de la ciudad capitalista mercantil, la ciudad renacentista (Korn, 1953) alcanzando su mayor amplitud y profundidad en el patrón de acumulación de capital con intervencionismo estatal que siguió a la SGM a mediados del siglo XX y hasta 1980. Las políticas urbanas no han desaparecido ni desaparecerán con el neoliberalismo; pero si se ha modificado profundamente su forma, contenido y objetivos (Pradilla).

Las PP surgen como espacios centrales de mediación y resolución de problemas entre colectivos con diferentes particularidades. Una política es una complicada y flexible interconexión de procesos en la que las dificultades y sus soluciones son frecuentemente redefinidos o re-inventados. Éstas se deben considerar como propuestas de regulación pública de los múltiples problemas y contradicciones que confrontan las sociedades presentes. Asimismo, entraña un mecanismo de asignación pública de recursos y oportunidades entre los distintos grupos sociales con intereses y preferencias en conflicto (Brugué y Gomà, 1998).

Las políticas urbanas componen la dimensión espacial del Estado de Bienestar y, la regulación pública de la división social y económica del espacio. Estas tienen el desafío de diseñar y poner en práctica nuevos y poderosos instrumentos de regulación pública de la ciudad, si no se quiere que ésta sea el resultado estricto de la lógica del mercado. El ámbito sustantivo de la política urbana incluye los sucesivos sectores de actuación pública y de la gestión del territorio urbano: la localización y reestructuración económica del territorio, la regulación de usos por medio del ordenamiento urbanístico, el transporte colectivo, la vivienda en todos sus aspectos, y los equipamientos e infraestructura conectados a la oferta de servicios públicos (Ariana, 2012). 


\section{Capacidad de Gobierno}

La capacidad de gobierno expresa la habilidad para conducir y superar las dificultades a las que se enfrenta el proyecto. "La capacidad de gobierno (C) es una capacidad de liderazgo (...) es una capacidad de conducción o dirección que se acumula en la persona del líder, en su equipo de gobierno y en la organización que dirige. Se basa en el acervo de técnicas, métodos, destrezas y habilidades de un actor y su equipo de gobierno requeridas para conducir el proceso social, dadas la gobernabilidad del sistema y el compromiso del proyecto de gobierno. Capacidad de gobierno es sinónimo de pericia para realizar un proyecto" (Matus, 2007b: 22). (Jose, 2013).

Estas tres variables -Proyecto, Gobernabilidad y Capacidad- se encuentran íntimamente relacionadas, y es por ello que se las considera los vértices de un triángulo, el Triángulo de Gobierno: "el proyecto de gobierno es un conjunto de propuestas de acción, la gobernabilidad del sistema se refiere a posibilidades de acción y la capacidad de gobierno apunta a las capacidades de acción" (Matus, 2007b: 24).

El proyecto determina cómo el gobierno se propone alcanzar la situación deseada de una manera eficaz, a través de una combinación de valores y aportes de las ciencias. Representa la piedra angular del triángulo: "no es posible gobernar son un proyecto de gobierno, porque el proyecto de gobierno vincula lo que nunca se debió separar: el gobierno de la sociedad" (Bernazza, 2006: 54).

Si bien es necesario revisar las políticas públicas que se han aplicado y encontrar nuevas que permitan mejorar las condiciones económicas y sociales de la población, no hay un conjunto de propuestas rígidas -al estilo del Consenso de Washington- que determine cuál es el conjunto de medidas que deben aplicarse hacia el mediano y largo plazo. Las principales recomendaciones se clasifican en dos grandes líneas:

- Políticas para fortalecer los mercados: en este caso se busca fortalecer la acción autónoma del mercado a través de sus políticas monetaria y fiscal; la planificación estatal tiene un margen de acción muy acotado que se limita a la coordinación entre las políticas sectoriales y regionales.

- Políticas para la transformación productiva: aquí el eje se encuentra en incentivar a las empresas a crear nuevas ventajas competitivas, orientadas fundamentalmente a aquellos bienes que contengan valor mayor agregado y tecnología, corrigiendo las fallas de mercados en cuanto a la asignación de recursos. En este caso la planificación estatal tiene un amplio margen de acción.

García (2009), señala que "la planificación gubernamental y los sistemas institucionales para realizarla son útiles para cualquier gobierno que no se limite meramente a labores de administración de la institucionalidad pública y a jugar un papel pasivo ante los procesos económicos y sociales del país. Entendemos aquí la planificación gubernamental (...) como un proceso que articula de manera sistemática tres actividades: i) construcción de una visión estratégica y un plan de acción para transitar desde una situación actual a un escenario deseable; ii) coordinación de acciones y orientación de actores en la implementación del plan; y iii) monitoreo y evaluación para retroalimentar el proceso (visión, planes e implementación)".

Las políticas sectoriales, y su debida aplicación en los ámbitos federales y regionales, requieren de una organización coherente del territorio que les permita la promoción del desarrollo interno de las regiones con un sentido de eficacia y equidad económica y social, en equilibrio con los crecientes procesos de democratización (Delgadillo, 2004).

Simultáneamente, se deben promover aquellas regiones cuyos potenciales expresados en recursos naturales y productivos les han permitido procesos de desarrollo más dinámicos a partir del aprovechamiento de sus propias gestiones regionales, sus relaciones intranacionales pero, sobre todo, el marketing internacional que hoy se manifiesta como un proceso de relaciones mundiales que está presente en las ciudades del país. 
Las funciones de gobierno tienen, por ende, corresponsabilidad con estos quehaceres de la promoción económica regional y de la sociedad civil organizada inmersa en estas unidades territoriales. Estas nuevas funciones deben plantearse por medio de mecanismos y maneras actualizadas de administrar los recursos locales, darle promoción al desarrollo regional y atender las demandas de la población que se manifiestan con argumentos cada vez más propios de una expresión colectiva.

Sin embargo, esta forma nueva de pensar, el trabajo público gubernamental está aún distante de manifestarse como una expresión muy general en el territorio nacional; lo que hoy se puede observar es una participación coordinada entre los niveles, municipal, estatal y federal que se manifiestan más como reacción a la presión que brota de las demandas sociales, económicas y políticas , con respuestas parciales y por lo general desarticuladas que hacen de lado una visión territorializada de los problemas que agobian al país en su conjunto y a las regiones en lo particular.

En lo internacional, como lo manifiesta Paolo Bifani (1998), la influencia que la globalización produce en el ámbito regional por la escala, intensidad, profundidad, complejidad y velocidad, afecta procesos de participación social y política, y determina, en varios casos, acciones de economía local a las cuales se deben atener las nuevas relaciones humanas en el campo, en las ciudades y en general en el conjunto de los procesos productivos que se realizan en el territorio nacional. El ámbito local e internacional se vigilan uno al otro y por lo tanto las exclusiones quedan demostradas, de manera que obligan a acciones prontas en las que todos los niveles regionales se miran en un mismo espejo de la globalización (Delgadillo, 2004).

\section{Utilización del agua en la planeación}

Otro factor muy importante en la planificación estratégica es el uso del agua, ya que este recurso es sin duda el agua, desde siempre civilizaciones antiguas, buscaban lugares para establecerse donde hubiera una fuente de agua, de ahí comenzaron a establecerse las primeras comunidades.

\section{El agua y asentamientos humanos en el futuro}

Uno de los más grandes retos del siglo XXI es mejorar la seguridad del agua potable y tener un saneamiento básico para todos. A la fecha, cerca de mil millones de personas no tienen acceso a fuentes mejoradas de agua y más de 2,600 millones de personas carecen de acceso a saneamiento básico; casi todas ellas viven en ciudades de países en vías de desarrollo. A la fecha, varias ciudades alrededor del mundo confrontan una gama de presiones dinámicas a escala regional e internacional, las cuales son crecimiento poblacional, cambio climático, deterioro de los sistemas de infraestructura urbana, entre muchas más. Debido a estas presiones, las ciudades del futuro sufrirán dificultades en el manejo eficaz de recursos hídricos cada vez más escasos y menos confiables, y en proporcionar suficiente saneamiento a la población (UNESCO, 2019).

En el pasado, las vías de desarrollo urbano crearon sistemas muy complejos de infraestructura y marcos institucionales que interactúan y se influyen mutuamente. Las estrategias para desarrollar sistemas de agua urbanos resilientes deben adoptar una perspectiva más amplia, que reconozca la interdependencia de los distintos sistemas hídricos. Las realidades en el terreno y los desafíos de las presiones futuras han hecho evidente que las cosas no pueden seguir operando por la misma vía. Es necesario desarrollar nuevos enfoques para el manejo de los recursos hídricos en las ciudades del futuro (UNESCO, 2019).

\section{Cuestión de derechos}

El agua es un elemento indispensable para la vida. La ONU reconoció el agua y el saneamiento básico como un derecho humano. Estos reconocimientos implican que los Estados firmantes, entre ellos los centroamericanos, deben garantizar que todas las personas tengan acceso al agua y al saneamiento en condiciones adecuadas. Estas condiciones son (Sanjuan, 2012):

- Suficiente: el abastecimiento de agua de cada persona debe ser continuo y en cantidad suficiente para beber y para usos personales y domésticos. 
- Sana: debe de estar libre de agentes contaminantes que puedan afectar la salud de quienes la utilizan.

- Accesible físicamente: tanto el acceso como el saneamiento del agua debe de estar al alcance de todos y todas, y nadie debe tener que recorrer grandes distancias para obtenerla.

- Accesible económicamente: debe estar al alcance económico de todas las personas, de modo que el tener poco dinero no represente una limitante para acceder al agua.

- Sin discriminación: las anteriores condiciones de acceso al agua y al saneamiento deben ser válidas para todas las personas, incluso para los sectores más frágiles y marginados de la población, sin ninguna discriminación.

- Acceso a la información: toda persona tiene el derecho de solicitar, recibir y difundir información sobre las cuestiones del agua.

\section{Cuestión de bienestar social}

Lógicamente, si el abastecimiento y el saneamiento son derechos fundamentales, éstos son necesarios para el buen desarrollo de las personas, y por ende la falta o el deficiente acceso repercuten en las condiciones de vida y en las posibilidades de progreso y realización individual y colectiva. Si el abastecimiento de agua estuviera garantizado, las mujeres podrían dedicar el tiempo que utilizan en ir a buscar agua cada día, a educarse o a otras tareas productivas o recreativas. Son las mujeres y las niñas quienes sufren en mayor medida las consecuencias de la falta de acceso al agua porque, además del trabajo de acarrearla, la falta de agua hace más dificultosas las tareas domésticas que les han sido asignadas. Esta situación profundiza las desigualdades de género en que viven. La falta de acceso al agua y su saneamiento no contribuye a que las personas salgan de la pobreza y la exclusión, por tanto, es un indicador negativo del desarrollo personal y económico en los países (Sanjuan, 2012).

\section{Lineamientos básicos de política pública sobre el uso del agua}

La formalización que exigen las políticas públicas solo será posible si se cuenta con una normativa adecuada en la que se incluyan las bases para su adopción y ejecución. Esa normativa debe proporcionar una estructura organizativa de los poderes públicos que sea facilitadora de la adopción, coordinación y ejecución de tales políticas y contemplar además una estructura institucional para la gestión del agua basada en la existencia de organismos de cuenca. Finalmente, la información de calidad es imprescindible para que los poderes públicos adopten decisiones, lo que debe tener su traducción específica en datos estadísticos, catastros y registros públicos, preferentemente georeferenciados utilizando tecnologías de la información actualizadas que reflejen la situación existente CEPAL, 2018).

\section{Normatividad adecuada}

Una normativa adecuada es una condición imprescindible para la posterior adopción y ejecución de las políticas públicas para un mejor manejo del Nexo. Todos los países de la región disponen de normativa en los ámbitos del agua, la energía y la alimentación. Ella proviene de distintas épocas. La cuestión básica es si esa normativa es adecuada para las exigencias que plantea la consideración conjunta de los componentes del Nexo teniendo en cuenta el sustrato ambiental de todos ellos y sus interrelaciones. Para ese ámbito se formulan a continuación una serie de recomendaciones generales con el objetivo de mejorar la forma y el fondo de las distintas normativas existentes en los países de América Latina y el Caribe (CEPAL, 2018). 


\section{Una ley de aguas moderna}

Una ley de aguas moderna significa una ley adecuada a la problemática actual; es decir, que contenga los elementos conceptuales y técnicas de acción imprescindibles que se han ido incorporando en los países más avanzados. En América Latina y el Caribe, se han elaborado varias leyes de aguas en los últimos diez años (Embid y Martin, 2015; Hantke-Domas, 2011), pero en la región todavía quedan países que no tienen una ley de aguas (como Colombia, El Salvador, Guatemala y Haití). Otros países cuentan con leyes de aguas, pero muy antiguas (Bolivia, Costa Rica, Panamá y República Dominicana); o también, sucede que las tienen con escasa posibilidad de aplicación debido a la ausencia de desarrollo reglamentario (como Paraguay). En otros casos se viven procesos de reforma normativa para adecuar antiguas leyes o crearlas de nuevo, pero estos intentos se alargan excesivamente (por ejemplo, Costa Rica, El Salvador, Guatemala y México) (CEPAL, 2018).

Una ley de aguas moderna debería cumplir al menos los siguientes requisitos generales (CEPAL, 2018):

- Consideración del agua como un recurso natural y, además, estratégico. Esto implica la regulación de técnicas de protección y conservación tanto del agua como de los ecosistemas, con atención especial a la preservación de las fuentes de agua. Todo con vistas a la trasmisión del recurso a las generaciones futuras con mejora (o, al menos, no deterioro) de su calidad, lo que implica: prever normativamente la depuración de las aguas residuales urbanas, el establecimiento de caudales o flujos ambientales y tener en cuenta las exigencias que, en relación con la utilización y protección del agua, determina el cambio climático.

- Consideración del agua como bien económico o que tiene valor económico. De ello se implica la existencia de un régimen económico-financiero racional con presencia de un sistema de precios del agua, con sus diversas denominaciones de tarifas, cánones o tasas. Mediante este recurso se busca que sirva, entre otras cosas, para desanimar los consumos excesivos y las descargas sin tratamiento apropiado o sin respetar la capacidad de asimilación de las masas de agua. Paralelamente, debe tenerse en cuenta la diferencia de capacidad económica entre los sujetos que deben acceder a ella y, también, que la asignación del agua (mediante autorizaciones, concesiones u otra figura jurídica) a las actividades económicas que la utilicen (industria, regadío, acuicultura, usos recreativos, etc.) sea expedita, con un procedimiento administrativo rápido y transparente, que se base en criterios objetivos y técnicos.

- Consideración del agua como un bien social, perspectiva que supone la incorporación de políticas de participación de la sociedad en la gestión del agua (fomento de las organizaciones de usuarios, procesos de información pública en relación con importantes decisiones, libre acceso a la información en poder de las administraciones públicas sobre el sector del agua, lo que implica la aplicación de una política de transparencia, consejos consultivos interinstitucionales, etc.). Esto significa también la necesidad de incorporar las diferentes realidades sociales que influyen en el aprovechamiento de agua en la región, como es el caso de la agricultura familiar (derecho de las comunidades rurales, mecanismos compensatorios, gestión de servicios ecosistémicos e incentivo para la protección y mantenimiento de los recursos naturales, entre otros).

Prever procedimientos que permitan en el marco de decisiones concretas aunar las tres perspectivas (ambiental, económica y social) del agua haciéndolas compatibles entre sí. A ello pueden servir la evaluación de impacto ambiental y territorial de planes hidrológicos y obras hidráulicas, y la planificación en el ámbito de cada uno de los tres sectores del Nexo con coordinación entre las distintas planificaciones.

Contemplar una estructura institucional adecuada para la gestión del agua basada en la existencia de organismos de cuenca (o denominaciones semejantes que reflejen la presencia de autoridades desenvolviendo sus competencias dentro de espacios "naturales" de gestión, como las cuencas hidrográficas). 
- Incluir la previsión de un registro o catastro de derechos de uso de agua que responda a la situación real de las utilizaciones, así como de un registro de las autorizaciones de vertido o vertimiento (descargas) a cauces públicos. Con políticas para conseguir la regularización de los usos y vertidos informales con los correspondientes incentivos para ello.

- $\quad$ Incorporar la planificación hidrológica con un régimen jurídico correspondiente.

\section{Planificación estratégica y desarrollo productivo local}

En este contexto, la planificación estratégica se puede definir como una forma sistemática de gestionar el cambio y de implantar el mejor futuro posible para una determinada organización, empresa, entidad, o territorio. Es un proceso creativo para reconocer y realizar las acciones de mayor importancia, pero hay que tener en cuenta los puntos débiles y fuertes, y los retos y oportunidades futuras.

La planificación estratégica puede auxiliar a los gobiernos locales y a los organismos privados y públicos a gestionar con éxito los cambios rápidos que se han experimentado en los últimos años.

La planificación estratégica aplicada al territorio local trata de fijar una serie de propósitos, a mediano y largo plazo, acerca de la organización del desarrollo del territorio y definir aquellas actuaciones que permitirán lograr los objetivos tomando en cuenta el comportamiento probable del entorno tanto externo como local.

Las características más relevantes del proceso de planificación estratégica a nivel local son las que siguen a continuación (Bitar, s.f.):

1. Se centraliza en los temas seleccionados como que son prioritarios y claves.

2. Considera claramente la disponibilidad de recursos.

3. Analiza los puntos débiles y fuertes del territorio en relación con su propio desarrollo.

4. Contempla los grandes acontecimientos y cambios que están sucediendo fuera del entorno estrictamente local (ya sea nivel internacional o nacional).

5. Se sitúa a la acción, con un énfasis fuerte en los resultados prácticos.

\section{La conurbación: acontecimiento urbano y ambiental}

La conurbación es un fenómeno por medio el cual dos o más ciudades se integran territorialmente, independientemente de su tamaño, de sus características particulares y de la adscripción administrativa que posean. El término conurbación fue acuñado en 1915 por Patrick Geddes cuando, hacía se refería un área de desarrollo urbano en donde una serie de ciudades diferentes habían crecido al encuentro unas de otras, unidas por intereses comunes: de negocios o industriales, o por un centro comercial o recreativo común (Moreno, 2008).

Este término tiene sentido de continuidad y se puede aplicar tanto al proceso como al resultado. La integración física -como hecho material- a la vez que es un resultado, es generador de varias dinámicas de interacción en lo cultural, lo social, lo económico, lo político, etc. Estas dinámicas no siempre tienen un correlato con el contexto político - administrativo en el cual se desenvuelven y en muchas ocasiones ello genera tensiones y rupturas que originan repercusiones territoriales. La conurbación, que además se califica como proceso de "juntamiento" o "pegamiento", da lugar a una nueva territorialidad a manera de un rizoma que extiende sus tallos horizontalmente bajo el suelo, para brotar de nuevo a la superficie con la forma de más vida. En la conurbación coexisten la integración y la escisión, pues se trata de rizomas en interacción en los que los encuentros y desencuentros se suceden al mismo tiempo y en forma cotidiana (Moreno, 2008). 
La conurbación, se entiende como proceso, es un fenómeno poco investigado. Usualmente se le estudia como el hecho físico de conjunción de ciudades en el espacio, y para ello se utilizan definiciones como la conurbación, el conurbano o el conurbio (vocablo italiano), se le reconoce como conformación territorial única pero raramente se habla de la conurbación como permanente dinámica.

Tal fenómeno ocurre en diferentes regiones en el mundo y en Colombia ha adquirido una gran dinámica en los cuarenta años (Moreno, 2008).

En la ciudad se da una conjunción de acontecimientos, inclusive contradictorios, ella misma actúa como un tejido, un "patchwork [formado por] enormes suburbios cambiantes, provisionales, de nómadas y de trogloditas, restos de metal y de tejido" (Deleuze y Guattari, 1994: 490) y la conurbación es un tejido constituido por otros diferentes tejidos que encuentra en la heterogeneidad su característica propia, una conexión de las diferencias que le hace un fenómeno culturalmente diverso a la vez que un hecho ambiental complicado.

Este fenómeno requiere ser leído e interpretado con una gran firmeza académica y una postura crítica pues en la dinámica de la conurbación se establecen, de un lado, interesantes tejidos sociales y culturales que forman nuevas territorialidades y de otro lado, una fuerte impronta dejada por las instituciones en el espacio a través de las fronteras y delimitaciones que se establecen para su administración y gestión. Un tratamiento no adecuado de las nombradas zonas de frontera o de borde es fuente de rupturas y desintegraciones que configuran un problema ambiental (Moreno, 2008).

El pensamiento ambiental complejo es la lente que permite la lectura e interpretación que se necesita para enfrentar la escisión y los dualismos que poco consultan con la trama de la vida que se presenta en las ciudades pues los desarrollos tecnológicos y las dinámicas culturales y urbanas han permanecido -y siguen estando- signadas por la modernidad como el gran paradigma de Occidente por medio de la aplicación de modelos como el desarrollo y algunas herramientas técnicas de la planeación urbana, la gestión ambiental urbana y la sostenibilidad ambiental urbana, entre otras más (Moreno, 2008).

En México se ha documentado desde el año de 1940 la presencia del fenómeno de conurbación y metropolización, originado por la expansión física y funcional de sus principales ciudades, quienes han desempeñado un papel importante dentro del proceso de urbanización del país. La formación de zonas metropolitanas en el estado de Guanajuato corresponde con el desarrollo, social, económico y tecnológico lograd por la sociedad en un período de tiempo determinado y que forma una estructura territorial compleja que comprende distintos componentes: la especialización económico-funcional, la concentración demográfica y la expansión física sobre ámbitos que implican dos o más unidades político-administrativas, ya sean éstas estatales o municipales. Es por esa razón que, las metrópolis son espacios estratégicos de vinculación entre las diversas regiones del país, fungiendo como centros de actividad económica y de otorgamiento de servicios a nivel regional. El estado de Guanajuato se destaca por contar con cinco zonas metropolitanas que están dentro de su territorio y con uno de los sistemas de ciudades más extensos y dinámicos del país, además de su infraestructura (Iplaneg, 2012).

\section{Zonas Metropolitanas en el Estado de Guanajuato}

Luego del análisis de la información en las zonas en donde se pone de manifiesto la presencia del fenómeno de conurbación y metropolización, se ratificaron las condiciones socio demográficas y económicas las cuales muestran el alto nivel de integración e interacción funcional que existen entre los municipios de las zonas metropolitanas, circunstancias que concuerdan con el sentido de pertenencia e identificación de los habitantes de las zonas, reconocidas en la entidad.

Dicho reconocimiento ha favorecido la implementación exitosa de programas estatales para el DR que durante años han permitido la ejecución de proyectos de alcance regional y estatal, y la consolidación de una cultura de coordinación y gestión intermunicipal presente en la zona (Iplaneg,2012). 
En complemento y respecto de los criterios definidos en conjunto por la SEDESOL, CONAPO e INEGI en el documento "Delimitación de Zonas Metropolitanas de México 2005", a continuación, se resumen los que para el caso aplican, para las zonas metropolitanas en el estado. Las cinco zonas metropolitanas en el estado se señalan a continuación:

- Z Zona Metropolitana de La Piedad, Michoacán-Pénjamo, Guanajuato.

- Zona Metropolitana de León Guanajuato.

- $\quad$ Zona Metropolitana Irapuato Guanajuato-Salamanca Guanajuato.

- Zona Metropolitana Rio Laja-Bajío.

- Zona Metropolitana Moroleón, Guanajuato-Uriangato, Guanajuato-Yuriria Guanajuato.

Las zonas metropolitanas abarcan el $32.2 \%$ de la superficie del total del estado. 19 de sus 46 municipios (42.22\%) forman parte de las 5 zonas metropolitanas (Iplaneg, 2012).

\section{EI Municipio como gestor de Desarrollo Sustentable}

El desarrollo se caracteriza por el peso asignado al papel del estado en la toma de decisiones; la separación marcada de las esferas políticas, económicas, y sociales ; el otorgamiento de un papel privilegiado a la economía; la promoción de políticas sociales sectoriales, centralizadas, y asistencialistas (Gómez Luna \& Estrada Frómeta, 2009); sin embargo, la incorporación de la sostenibilidad a los diferentes ámbitos de la sociedad involucra un proceso de adaptación y constituye un desafío, sobre todo en el ámbito local (Garizurieta, Garizurieta, Mavil, 2013).

El tema del desarrollo municipal se relaciona con progreso y crecimiento, aunque, es necesario ir más lejos de la construcción de obra física y del progreso de los indicadores económicos, se debe traducir en impacto favorable en la calidad de vida de sus habitantes (Gómez, 2011). Para Gómez Luna \& Estrada Frómeta (2009), el desarrollo es un proceso de propósitos múltiples que, por su carácter y dinámica, solicita una adecuada planificación y gestión estratégica; por lo que las condiciones que consigan establecer los gobiernos municipales va a determinar su capacidad de competencia. De acuerdo con López y Sanín citados por Gómez Díaz (2011), el desarrollo municipal tiene que atender elementos, económicos, sociales y productivos, el desarrollo sustentable, gestión de recursos, demandas ciudadanas, tecnología, conocimiento, servicios públicos, competitividad, educación ciudadana, participación, bienestar, gestión institucional, y calidad de vida. Lo que involucra un esfuerzo conjunto y responsable por cada uno de los actores que intervienen (autoridades, servidores públicos y habitantes).

Tanto la Administración, como la gestión municipal son fundamentales para atender de manera oportuna los asuntos gubernamentales, así como lograr un adecuado manejo de los recursos públicos.

Se sabe que, aunque muchas de las veces las administraciones locales no cuentan con los recursos necesarios para emprender determinadas acciones, tienen el conocimiento específico del territorio, para identificar los recursos que de manera potencial permitirán impulsar el cambio (Garizurieta, Garizurieta, Mavil, 2013).

Alburqueque (2004), determina que el enfoque del desarrollo económico local viene a acentuar fundamentalmente los valores territoriales, de diversidad, identidad, y flexibilidad que han existido en el pasado en los modos de producción no basadas tan sólo en la gran industria, sino en las características locales y generales de un determinado territorio (Garizurieta, Garizurieta, Mavil, 2013).

El DL, de acuerdo con Gómez \& Estrada (2009), es un proceso que incluye actores, poderes y niveles de organización interconectados entre sí, para que se garantice el mejoramiento de la calidad de vida. Por lo tanto, las organizaciones municipales tienen que ejercer un protagonismo basado en su capacidad de gestión, la toma de decisiones a tiempo y la correcta articulación de las variables inmiscuidas en los procesos específicos. 
La gestión es entendida como la herramienta que ayuda a armonizar las relaciones entre lo nacional y lo local, la centralización y la descentralización, entre los diferentes tipos de recursos $(O ́ p$. Cit.). Esto involucra incorporar a la lógica de la gestión municipal, la lógica del desarrollo económico local; adoptando una actitud proactiva, no subordinada y capaz de formular iniciativas concretas de desarrollo y generación de trabajo productivo (Alburqueque, 2004), lo que permitiría viabilizar el mejor uso de los recursos, mediante un entorno innovador, en el que la dimensión ambiental del desarrollo posea un tratamiento adecuado (Garizurieta, Garizurieta, Mavil, 2013).

Para Vargas (2003), los proyectos de DL, deben tener como fundamento la reconstrucción de su propia realidad, de tal manera que tome en cuenta las necesidades de desarrollo locales, los recursos y capacidades locales existentes, las áreas prioritarias y el involucramiento de los transcendentales agentes económicos actores sociales y políticos. Por lo tanto, no existirá un modelo único de DL sino diferentes propuestas de proyectos.

Para poder llevar a cabo un modelo tal de gestión, se tienen que cambiar las estructuras de organización con el objetivo de aumentar los niveles de eficacia, pero también la consecución de una mayor equivalencia en el acceso a los recursos y beneficios del crecimiento económico. Simultáneamente, deben ser transformados los modos de administración, contenidos e instrumentos locales, de tal forma que se ayude el reconocimiento de la variedad y la participación real en todas sus dimensiones; transformando al municipio en un actor dinamizador primordial del desarrollo, sin quitar importancia a las demás administraciones publicas de ámbito superior (Garizurieta, Garizurieta, Mavil,2013).

\section{Planeación Municipal}

La planeación dentro de una organización gubernamental es definida por Messina (2011), como aquella que promueve el reconocimiento y el mantenimiento de una manera de gobierno establecido en la interdependencia funcional sobre un cimiento común, y constituye un paso definitivo también hacia la práctica del federalismo funcional (Aguilera, 2013).

La planeación, en materia de desarrollo sostenible, es tal vez aún más amenazante, ya que se fundamenta en difusos objetivos globales (Mannberg \& Wihlborg, 2007). Actualmente, el PND del país adopta la sustentabilidad, sembrando la participación social en la toma de decisiones, identificando los recursos naturales claves, como temas de seguridad nacional, proponer la valoración social y económica de los mismos, y requiere la aplicación de la legislación ambiental sin excepción (Rojas, 2003). Sin embargo, dentro de la amplitud de instrumentos que existen para la gestión de la sustentabilidad, la que más trascendencia está cobrando en la actualidad es la llevada a nivel municipal; debido a su papel crítico en la protección y mejora de los ambientes urbanos, mediante la entrega y manejo apropiado de la tierra, la energía, el agua, el transporte, y los residuos, a la vez que salvaguarda la biodiversidad, el agua y promueve la prosperidad económica, bienestar humano y equidad social de las generaciones actuales y futuras.

La planeación municipal es una herramienta que permite no solamente obtener información sobre la gestión de los gobiernos locales, sino también, ayuda a producir cambios y apunta posibles maniobras de intervención desde estos gobiernos. Sánchez (2012), dice que la planeación en este nivel debe buscar edificar localidades dinámicas, participativas e incluyentes, adecuadas a las cambiantes exigencias de la sociedad e integradas a su medio ambiente; de manera que puedan aportar soluciones a problemas existentes dentro del marco de su legislación. Nemaţu (2012), define la planeación municipal sustentable como un enfoque a largo plazo para la toma de decisiones que involucra diversas disciplinas, intereses y enfoques analíticos, la cual da una nueva apreciación de la importancia del lugar, y la intervención activa en las sociedades y los ecosistemas (Garizurieta, Garizurieta, Mavil, 2013).

Como se puede apreciar, el aspecto fundamental que muestra el conjunto de ordenamientos consiste en que las actividades de gobierno se establezcan con los diversos grupos de la sociedad. 
Por otro parte, el logro de la sustentabilidad en el desarrollo nacional y local demanda un enfoque estratégico a largo plazo que enlace diferentes procesos de desarrollo a fin de que estos puedan ser tan sofisticados como los desafíos son complejos; se debe ser conscientes de que este es un proyecto a largo plazo y que todas las dimensiones sociales tienen que participar (Miltojevic \& IlicKrstic, 2011). Por ello, es necesario llevar a cabo una planeación estratégica la cual, busca prever los eventos, y con ellos, el futuro de las decisiones actuales, haciendo énfasis en la búsqueda de respuestas a necesidades de un futuro incierto y complejo.

La planeación estratégica le permite a una organización calcular las diferencias entre un período previsto de tiempo para solucionarlas e implementar y desarrollar una hoja de ruta que brinda actividades y resultados (Kerman, Altan, Aktel, \& Öztop, 2012). A nivel municipal, es una herramienta que promueve enfoques innovadores de colaboración para la gestión urbana que implican gobierno, negocios, académicos y otros asociados en el proceso; permitiendo la intervención de respuesta y selectiva (Miltojevic \& Ilic-Krstic, 2011).

El plan estratégico recoge la misión global de la organización y las metas generales y propósitos a largo plazo obligatorios para su consecución, así como el plazo temporal fijado para lograrlos (Prado \& García, 2006). En este sentido, es necesario reunir a los actores importantes de los procesos nacionales de planificación estratégica con los representantes locales, con el objetivo de darle fuerza al proceso nacional y para la inserción de los actores locales en el proceso global.

Sintetizando, es necesaria la articulación de un proceso de planeación estratégica que apruebe la participación social en relación a las acciones de elaboración/actualización, instrumentación, seguimiento y evaluación de los mismos; con el objetivo de alcanzar una vinculación de la sociedad con el seguimiento y vigilancia de la aplicación de la normatividad incluida en los planes. Para que esto sea posible llevarlo a cabo, se tiene que iniciar en el municipio, que es célula básica de articulación e integración entre el desarrollo sectorial y ramal (Gómez \& Estrada, 2009). 


\section{Capítulo III Planeación estratégica territorial en el estado de Guanajuato}

Al estar ubicados los municipios de esta investigación Moroleón y Uriangato en el estado de Guanajuato, este capítulo pretende mostrar la planeación en el estado, cabe mencionar que la planificación territorial, aún no se refleja adecuadamente en varios de los municipios que conforman el estado, y ha sido hasta en estos últimos años, que se han preocupado por implementar esta valiosa herramienta urbana en la mayoría de los municipios, resalta el municipio de León, Guanajuato al ser el municipio más grande del estado y tener una economía fuerte, es punta de lanza en este sentido, con la fundación del Implan hace varios años y tiene algunos avances significativos en este rubro siendo la industria del zapato, una de las principales actividades económicas en la región.

En el estado de Guanajuato, la planeación estratégica territorial se ha manifestado a través de documentos denominados Planes de Desarrollo Municipal, así éstos existen en más de la mitad de los 46 municipios del estado.

\section{Orientación de la visión estratégica en León, Guanajuato}

Se hizo un ejercicio de orientación de la visión estratégica, partiendo de la exposición de temas clave por parte de expertos internacionales y nacionales con la finalidad de construir una primera visión de futuro, en función de las importantes tendencias internacionales para lograr el equilibrio territorial bajo un modelo de desarrollo sustentable. Como parte del proceso de orientación de la visión se desarrolló el estudio llamado: "Clústers, Rumbo Económico para el Municipio de León. Visión 2040", el cual tuvo como propósito general, identificar el desarrollo de las capacidades locales y hacer valer la concentración de actividades económicas complementarias (Plan Municipal de Desarrollo León Hacia el Futuro 2040, 2014).

Con la finalidad de contribuir al diseño de una ciudad con barrios y colinas más seguras y contar con estrategias generales de prevención del delito y la violencia que puedan desarrollarse a largo plazo, con una fuerte base comunitaria, se contó con el "Diseño de la Estrategia de Seguridad con Criterios CPTED para el Plan Municipal de Desarrollo 2040 de León, Guanajuato".

\section{Proceso de consulta ciudadana y participación social}

De acuerdo con el artículo 44 de la Ley de Planeación para el Estado de Guanajuato, se hicieron una serie de ejercicios de consulta ciudadana con el objetivo de conocer las propuestas y opiniones de los habitantes. En este sentido, se publicó una convocatoria en dos diarios de circulación local, se colocó un buzón en las instalaciones de la Presidencia Municipal y se puso a disposición de la ciudadanía un portal de consulta en la página de internet del IMPLAN. En dicho proceso de consulta ciudadana y participación social, tuvieron una participación un total de 4,366 habitantes distribuidos en diversos ejercicios y mecanismos. Se realizaron 34 talleres en ámbitos territoriales estratégicos con una colaboración aproximada de 1,500 ciudadanos:

Talleres con comités de colonos y con representantes de las comunidades rurales, también de consultas en espacios públicos de la ciudad con la finalidad de conocer las expectativas y necesidades de desarrollo tanto en el ámbito urbano como en el ámbito rural del municipio. Como parte del proceso se realizó un taller con los consejeros ciudadanos del Consejo de Planeación para el Desarrollo Municipal.

Talleres en los polígonos de pobreza, donde se encuentran cerca de 600 mil habitantes del municipio: Medina, Piletas, Los Castillos, Diez de Mayo Medina, San Francisco, Jacinto López, San Juan de Abajo, y Las Joyas.

En todos estos procesos de consulta se contó con la asistencia y colaboración del Parque de Innovación De La Salle A.C. y de Gestión Social Consultores.

- Se desarrollaron consultas con segmentos de población estratégica que implico a más de 1,800 personas. 
- $\quad$ Talleres con niños de 9 años a 12 años, correspondientes al cuarto, quinto y sexto año de primaria de diversos estratos socioeconómicos.

- Talleres con jóvenes de 12 años a 29 años, de diversos estratos socioeconómicos abarcando los niveles educativos de primaria a licenciatura.

- Entrevistas a adultos mayores de 60 años en relación con la problemática del municipio con el objetivo de lograr aportaciones útiles para la conformación de la visión, basadas en la experiencia y el conocimiento obtenidos a través de los años.

En estos ejercicios se tuvo la colaboración valiosa de la Universidad Iberoamericana León, de Estudio Entorno Vital y de Gestión Integral Consultores S. C.

Se realizaron 7 talleres con ciudadanos, asimismo se realizaron entrevistas con más de 70 especialistas y más de 50 autoridades responsables de las PP, donde participaron más de 1,000 personas (Plan Municipal de Desarrollo León Hacia el Futuro 2040,2014).

El Consejo Directivo del Instituto Municipal de Planeación IMPLAN implemento un proceso de trabajo en el marco de las Comisiones de Planeación Estratégica:

- Desarrollo Sustentable.

- $\quad$ Infraestructura y Equipamiento para el Desarrollo.

- $\quad$ Educación.

- $\quad$ Salud.

- Cultura.

- $\quad$ Buen Gobierno y Estado de Derecho.

- Estas comisiones las encabezan los consejeros del Instituto y sesionan con la participación de los representantes de los colegios de profesionistas (colegio de abogados, colegio de contadores, colegio de ingenieros y arquitectos etc.), de las cámaras empresariales, asociaciones civiles y en general personas de la sociedad civil que tiene interés en participar en la Planeación Integral del Municipio.

- Cada comisión se reunió periódicamente contando con la colaboración de un asesor externo, encargado de realizar un diagnóstico desde la perspectiva de cada zona sectorial y de coordinar la definición de las estrategias, objetivos, y programas a largo, mediano y corto plazo del PMD.

\section{Taller internacional de urbanismo}

El Instituto de Planeación Municipal (IMPLAN) y el Instituto para la Planeación del Estado de Guanajuato (IPLANEG), en colaboración con la Embajada de Francia en México organizaron un taller internacional de urbanismo con la coordinación y el acompañamiento metodológico de Les Ateliers de Cergy. El propósito del taller fue explorar nuevas visiones y enfoques de análisis urbano territorial con los representantes responsables de la administración del territorio de la Zona Metropolitana de León, formada por los municipios de, San Francisco del Rincón, Purísima del Rincón, Silao y León, (Plan Municipal de Desarrollo León Hacia el Futuro 2040,2014).

El tema seleccionado para el taller fue: "Paisaje y suelo a compartir. ¿Cómo los espacios baldíos y los terrenos abandonados pueden contribuir a la reestructuración de la ciudad y del entorno metropolitano?". 
Para poder participar en el taller se emitió una convocatoria internacional y 24 profesionales (ingenieros, arquitectos, paisajistas, urbanistas, etc.) de distintas nacionalidades fueron elegidos para formar cuatro equipos multidisciplinarios de trabajo. Durante dos semanas (del 25 de noviembre al 6 de diciembre de 2013) se promovió el intercambio de experiencias con especialistas de otras zonas metropolitanas en el mundo y se establecieron las bases para plantear PP de coordinación y gestión metropolitana. Como resultado se consiguió un conjunto de estrategias con un enfoque metropolitano (Plan Municipal de Desarrollo León Hacia el Futuro 2040,2014).

Las estrategias, programas y acciones de carácter metropolitano que corresponden a las atribuciones municipales, se integraron a la propuesta del PMD con el apoyo y asesoría técnica de Aude Jahan.

\section{Conformación de la visión 2040 del Centro Histórico de León}

Durante el proceso se realizó un ejercicio para la conformación de la visión 2040 del centro y colonias y barrios históricos de la ciudad de León, en el cual tuvieron participación los consejeros ciudadanos del Consejo Consultivo para la Protección y Promoción del Patrimonio Histórico del Municipio de León, todos bajo la coordinación y asesoría técnica de Rafael Pérez Fernández (Plan Municipal de Desarrollo León Hacia el Futuro 2040,2014).

\section{Proceso de integración final del PMD}

El proceso consistió en un acompañamiento técnico - metodológico con la colaboración del Instituto Tecnológico y de Estudios Superiores de Monterrey (ITESM), Campus León, para realizar el análisis de congruencia de los dictámenes sectoriales y de los ejercicios de participación ciudadana, así como el proceso de integración final del PMD y la conformación de la visión 2040 (Plan Municipal de Desarrollo León Hacia el Futuro 2040,2014).

\section{Contenidos del Plan Municipal de Desarrollo}

El Plan Municipal de Desarrollo contiene los siguientes elementos (Plan Municipal de Desarrollo León Hacia el Futuro 2040,2014).

- Un marco de referencia (jurídico y de planeación) y una descripción general del contexto en el que se sitúa el municipio de León.

- Un diagnóstico estratégico que muestra la situación presente en los temas fundamentales para el desarrollo del municipio, así como los primordiales retos municipales.

- $\quad$ El planteamiento de los escenarios tendencial, factible y deseable.

- El Modelo de Desarrollo formado por un modelo de desarrollo territorial, una visión de largo plazo, así como por las estrategias, objetivos y el portafolio de programas y sus actores involucrados, estos últimos organizados por Línea Estratégica.

- Un apartado de evaluación y seguimiento del plan, en el cual se implantan los procesos de instrumentación de los programas por parte de las Comisiones de Planeación Estratégica, así como una lista de indicadores a por medio de los cuales se monitoreará y evaluará la consecución de los objetivos.

- Un anexo denominado "LEÓN EN NÚMEROS" que incluye un conjunto de cuadros y gráficos con los principales datos de los temas clave para el desarrollo.

- $\quad$ Un segundo anexo con el estudio "CLÚSTERS. RUMBO ECONÓMICO EN EL MUNICIPIO DE LEÓN. VISIÓN 2040", que es complementario del enfoque de desarrollo integral del municipio, al implantar los sectores económicos que cuentan con mayor potencial de desarrollo en el corto, mediano y largo plazo. 


\section{Sistema de planeación}

Lo establecido en el Plan Estatal de Desarrollo Visión 2035 y las Líneas Estratégicas atienden sus 4 dimensiones del desarrollo:

1. Humano y social (Educación, Cultura y Salud).

2. Administración Pública y Estado de Derecho (Buen gobierno y estado de Derecho).

3. Económica (Rumbo Económico).

4. Medio Ambiente y Territorio (Desarrollo Sustentable, Infraestructura y equipamiento para el Desarrollo, Vivienda y Asentamientos Humanos).

En 2013, el marco jurídico y de planeación establece que la Administración Municipal, y de manera particular, el IMPLAN debe elaborar los siguientes instrumentos del Sistema de Planeación:

- Plan Municipal de Desarrollo. Contendrá los objetivos y estrategias para el desarrollo del municipio por un periodo de veinticinco años; el PMD tiene que ser evaluado y actualizado por lo menos cada cinco años, en y debe concordar con los planes nacionales y estatales de desarrollo. Para el caso del municipio de León cuenta con una visión y un modelo de desarrollo territorial de un largo periodo al año 2040, basado en un proceso de participación social para conocer las opiniones y propuestas de los pobladores de la ciudad.

- Programa Municipal de Desarrollo Urbano y Ordenamiento Ecológico y Territorial. Contendrá los objetivos y estrategias de uso y ocupación del suelo, así como la estrategia general de usos, reservas, destinos y provisiones de conformidad con el Código Territorial para el Estado y los Municipios de Guanajuato. Esta herramienta permitirá hacer más fuerte la política de ordenamiento territorial y ecológico vigente, mediante una política de desarrollo urbano que haga favorecer la consolidación de la ciudad y el desarrollo equilibrado de las principales actividades económicas y sociales en el territorio municipal.

- Programa de Gobierno. Contendrá las estrategias que sirvan de base a las actividades de la administración pública para asegurar el cumplimiento del PMD; el programa será elaborado por el organismo municipal de planeación, con la colaboración de las dependencias y entidades de la administración pública municipal y el Consejo de Planeación de Desarrollo Municipal.

\section{Objetivos del Programa Nacional de Desarrollo}

Principales líneas y estrategias de acción transversales México en Paz:

- $\quad$ Objetivo 1. Promover y hacer más fuerte la gobernabilidad democrática.

- Objetivo 2. Se debe garantizar la Seguridad Nacional.

- $\quad$ Objetivo 3. Hacer mejoras en las condiciones de seguridad pública.

- $\quad$ Objetivo 4. Garantizar un Sistema de Justicia Penal imparcial, eficaz, transparente y expedito.

Objetivo 5. Garantizar la protección de los derechos humanos, el respeto y la eliminación de la discriminación.

- Objetivo 6. Mantener a salvo a la población, a su entorno, y a sus bienes ante un desastre de origen natural o provocado por el hombre. 


\section{Enfoque transversal (México en Paz) México Incluyente}

Objetivo 1. Garantizar el ejercicio de una manera efectiva de los derechos sociales para toda la sociedad.

- Objetivo 2. Caminar hacia una sociedad equitativa, más justa e incluyente.

- Objetivo 3. Garantizar el acceso a los servicios de salud.

- Objetivo 4. Ampliar el acceso a la seguridad social.

Objetivo 5. Proporcionar un entorno apropiado para el desarrollo de una vida digna. Enfoque transversal.

\section{México con Educación de Calidad (México Incluyente)}

- $\quad$ Objetivo 1. Desarrollar el potencial humano de los mexicanos y las mexicanas con una educación de calidad.

- $\quad$ Objetivo 2. Garantizar la inserción y la equidad en el Sistema Educativo.

- Objetivo 3. Hacer más amplio el acceso a la cultura como un medio para la formación integral de la población.

- Objetivo 4. Hacer promoción del deporte de forma incluyente para fomentar una cultura de salud.

- Objetivo 5. Hacer del desarrollo, tecnológico, científico y la innovación bases para el progreso económico y social sostenible. Enfoque transversal.

\section{México Próspero (México con Educación de Calidad)}

- Objetivo 1. Conservar la estabilidad macroeconómica del país.

- Objetivo 2. Democratizar el acceso al financiamiento de proyectos con potencial y planes de crecimiento.

- $\quad$ Objetivo 3. Promover el empleo de calidad, en todas sus modalidades.

- Objetivo 4. Impulsar y orientar un crecimiento verde facilitador e incluyente que preserve el patrimonio natural y que al mismo tiempo genere riqueza, empleo y competitividad.

- $\quad$ Objetivo 5. Democratizar el acceso a medios de telecomunicaciones.

- Objetivo 6. Dotar de energía al país con precios competitivos, eficiencia y calidad a lo largo de la cadena productiva.

- Objetivo 7. Garantizar normas claras que estimulen el desarrollo de un mercado interno competitivo.

Objetivo 8. Desarrollar los sectores trascendentales del país.

Objetivo 9. Contar con una infraestructura de transporte que se vea reflejada en menores costos para efectuar la actividad económica.

- Objetivo 10. Edificar un sector productivo agropecuario y pesquero que garantice la seguridad alimentaria del país.

- Objetivo 11. Aprovechar al máximo el potencial turístico de México para generar una mayor derrama económica de capital en el país. 


\section{Enfoque transversal. México con Responsabilidad Global}

- $\quad$ Objetivo 1. Fortalecer y ampliar la presencia de México en el mundo.

- Objetivo 2. Promover el valor de México en el mundo a través de la difusión cultural, turística y económica.

- Objetivo 3. Reafirmar el compromiso del México con la movilidad de capitales, el libre comercio y la integración productiva.

Objetivo 4. Vigilar los intereses de los mexicanos en el extranjero y asimismo proteger los derechos de los extranjeros en el territorio nacional (Fuente PND 2013-2018 Gobierno de la república).

\section{La planeación en Guanajuato}

La planeación estratégica, concebida como la ordenación racional y sistemática de las acciones gubernamentales, tiene como propósito impulsar un desarrollo sustentable, equilibrado y equitativo (Velázquez, 2017).

Este proceso es vital para la evolución de las instituciones y el mejoramiento de las condiciones de vida de la población; sin embargo, no reviste el carácter de ser una actividad exclusiva del quehacer del Estado o del ejercicio coordinado e integrado de las políticas públicas.

La planeación ayuda a la definición de metas y objetivos orientados para la toma de decisiones que trascienden al entorno social, político y económico del Estado y que contribuyen a su desarrollo; es un proceso integrador de la visión de los tres órdenes de gobierno, así como de las necesidades del sector privado y social, de ahí su carácter democrático (Velazquez, 2017).

Dentro de este proceso, la participación de la ciudadanía en la construcción de estrategias de desarrollo se torna indispensable, por ello la importancia de aplicar herramientas que fortalezcan la planeación participativa, entendida ésta como un proceso mediante el cual se aprende y actúa desde, con y para los actores sociales y que permite involucrar a la sociedad en la identificación de necesidades y problemáticas, así como en la construcción de objetivos comunes para mejorar su calidad de vida (PlanGto2035,2012).

En el estado de Guanajuato, uno de los ejercicios más relevantes de planeación participativa en la identificación de estrategias de desarrollo se llevó a cabo hace casi dos décadas. En el año de 1992, el Gobierno de Guanajuato, en conjunto ambos con la Fundación Guanajuato Siglo XXI y el Centro de Estudios Estratégicos del ITESM Campus León, elaboró un estudio de diseño estratégico para el estado de Guanajuato denominado «Guanajuato Siglo XXI». El horizonte de un periodo de tiempo contemplado fue de 28 años, abarcando desde 1992 hasta el año 2020. Con la finalidad de dar validez al proceso, además de aportar experiencias y participar en el diseño de escenarios y propuesta de estrategias, la Fundación Guanajuato Siglo XXI conformó un consejo directivo constituido por ciudadanos representantes de las diversas regiones del Estado, vinculados a diferentes sectores sociales. El estudio estuvo dividido en cinco etapas donde la participación de la ciudadanía fue el común denominador (PlanGto2035, 2012).

\section{Planeación estratégica del crecimiento urbano regional en el estado de Guanajuato}

Con cerca de cuatro millones de habitantes en 1990, el estado de Guanajuato es el sexto estado más poblado del país. El crecimiento esperado de la población estatal del año 1990 para el año 2000, sería de 700000 habitantes en una proyección que estima una tasa de crecimiento baja de $1.3 \%$ anual o bien de 1600000 con una tasa elevada de $2.4 \%$. Si se adopta un horizonte de mediano plazo, hacia el año 2010 Guanajuato llegará posiblemente a poco menos de seis millones de habitantes. Esto significaría un aumento de casi dos millones de personas en los próximos veinte años (Graizbord, 1995). 
Desde el punto de vista de la administración pública, cubrir la demanda de, servicios, vivienda, empleo e infraestructura de este crecimiento requeriría plantear una estrategia que permitiera, por un lado, inducir un crecimiento económico y una distribución geográfica de la población de acuerdo con los objetivos del desarrollo de la región, de la entidad y del país, y por el otro, aprovechar a su máxima expresión la infraestructura y el equipamiento social actuales del Sistema Urbano Estatal (SUE). Para así poder cumplir con estos propósitos el gobierno estatal, y en general cualquier organismo con poder de decisión debería observar las múltiples posibilidades que brinda la entidad para su desarrollo y evaluarlas ex-ante (Graizbord, 1990) de en concordancia con criterios tanto de eficacia (que espacialmente se dan por la concentración y las economías de aglomeración) como de equidad (referidas a la justicia distributiva y a la disminución de las desigualdades entre ciudades y regiones) (Graizbord, 1995).

Para el caso del estado de Guanajuato, el futuro crecimiento económico y poblacional afectará de manera diferente los diferentes municipios, localidades y regiones de la entidad. Lo más probable es que, como ha ocurrido a través de historia, la concentración siga extendiéndose en la región centro del estado que corresponde al corredor industrial a través del eje carretero que une a Celaya con León en los 128 kilómetros de longitud de una de las más densas regiones pobladas del país. Pero, ¿cómo poder ordenar este crecimiento? ¿Cómo racionalizar la asignación de los recursos? ¿En dónde localizar la oferta de bienes y servicios públicos con efectos que sean favorables para el mayor número de habitantes o para aquellos que más los requieren? ¿Cómo hacer favorable la actividad productiva de forma más eficiente? La respuesta a esta serie de preguntas no es de ninguna manera fácil, pero abordarla permitiría conseguir los objetivos económicos y sociales de la política estatal de desarrollo, ajustarse a las exigencias actuales de la población, utilizar los recursos materiales existentes y aprovechar en un futuro cercano las oportunidades que sin duda, ofrecerá la apertura comercial del país y el TLC entre México, EE.UU y Canadá (Graizbord, 1995).

\section{Consejo de Planeación para el Desarrollo del Estado de Guanajuato}

A continuación, se define como la forma en que está constituido (el COPLADEM) y en los artículos en que se creó y se basa:

Artículo 16. El consejo estatal es un organismo consultivo auxiliar del Poder Ejecutivo en materia de planeación.

- $\quad$ Artículo 17. El consejo estatal y sus órganos se integrarán mayoritariamente por representantes de la sociedad organizada.

Artículo 18. El consejo estatal se integrará con:

El titular del Poder Ejecutivo, quien lo presidirá:

- $\quad$ Los titulares de las dependencias de la administración pública estatal que determine el titular del Poder Ejecutivo.

- Representantes de la sociedad organizada.

Representantes de los ayuntamientos del Estado. Los representantes en el Estado de las dependencias federales vinculadas a la planeación serán invitados permanentes. En el reglamento de esta Ley se establecerán el número y los mecanismos de integración de los representantes de la sociedad organizada y de los ayuntamientos ante el consejo estatal y lo relativo a su funcionamiento (DOF, 2011).

Artículo 19. El Consejo estatal para el ejercicio de sus atribuciones se auxiliará de:

- $\quad$ Los consejos regionales.

Los consejos sectoriales.

Los consejos especiales. 
Artículo 20. Son atribuciones del consejo estatal las siguientes:

Participar en el proceso de elaboración de los instrumentos de planeación.

Fungir como órgano de consulta en los procesos de diagnóstico, planeación, seguimiento y evaluación de los instrumentos de planeación.

Implementar mecanismos de consulta y participación social en los procesos de planeación.

Vigilar el cumplimiento de las acciones de difusión en materia de planeación.

Realizar propuestas relativas al desarrollo del Estado.

Impulsar la planeación regional con la participación de los consejos para el desarrollo municipal en congruencia con los objetivos, metas y estrategias de los instrumentos de planeación.

Establecer las comisiones de trabajo necesarias para el cumplimiento de sus funciones.

Promover la celebración de convenios tendientes a orientar los esfuerzos para lograr los objetivos del desarrollo integral de la entidad.

Propiciar vínculos de coordinación con otras estructuras de planeación para el desarrollo de los estados, a fin de intercambiar programas y proyectos para el desarrollo sustentable de las regiones interestatales.

- $\quad$ Las demás que señale el reglamento de esta Ley (DOF, 2011).

\section{Estrategia de política pública e iniciativa privada en el contexto del desarrollo estatal}

La estructura territorial que por la que el estado de Guanajuato se caracteriza no se parece al patrón centro-periferia que impera en el país o en la mayoría de los demás estados de la república. Esta entidad federativa cuenta con localidades de todo tipo y especializadas, las más importantes de ellas están localizadas en el corredor, a lo largo del tramo central del eje carretero (carretera federal 45) más importante de nuestro país, que conecta la Zona Metropolitana de la Ciudad de México (ZMCDM) con la de Guadalajara (ZMG), y a ambas con la frontera norte. El sistema de ciudades como se conoce en la actualidad se generó en los siglos XVII y XVIII de la época colonial. El motor principal del proceso de crecimiento y urbanización que experimentó el estado y la región del Bajío a la que ésta pertenece, fue la actividad dedicada a la minería, que se generó en las minas cercanas a la ciudad de Guanajuato, y posteriormente más al norte, en Zacatecas. Debido a la importancia económica de la minería de la plata en estas zonas del país esta propició la formación, alrededor suyo de los reales mineros, de unidades económicas interdependientes y formadas por ranchos agrícolas, ranchos ganaderos y centros de manufactura y de abasto, que la función era justamente proveer de alimentos, materiales y animales diversos a la población establecida en las minas (West, 1949). El desarrollo de un conjunto de ciudades económicamente especializadas también se debió a otros factores, entre los que resalta la posición estratégica del Bajío con relación al centro de consumo más importante del país, como es la ciudad de México (Graizbord, 1995).

En los años recientes se ha consolidado el SUE y está estructurado jerárquicamente por una gran ciudad de carácter metropolitano: León; tres ciudades de segundo rango: Guanajuato, Irapuato y Celaya; diez de tercer rango: Salamanca, Silao, San Francisco del Rincón, San Miguel de Allende, Dolores Hidalgo, San Felipe, Acámbaro, Pénjamo, Salvatierra y Valle de Santiago, y un número considerable de localidades de cuarto rango, con más de 5000 habitantes, que son cabeceras municipales o lugares centrales sin estatuto político, pero que concentran, con las anteriores, a casi toda la población urbana estatal. Algunas de las ciudades más grandes mantienen vínculos directos con otros sistemas estatales. Así, a través de la ciudad de León, el sistema guanajuatense se relaciona con Lagos de Moreno y Guadalajara (Jalisco), Aguascalientes (Aguascalientes) y La Piedad (Michoacán); a través de Irapuato, con La Piedad (Michoacán) y a través de Celaya, con Querétaro (Querétaro) y con San Luis Potosí (San Luis Potosí) (Graizbord, 1995). 
La estructura urbana descrita permite relaciones funcionales que se deben aprovechar en el nuevo ciclo de competencia abierta que se deberá intensificar entre localidades (más que entidades), para influir o estimular decisiones de ubicación del capital internacional y nacional, especialmente en la actualidad cuando es sabido que la planta productiva del país se encuentra demasiado vinculada a los procesos económicos mundiales (véase Centro de Estudios Económicos del Sector Privado, 1994). Por otra parte, y desde el punto de vista económico, si bien las relaciones sectoriales entre las actividades primaria, secundaria y terciaria son aceleradas en el estado, no hay nada escrito en relación con la forma en que se debe encauzar el esfuerzo para estimular el DR sustentado en una economía moderna con eficientes servicios para la producción y encauzado "hacia afuera" con base en productos del campo y manufactureros de calidad para la exportación. En efecto, qué tipo de infraestructura física y equipamiento social, qué calidad y cantidad de bienes y servicios y dónde se deben brindar a los inversionistas, a la fuerza de trabajo y a la población en general, son asuntos abiertos que sin embargo deben ser resueltos en el menor tiempo y con la mayor eficiencia posibles (Graizbord, 1995).

Contar con herramientas de política y una estrategia que respondan en el tiempo y con el conocimiento requerido a las interrogantes que plantea el desarrollo estatal se hace aún más urgente y necesario , si se considera el impacto global que originarán en el SUE los proyectos de desarrollo industrial y de servicios privados y públicos y de recién concreción o de próxima realización, y en especial tres grandes proyectos : la planta General Motors de Silao, el proyecto "Guanajuato Nuevo Horizonte " y el Tren Interurbano de Guanajuato; el primero de capital privado y los otros dos de capital mixto, pero los tres con impacto y efectos complementarios en el presupuesto estatal, y tal vez federal (Graizbord, 1995).

Las grandes inversiones productivas que están localizadas en Guanajuato reconocen las ventajas que les ofrece la infraestructura existente. Éstas se concentran en la región centro de la entidad, o en el mencionado corredor industrial localizado a lo largo de la carretera federal 45. En otras palabras, factores relacionados a economías de aglomeración, en general, y de urbanización (presencia de grandes centros urbanos con oferta de bienes y servicios públicos) o localización (existencia de unidades de producción industrial e infraestructura básica) en particular, representan un poder de atracción que tiene influencia en las decisiones referentes a la localización del capital. Ejemplo de ello son los enormes proyectos de inversión productiva (industrias manufactureras) del sector privado, concretados en la administración estatal (panista) durante los últimos años (1992 a 1994). Así, los proyectos identificados por la Secretaria de Comercio y Fomento Industrial SECOFI rebasan los 1660 millones de dólares estadounidenses (mdd) y la creación de más de 17700 empleos directos, la mayoría de estos emporios (incluyendo a la General Motors) se localiza en este corredor. Sin embargo, de acuerdo con la información disponible, los nuevos proyectos de inversión recreativa y turística (entre los que se incluyen hoteles, campos de golf, centros deportivos, clubes hípicos, etc.) que crearían más de 1000 empleos directos.se muestran una ubicación dispersa que tiende a favorecer a la región norte del estado (Graizbord, 1995).

\section{Estrategia general del desarrollo en zona conurbada Moroleón-Uriangato}

Este fue el antecedente de la información sobre planificación de la zona conurbada Moroleón Uriangato, llamado Plan Director de Desarrollo Urbano, el cual se publicó en 1991, y que fue elaborado por Gobierno del Estado de Guanajuato, a través de la Secretaria de Desarrollo Urbano y Obra Pública, aquí el gobierno del estado si hizo una estrategia de planificación conjunta con ambos municipios (SDUOP, 1991).

Se pretende que todo núcleo poblacional continúe creciendo de forma compactada, que aproveche racionalmente el suelo y las ampliaciones que se vayan dando a las redes de infraestructura, previendo en todos los casos los futuros requerimientos en cuanto a la dotación y la capacidad de los servicios de agua potable y drenaje, respectivamente, así como lo referente a la adquisición de reservas para la instalación del equipamiento urbano adecuado (SDUOP, 1991). 
El potencial de usos susceptibles para uso urbano es de 5000 hectáreas y de acuerdo a las tendencias de crecimiento actuales a la zona conurbada requerirá para el corto y mediano plazo de 250 hectáreas conservando las densidades actuales de ocupación del suelo y considerando una moderada elevación de la densidad, tanto respecto a la población como a la construcción de viviendas de 105 habitantes/hectárea a 150 habitantes /hectárea y se reduciría el área requerida (SDUOP, 1991). De tal forma las opciones para la expansión de la mancha urbana serian en Moroleón, según SDUOP, 1991:

- Crecimiento moderado hacia el poniente, condicionando a la dotación de agua potable principalmente, requiriéndose la construcción de la infraestructura necesaria para tal fin, es decir fuente de abastecimiento y tanque elevado para agua potable y colector de aguas negras.

Crecimiento moderado hacia el sur poniente, con posibilidad para para la localización de fuentes de agua potable en la zona conurbada del Jinete, y con la posibilidad a futuro de llegar a conurbarse con las comunidades de San Lucas y El Terrero, requiriendo encausar las aguas negras mediante colector a través del cauce del Rio Moroleón.

- Crecimiento hacia el sur entre el camino a Piñicuaro y la carretera federal 43 con disposición de fuentes de abastecimiento de agua potable, y posibilidad de desarrollo a nivel residencial con densidad menor de 100 habitantes/hectárea, por razón de la limitante en cuestión de drenaje, lo que implica resolver el tratamiento de las aguas negras mediante la construcción de cisternas sépticas para cada vivienda.

En el caso de Uriangato, la factibilidad de expansión urbana es mayor, pues el área susceptible de desarrollo urbano rodea materialmente la mancha actual. De tal manera que las opciones de crecimiento son: (SDUOP, 1991).

- Al norte consolidando la colonia llamada Plan de Ayala, actualmente irregular, con la limitante que ocasione el terreno rocoso al requerirse mayor inversión.

Al nororiente con crecimiento condicionado por la limitante formada por el canal de Huahuemba, a la vez salvada mediante las obras de infraestructura apropiadas, no será obstáculo para el desarrollo y será factible hasta su conurbación con la comunidad El Cuitzillo.

- Hacia el oriente donde se localiza la comunidad La Deseada con asentamientos irregulares en terreno ejidal, la factibilidad de crecimiento es positiva, dadas las condiciones y características del terreno y su facilidad de dotación de infraestructura, así como una posible ubicación de futuro equipamiento y la existencia de caminos de acceso que comunican a la zona urbana con el libramiento carretero de la ruta Salamanca-Morelia.

Al sur oriente como consolidación y ampliación de la Joyita, actualmente irregular, en un área que se extiende hasta el libramiento carretero (SDUOP, 1991).

\section{Programa municipal de Desarrollo Urbano y Ordenamiento Ecológico Territorial Moroleón Guanajuato}

El Programa Municipal de Desarrollo Urbano y Ordenamiento Ecológico Territorial es la herramienta de planeación, con enfoque prospectivo de largo plazo, en el que se representa la extensión territorial y ecológica del Municipio, se establece la zonificación del territorio municipal, donde se asignan los usos y destinos para áreas y corredores urbanos, así como la modalidad y restricciones al uso del suelo y a las nuevas construcciones, definiendo el marco para ordenar las actividades económicas y sociales en el territorio, desde una perceptiva sustentable e integral, atendiendo los aspectos económicos, ambientales y sociales, dentro del nuevo marco de la planeación estatal.

"La Ley de Desarrollo Urbano para el Estado de Guanajuato" define al ordenamiento territorial como: "el proceso de distribución sustentable y equilibrada de la población y de las actividades económicas en el territorio". Este instrumento de planeación va a permitir determinar la zonificación del territorio municipal, estableciendo sus principales usos y destinos, además de planear ordenar, y regular la conservación, mejoramiento y crecimiento de los caseríos, localidades, rancherías, pueblos, de la ciudad y del municipio en su conjunto. 
En el municipio de Moroleón el objetivo es claro y es lograr una planeación integral y sustentable, imparcial, que asegure el vínculo entre los planes y programas que son responsabilidad de la administración pública municipal.

\section{Población económicamente activa}

De acuerdo con censos del INEGI del año 2010, el 78\% de la población, es decir 38,463 habitantes se encuentran en edad productiva; de ellos la población económicamente activa (PEA) del Municipio de Moroleón es de 21,135 habitantes (el 56\%) mientras que el 34\% de la población (16,793 habitantes realizan actividades del hogar, están estudiando o cuentan con alguna discapacidad laboral. De la PEA el $94 \%$ es población ocupada, es decir cuenta con un empleo (19,909 habitantes; mientras que el 6\% (1,226 personas) se encuentra sin empleo (PMDUOET, 2013).

\section{La actividad económica en el municipio se distribuye de la siguiente manera}

- Sector primario $6.2 \%$ (agricultura y ganadería), sector secundario $46.6 \%$ (industria manufacturera: textil) y sector terciario $44.8 \%$ (comercio textil y servicios).

- $\quad$ La industria textil ocupa el mayor porcentaje de empleo en el municipio.

Existen cerca de 2,000 empresas en sus diversas modalidades. La economía en Moroleón tiene una peculiaridad, por principio es una economía estable con variaciones importantes pero que ha funcionado durante más de dos décadas ya que ha logrado concatenar en su municipio los dos eslabones más importantes, la producción manufacturera y la venta lo que le ha dado solidez y adaptabilidad al negocio textil al tener control de la mayor parte de la cadena productiva y sin depender de intermediarios o agentes externos, por otro lado se ha generado una economía mono funcional con muy poca variedad fuera de la industria textil, lo que podría ser un riesgo en caso de una crisis del sector ya que no hay alternativas evidentes.

\section{Áreas en las que se encuentra capacitada la población}

Por el tipo de industria, mayormente familiar, el personal no tiene una capacitación técnica definida, existen escuelas técnicas, pero en su gran mayoría los empleados de la rama textil son formados al interior de las empresas, en muchos casos es una cuestión familiar y no existe un centro importante que capacite e innove.

Por otro lado, la oferta laboral en maquiladoras de ropa es tan atractiva que hay pocas expectativas de la sociedad de capacitarse o de incurrir en nuevas opciones, manteniendo un estado pasivo y conservador de la producción, aunado a la alta competencia de productos chinos que obligan a bajar precios y calidad para poder competir contra productos netamente inferiores.

En el aspecto comercial tampoco hay una capacitación a denotar, en general es una negocio familiar y la administración de los negocios es una cuestión empírica y con base a la experiencia, pero sin grandes innovaciones y con prácticas poco eficientes, tanto en la administración de los negocios como en el aspecto de mercadotecnia, esto es notable en la calle comercial principal donde la exposición de ropa sigue un patrón empírico sin innovaciones en el aspecto de diseño de aparadores o imagen de la tienda, lo que es un área de oportunidad de alto impacto para el comercio en Moroleón (PMDUOET, 2013).

\section{Producto Interno Bruto}

La economía de Moroleón es sin duda única en el estado por todo lo descrito anteriormente, esto se puede corroborar con los datos estadísticos económicos publicados por la Secretaria de Desarrollo Económico Sustentable del estado de Guanajuato.

Entre los datos más relevantes nos indica que Moroleón siendo el municipio número 28 en población, es el $9^{\circ}$ en fuerza laboral y el $7^{\circ}$ en Unidades económicas, según datos de la SDES con datos de la Coordinadora de Fomento al Comercio COFOCE. 
El producto Interno Bruto Municipal en el 2009 es de 302.2 millones de dls. lo que representa el $1 \%$ del PIB estatal, lo que es muy significativo para un municipio de su tamaño y que además no se encuentra en el corredor industrial del estado, el PIB per cápita 2009 es de 6,645 dólares (según datos de SIREM y CONAPO) con una población económicamente activa de 24,071 personas y un requerimiento de empleo anual de 532 personas, lo que denota una economía sana y estable a pesar de tener algunos procesos de retroceso frente a los procesos económicos globales, pero aun así sigue siendo una entidad que se caracteriza por su productividad, lo laboriosa de su gente y por dominar un mercado a nivel nacional (PMDUOET, 2013).

En lo que respecta a exportaciones se registró un intercambio comercial por $\$ 125,360.09$ dls., en el 2010, que representa un descenso del 9.18\% con respecto a lo exportado en el 2009.

\section{Crecimiento demográfico}

La cabecera municipal ha crecido del 2000 al 2010 en 8,262 personas lo que corresponde al 19\% neto, mientras que la superficie paso de $501 \mathrm{Ha}$ a $702 \mathrm{Ha}$ lo que corresponde a un incremento del $29 \%$, que si bien no es tan dramático como en otras ciudades del estado si demuestra que la ciudad va perdiendo densidad, expandiéndose en mayor proporción de lo que se puebla (PMDUOET, 2013).

A nivel geométrico el mapa de crecimiento indica claramente que el crecimiento de la ciudad se ha dado hacia el sur oeste, primordialmente a lo largo de la calle Morelos. Esto claramente definido por que al norte y al este limita con la ciudad de Uriangato, por lo tanto, no es posible el crecimiento hacia estas zonas y al norte se inician las pendientes más abruptas y la parte serrana de la cabecera, limitando fuertemente el desarrollo urbano, los únicos crecimientos hacia el norte se encuentran en el cerro y son asentamientos irregulares muy poco poblados.

Por el contrario, la redistribución de la población presenta un decrecimiento de todo el centro de la ciudad, impulsado por la terciarización y la oferta de vivienda barata, y de baja calidad, en las periferias, ya que se puede observar, en lo tonos verdes y azules, como al sur y al oeste se produce el crecimiento demográfico y las manzanas son más regulares y más alargadas, características de fraccionamientos. Dentro de la cabecera municipal la densidad poblacional se concentra en el centro y norte, sin embargo, hay pequeños asentamientos muy densos hacia el sur de la ciudad, aislados por grandes extensiones de terrenos baldíos (PMDUOET, 2013).

Actualmente la compra - venta de predios en Moroleón se encuentra estática debido a los costos altos que han alcanzado los predios, además de la inseguridad que se presenta al vender o comprar inmuebles. Con respecto a los fraccionamientos, en general, cuentan con buenos servicios y se identificaron pocos asentamientos humanos irregulares. Sin embargo, existe un interés por parte de los funcionarios por evitar la proliferación de AHI, por lo que les interesa promover la ejecución de los reglamentos de construcción y planes de ordenamiento territorial.

\section{Políticas generales de ordenamiento}

Para poder ordenar el desarrollo del territorio es necesario contar con políticas transparentes que se basen en un nuevo reglamento de Desarrollo Urbano y Ecología y forjen instrumentos técnicos de control y que demarque claramente los derechos y obligaciones de todos los que están involucrados en el desarrollo.

\section{Uso Mixto Urbano}

Superficie 838.74 Has, que corresponde al $4.7 \%$ de la superficie Municipal y el $65 \%$ de la Zona Urbana. Este uso corresponde al área urbana de la cabecera municipal en el cual se desarrolla una mezcla de usos compatibles entre sí como son; Habitacional, Comercial, Servicios e Industria ligera (PMDUOET, 2013).

El desarrollo en esta zona se debe promover la mezcla de usos afines entre sí y de alta densidad, debidamente planeados para garantizar la movilidad y calidad de vida de los habitantes. 
En el caso de que los proyectos de obra sean comerciales o industriales deben someterse a un estudio de impacto urbano y para la industria también será el estudio de impacto ambiental; en todos los casos se debe considerar que esta zona cuente con equipamiento, espacios abiertos de recreación e infraestructura urbana necesaria según sea el caso.

\section{Uso primario: Crecimiento Mediano Plazo (2020 a 2030)}

Esta zona se ubica al sur de la ciudad, destinada al desarrollo de tres células urbanas en un horizonte de 10 años, con equipamiento, recreación y usos mixtos, esta zona requiere un plan de manejo que busque insertar la zona dentro de la trama urbana, dotando a la ciudad de un desarrollo urbano consistente con los procesos de integración y conectividad urbana que se busca en el resto de la ciudad, evitando unidades aisladas, dispersión y procesos de especulación (PMDUOET, 2013).

\section{Uso primario: Crecimiento Largo Plazo (2030 a 2040)}

Superficie $57.85 \mathrm{Ha}$, que corresponde al 4\% de la superficie Urbana.

Zona destinada para uso mixto en un horizonte de 10 años, con todos los atributos de la Zona de Uso Mixto Urbano; mientras no se consolide el continuo urbano de los plazos anteriores no se debe de permitir ningún desarrollo en esta región, con la finalidad de presionar el mercado inmobiliario y fortalecer la oferta de suelo dentro del continuo urbano (PMDUOET, 2013).

\subsubsection{Programa Municipal de Desarrollo y Ordenamiento Territorial Ecológico de Uriangato Guanajuato}

El objetivo general de Programa Municipal de Desarrollo y Ordenamiento Territorial Ecológico de Uriangato, Guanajuato, es el establecer los lineamientos para regular los procesos de distribución territorial de la población y sus actividades, considerando la dinámica funcional de los asentamientos humanos en condiciones para la equidad social a través del mejoramiento de las formas de acceso a servicios y equipamiento básico, así de seguridad de la población ante fenómenos naturales y uso sustentable de los recursos naturales. Por su parte se persiguen los siguientes objetivos particulares. Establecer las bases y mecanismos para la coordinación, coordinación, formulación, seguimiento e instrumentación del programa. Medir la estructura y forma de distribución territorial de los asentamientos humanos, así como su articulación funcional, recalcando la integración de procesos productivos, que favorezcan al desarrollo local y a la generación de empleo, procurando el ascenso en la calidad de vida de la población. Inducir en la mejor ubicación de las actividades económicas y de la población, infraestructura y equipamientos en función de las vocaciones productivas y limitantes del medio físico-biótico (Periódico Oficial del Estado de Guanajuato, 2018).

Establecer lineamientos para regular los procesos de ocupación territorial procurando la integración de las localidades, el aprovechamiento del equipamiento y la infraestructura instalada y promover el uso eficiente de los recursos públicos, a través de la definición de una cartera de proyectos prioritarios para el municipio consensuado con los actores locales (Periódico Oficial del Estado de Guanajuato,2018).

\section{Población económicamente activa}

De acuerdo con los resultados tabulados de la encuesta intercensal 2015(INEGI, 2015) la población de 12 años y más en el municipio de Uriangato asciende a 50175 habitantes donde la población económicamente activa (PEA) representa el $50.15 \%$. Por otra parte, la población económicamente activa ocupada en las últimas décadas presenta una tendencia a la baja, en 1980 este grupo de población representaba el 99.14\% mientras que para el último año con registro (2015) su proporción se redujo al $92.70 \%$. 


\section{Distribución económica de la población por sector de actividad}

En términos relativos durante las últimas 4 décadas la población ocupada dentro del sector primario disminuyo al pasar del $23.00 \%$ a $4.16 \%$ mientras que los sectores secundario y terciario se incrementaron para este mismo periodo al pasar de $24.90 \%$ a $39.83 \%$ y de 8.84 a $54.61 \%$ respectivamente. Esto representa una disminución de personas ocupadas en actividades relacionadas entre otras con la agricultura, la ganadería y la silvicultura y por otra parte, un mayor número de personas ocupadas en actividades de la industria, el comercio y los servicios.

\section{Distribución económica de la población por nivel de ingreso}

En el municipio de Uriangato, al año 2015 el $41.82 \%$ de la población ocupada recibe más de dos salarios mínimos, el $39.09 \%$ de la población ocupada percibe de uno a hasta 2 salarios mínimos y el $11.35 \%$ recibe un salario mínimo o menos. En términos relativos, el grupo de personas ocupadas que no percibe ingreso o perciben menos o hasta un salario mínimo, muestra una tendencia a la baja, ya que paso de representar el $27.52 \%$ de la población ocupada en 1990 al $11.35 \%$ de la población ocupada en 2015. Finalmente, actualmente el salario mínimo que estableció la Comisión Nacional de los Salarios Mínimos mediante resolución publicada en el Diario Oficial de la Federación del 21 de diciembre de 2017 y vigente a partir del 1 de enero de 2018 es de $\$ 88.36$ el cual es establecido para todo el país como área geográfica única (SHCP, 2017) lo que incluye a la entidad y al municipio de Uriangato.

\section{Producto Interno Bruto}

El producto interno bruto permite conocer el comportamiento y composición de las actividades económicas y el INEGI maneja como sinónimo el Valor Agregado Bruto y el producto interno bruto. El valor agregado censal bruto total del municipio ha mostrado una tendencia creciente en la última década, paso de un total de 494.01 millones de pesos en 2004 a 982.80 millones de pesos en 2009 y paso a 1095.64 millones de pesos al 2014. Del valor agregado censal bruto total del municipio al 2014 (que fue de 1 095.64) millones de pesos) las actividades económicas 3133 industrias manufactureras (20.06)\% 43 comercio al por mayor (28.41)\% y 46 comercio al por menor (28.07)\% aportan aproximadamente en conjunto el $76.54 \%$ es decir casi tres cuartas partes del resto de actividades económicas, cabe destacar que la actividad 61 Servicios educativos la cual aporta el $0.79 \%$ del valor censal bruto total del municipio, es la única que para los tres periodos censados presenta una tendencia a la baja, ya que en 2004 represento una producción de 18.417 millones de pesos, disminuyo a 13.48 millones de pesos en 2009 y finalmente pasó en 2014 a 8.652 millones de pesos.

\section{Áreas en que se encuentra capacitada la población}

En materia de educación al 2015 Uriangato el 14.16\% de población de 15 años y más cuenta con educación media superior -al menos un año aprobado- y el 8.05\% cuenta con educación superior -al menos un año aprobado- y finalmente el grado promedio de escolaridad que se presenta es del 7.34. por otra parte, el $7.22 \%$ de la población de 15 años y más presentan condiciones de analfabetismo es decir personas de 15 años y más que no saben leer ni escribir, son personas que no cuentan con las competencias básicas de saber leer y escribir (Periódico Oficial del Estado de Guanajuato, 2018).

Por otra parte, existen subsectores relevantes para la actividad municipal por el número de personas ocupadas en cada una de ellas, siendo las dos más relevantes las denominadas como 463 Comercio al por menor de productos textiles, bisutería, accesorios de vestir y calzado (18.12 de la población ocupada) y la 315 Fabricación de prendas de vestir (14.61 de la población ocupada) ambas actividades concentran el 32.73 de la población ocupada. A estas actividades les siguen la 461 Comercio al por menor de abarrotes, alimentos, bebidas, hielo y tabaco $(11.40 \%$ de la población ocupada) 43C Subsectores agrupados por el principio de confidencialidad $(9.70 \%$ de la población ocupada) 722 Servicios de preparación de alimentos y bebidas (7.27\% de la población ocupada) 311 Industria alimentaria (4.24\% de la población ocupada) y 811 Servicios de reparación y mantenimiento (3.57\% de la población ocupada) (Periódico Oficial del Estado de Guanajuato,2018). 
Las actividades económicas antes señaladas representan el $68.91 \%$ de la población ocupada, es decir, que siete de cada 10 personas ya han adquirido y desarrollado habilidades y aptitudes, en oficios y actividades muy específicos y característicos para el municipio (Periódico Oficial del Estado de Guanajuato, 2018).

\section{Crecimiento poblacional}

La población del municipio de Uriangato pasó de tener 30,311 habitantes en 1980 a 59,305 habitantes para el año 2010 lo que representa una tasa de crecimiento medio anual de $2.26 \%$, casi duplica su población en 30 años. El municipio de Uriangato presenta variaciones en este sentido variaciones en cuanto al aumento de la población en cada de los periodos señalados; presenta una tasa de crecimiento positiva en todos. Para el periodo 1980-1990 su Tc fue de 4.42\% (la mayor en los cuatro periodos analizados). La Tc para la década 1990-2000 fue de 1.26\%, mientras que para el periodo 2000-2010 fue de $1.4 \%$ misma que se mantuvo en el periodo 2010-2015. Por otra parte, la cabecera del municipio concentra el $86.60 \%$ de la población y el resto de 13.30 se distribuye en las localidades diseminadas del municipio. En base a datos de INEGI, en 2015 contaba con 62761 habitantes (Periódico Oficial del Estado de Guanajuato, 2018).

\section{Escenario estratégico}

El escenario es construido considerando las aportaciones de la participación social la sociedad civil organizada y funcionarios, así como aportaciones con base en la experiencia del consultor responsable del estudio.

\section{Uso de suelo y vegetación}

El uso de suelo y vegetación plantea la hipótesis de que se materializarán y cumplirán las políticas que han sido establecidas dentro de las unidades de gestión ambiental y territorial del programa estatal. En este escenario se considera que existirán presiones económicas y de crecimiento en el área de asentamiento humano de cabecera municipal.

El noroeste, este y suroeste se mantendrán áreas de flora y fauna relevantes del municipio, además de interrumpir la degradación (Periódico Oficial del Estado de Guanajuato, 2018).

\section{Estrategia de desarrollo urbano de la cabecera municipal}

El programa establece dentro de su estrategia de desarrollo urbano, la zonificación de la cabecera municipal, la cual define las bases generales para el uso y destino a que podrán dedicarse las áreas o predios del área la cabecera municipal. En particular para la estrategia de desarrollo urbano, se integran como parte de la cabecera municipal aquellas localidades (clasificadas como tal por INEGI) que de manera paulatina se han integrado a la zona urbana de la cabecera municipal, entre ellas las siguientes al norte Huahuemba, Las Misiones y Buenavista, al oriente Colonia Juárez al sur Fraccionamiento La Mesa, San José Cuaracurio y Buenavista, al sur poniente Villaparaiso del Sur, Fraccionamiento Buganvilia, y Colonia Magisterial y al poniente Nuevo Uriangato. En este sentido las estrategias generales para el desarrollo urbano de la zona del Programa y que permitan orientar las acciones específicas para el ordenamiento territorial (Periódico Oficial del Estado de Guanajuato, 2018).

\section{Zonificación}

La zonificación secundaria para el centro de población (Zonificación de usos y destinos del suelo en la cabecera) ha sido definida teniendo como principales insumos los resultados de las fases anteriores. En el presente programa los usos y destinos se han definido mediante la delimitación de zonas y corredores de usos del suelo, entendiendo por corredores aquellos, aquellas áreas en forma longitudinal en las que se asignan usos y destinos a los predios y lotes que colindan o tienen frente hacia las vías primarias, secundarias o colectoras (Periódico Oficial del Estado de Guanajuato, 2018). 
Modificación de la actual Dirección de Desarrollo Urbano para consolidar Unidad Administrativa Municipal en Materia de Administración Sustentable del Territorio (Dirección de Desarrollo Urbano)

Se considera necesario fortalecer el área administrativa responsable del desarrollo a través de dos coordinaciones. La primera correspondería a un especialista jurídico que de mayores garantías de aplicación del marco legal en materia de desarrollo urbano y vivienda y la segunda una que en coordinación destinada a la regularización de la tenencia de la tierra. Estas figuras tendrán como objeto materializar algunos de los objetivos más importantes del programa, como la regulación del uso del suelo, la emisión de permisos en materia de construcción y usos del suelo, la revisión de estudios de evaluación de impacto territorial, evaluación de manifestación de impacto ambiental, así como en la inspección y vigilancia permanente dentro del territorio municipal en materia de desarrollo y medio ambiente. La dirección dará certeza al cumplimiento de funciones y atribuciones señaladas en el código territorial que corresponden a la unidad administrativa municipal en materia de administración sustentable del territorio.

Es evidente la falta de una planificación territorial en ambos municipios, esta fue toda la información que se encontró, y es notoria lo limitante que es, además queda de manifiesto que cada municipio hizo una planeación por su cuenta y nunca considerando que están juntos por el fenómeno de la conurbación en el que están inmiscuidos, cuando lo ideal y correcto es que se debería de hacer una planificación conjunta y adecuada a largo plazo entre ambos municipios, este problema ya tiene mucho tiempo de presentarse y está muy arraigado en la sociedad de ambos municipios, hay gente muy preparada aquí y sin embargo siguen con la misma de ser de un municipio o de otro, pero nunca pertenecer a los dos, al revisar la planeación que cada municipio posee, es evidente que no hay una estrategia de crecimiento definida para cada municipio, únicamente lo que existe es información del municipio pero muy poco de planeación estratégica territorial (Periódico Oficial del Estado de Guanajuato, 2018). 


\section{Capítulo IV Diseño metodológico de la planeación territorial}

En el presente capítulo se mencionan los retos de gobernabilidad en las ciudades, así como también se abordan los factores del desarrollo urbano sustentable y se establece la metodología para la realización del trabajo de campo, se diseña la investigación, que incluye el análisis de las variables y la determinación de los índices e indicadores que las componen. Así como su operacionalización mediante la metodología propuesta en esta investigación, que es prácticamente descomponer deductivamente las variables que componen el problema de investigación.

\section{Los retos de la gobernabilidad de las ciudades}

Las ciudades en la época de la globalización económica y la mundialización social y cultural propia de la era de la información, se ven en la necesidad de (Pascual, 2001).

- Definir una estrategia urbana.

- $\quad$ Articularse en los sistemas urbanos.

- Desarrollar la gestión relacional.

\section{Definir una estrategia urbana}

Las ciudades integran los puntos nodales en que se organiza la red que caracteriza la economía global contemporánea.

La globalización económica es caracterizada por el flujo de información, capitales, bienes y personas, que recorren todo el mundo. Las ciudades forman los nudos de infraestructuras y servicios avanzados de esta trama de flujos. Forman los elementos organizadores y de soporte de la economía global. Las ciudades que no pueden articularse en este sistema de flujos mundial, continental o regional, se quedan al margen de los procesos de desarrollo. Las ciudades, en definitiva, se ven en la exigencia de definir una estrategia de cualificación de sus recursos humanos, infraestructurales y de servicios, para obtener la suficiente singularidad y notoriedad en los diversos subsistemas de ciudades a los que pertenecen o se inscriben, y conseguir la suficiente competitividad y capacidad de proyección para atraer nuevos flujos y/o acrecentar su capacidad de orientación y organización de los mismos (Pascual, 2001).

La estrategia no solamente es propia de que la deben definir las áreas metropolitanas o las ciudades centrales o direccionales de las mismas, sino que la experiencia de la planificación estratégica da énfasis la importancia que, inclusive para los municipios metropolitanos, tiene el hecho que éstos determinen su propia estrategia. No solamente por los efectos en la competitividad del área metropolitana, sino sobre todo a nivel interno para cualificar la vida del municipio y sus pobladores.

En circunstancias de cambio urbano tan remarcado que provoca el impacto de la utilización de las tecnologías de la información y comunicación, las ciudades deben de orientar sus procesos y reorganizar sus funciones urbanas para así lograr producir conocimiento en la era de la información.

Las ciudades apuestan por el desarrollo de los servicios vanguardistas, y por convertirse en centros de producción y/o difusión de ciencia y tecnología, y así buscar un nuevo modelo de desarrollo en que la creatividad y capacidad de innovación de los individuos, empresas e instituciones, sean cada día una fuente más importante de valor añadido urbano. 
Este novedoso modelo de desarrollo involucra al conjunto de la ciudad, puesto que este mismo desarrollo se debe administrar por criterios de sostenibilidad. La educación y la cultura se vuelven en los principales factores de competitividad de la ciudad y de calidad de vida de los pobladores. La política social no solamente debe afrontar a nuevas formas de desigualdad y pobreza, para las que no es suficiente el garantizar prestaciones y servicios, sino que debe promover una acción social que sea capaz de organizar la comunidad hacia fines solidarios y reducir las desigualdades en el acceso al capital cultural. Las PP deben gestionarse con calidad y ser capaces de articular la colaboración de todos los actores involucrados, y localizar las fórmulas para organizarse en función de los intereses y demandas de las ciudadanas y los ciudadanos.

Las ciudades deben observar permanentemente los cambios en el entorno urbano que comporta la revolución tecnológica y la globalización son continuos y las variaciones de su posición en el sistema de ciudades, para así lograr identificar los procesos que resulten más adecuados de adaptación y ajuste de la estrategia urbana.

\section{Articularse en un sistema urbano}

Mediante los intercambios de flujos entre ciudades se forma el sistema mundial de ciudades, que es un sistema jerárquico, asimétrico, pero que está dotado de alta flexibilidad o variabilidad, puesto que la posición jerárquica de cada ciudad no es fija, sino que contiene un alto grado de cambios.

Las ciudades, en la red de flujos e intercambios entre sí, establecen relaciones de competencia para atraer inversiones, sedes de empresa e instituciones, para consolidarse como centros logísticos, para atraer eventos culturales y dispositivos que le den proyección exterior, pero también establecen esto es mucho más importante- relaciones de complementariedad para constituir subsistemas urbanos cualificados. De esta manera, las ciudades europeas portuarias del Mediterráneo se alían para afrontar a la competencia de los puertos atlánticos, pero entre ellas también instituyen competencia para así lograr atraer mercancías y pasajeros turísticos que acceden a Europa por el mar Mediterráneo.

Si las ciudades son los puntos nodales de la estructura del mundo contemporáneo, los subsistemas urbanos constituyen sus ejes. Una ciudad puede pertenecer a diferentes subsistemas urbanos en función de sus opciones estratégicas, ya sean de desarrollo económico sectorial, portuario, turístico, cultural, tecnológico o de seguridad policial frente a la delincuencia internacional.

Las ciudades se ven en la necesidad de establecer alianzas estratégicas entre ellas, para mejorar su cuota de mercado y su notoriedad a nivel macrorregional o internacional. La constitución de redes o asociaciones de ciudades constituye los primeros inicios de estas alianzas urbanas para cualificar sus subsistemas de ciudades. Los Estados, en una perspectiva a medio y largo plazo, apoyarán la cualificación de los sistemas urbanos a los que pertenezcan sus principales ciudades como garantía de desarrollo y competitividad en su territorio.

\section{Desarrollar la gestión relacional}

Desde el año 2009, año de las primeras elecciones de los gobiernos locales democráticos, en las ciudades se puede distinguir tres etapas tipo, cuyo calendario es diferente por ciudad y no necesariamente todos los ayuntamientos han pasado por estas etapas.

La primera etapa se denomina de provisión de equipamientos y servicios públicos. Los ayuntamientos incrementaron el gasto público para superar los déficits de las ciudades en relación con sus homólogas europeas; son la referencia de la gestión municipal. Los movimientos ciudadanos se dirigen a los ayuntamientos, en tanto gobierno de proximidad, para reclamar sus derechos sociales. Es una etapa en que los ayuntamientos obtuvieron un mayor prestigio ante los ciudadanos, y en ellos predominó una orientación política asistencial, combinada con el impulso de procesos de descentralización y participación ciudadana en las decisiones sobre política municipal de servicios. 
Una segunda etapa, en la que se encuentran la mayoría de los ayuntamientos españoles, centrada en la gestión y la eficiencia. Es una etapa de predominio de las funciones gerenciales por encima de las políticas. Los ayuntamientos tienen importantes, e incluso insuperables restricciones para aumentar las inversiones, y su preocupación está en dar máximo rendimiento a los equipamientos y servicios municipales existentes. Es una etapa caracterizada por la imitación de la gestión empresarial, reingeniería de procesos, gestión y control de calidad, técnicas de organización de los espacios productivos, estructuras flexibles de organización y retribución del personal, en la que la política se subordina a la gestión.

Una tercera etapa, la de la gestión relacional, se encuentra en sus inicios en aquellos ayuntamientos que han promovido planes o proyectos sectoriales estratégicos con éxito, y que ha consolidado una cultura de colaboración entre los diferentes agentes económicos, sociales e institucionales que actúan en la ciudad.

En esta etapa, los gobiernos locales son conscientes no sólo de las limitaciones del gasto público, sino también de las mejoras de gestión en relación a su impacto ciudadano; y ello en una época, como se ha analizado, caracterizada por la emergencia de lo local, que exige un mayor protagonismo político de los ayuntamientos, que ha llevado a considerar que el papel fundamental de las administraciones públicas, y muy especialmente los gobiernos locales y regionales, es el de impulsar el desarrollo económico y social a partir del reconocimiento de todos los actores urbanos, de su interdependencia y de su capacidad de incidir en el desarrollo del territorio. Gestionar un territorio significa cada vez menos centrarse en la economía, eficacia y eficiencia de los recursos públicos, para priorizar el establecimiento de unas relaciones de calidad entre los actores urbanos porque produzcan efectos sinérgicos. De lo que se trata es de la capacidad de orientar en una dirección de futuro, o a través de un proyecto concreto, la acción coordinada de los diferentes actores urbanos.

Se dará a conocer ahora un artículo de la CEPAL, que dice: En este inicio de siglo, América Latina debe plantearse cómo volver a tomar el crecimiento, y debe aprovechar los avances que se han producido en la gestión macroeconómica, especialmente en cuestión de control de la inflación. Mas, sin embargo, tales avances no han bastado para promover el desarrollo, sobre todo en el ámbito local; de tal forma que es preciso encontrar un nuevo enfoque, que rescate la identidad local con sus fisonomías culturales propias. Simultáneamente, habrá que renovar los mecanismos de fomento y financiamiento que hagan más fácil la conformación de redes empresariales y fortifiquen el tejido social en el plano territorial.

Como pieza de este proceso, es de resaltar el fomento de las aglomeraciones industriales como maneras de organizar la producción en un determinado territorio, en específico los distritos industriales, qué con sus fisionomías de acción colectiva, hacen posible una mayor flexibilidad de la industria frente al fenómeno de la globalización. En Latinoamérica, las circunstancias espaciales y culturales no son las más idóneas para concretar aglomeraciones industriales del tipo distritos, al estilo europeo. Sin embargo, existe la posibilidad de inducir estos métodos, para lo cual se requiere la elaboración del PP destinadas a la creación de redes empresariales y a darle fuerza a las alianzas estratégicas entre el sector público y el privado. Sólo de esta manera será posible posicionarse en los mercados de un mundo conformado por bloques comerciales (CEPAL, 2003).

En los casos analizados en este estudio se puede observar que la localización de las aglomeraciones industriales y sus características obedecen a tres factores: la presencia de empresarios innovadores (también llamados pioneros); el apoyo de centros tecnológicos o universidades con una profunda relación de investigación y desarrollo con las empresas localizadas en el territorio; y la mano de obra barata, principalmente en las aglomeraciones asiáticas y en la emigración industrial hacia el nordeste de Brasil.

\section{Factores que afectan el desarrollo urbano}

La planeación urbana, también conocida como desarrollo urbano, incorpora la planeación para los sistemas de transporte y uso del suelo para hacer mejor la estructura de una ciudad o un pueblo. El desarrollo urbano contiene la renovación urbana, la cual atiende asuntos como el deterioro y la falta de inversión en regiones determinadas. Los factores como el uso del suelo, edificaciones deterioradas, seguridad y el transporte afectan el cómo se planean las ciudades (Helaine, 2017). 


\section{Uso de la tierra}

Las personas que se dedican a planificar las ciudades intentan manejar el incremento de una ciudad al emitir leyes regionales para poder manejar el cómo se utiliza la tierra, pero esto igualmente afecta el crecimiento de una ciudad. Los planificadores pretenden regular los aspectos de la construcción, como el tamaño de los edificios nuevos, los usos que se les dará y qué características tendrán. Aun así, algunos planificadores tratan de proporcionar mucha libertad al arquitecto, también necesitan imponer la seguridad y consideran el cómo desarrollar la ciudad de manera inteligente evitando la aglomeración y considerando asuntos como el consumo de agua.

\section{Estética}

En varias ciudades, la estética o la fuente de belleza y su expresión, es tomada en cuenta en el desarrollo urbano. Las ciudades a frecuentemente intentan reducir la aglomeración o mantener un perfil de estilo arquitectónico. Esto se hace evidente sobre todo en las áreas históricas de muchos poblados. Las ciudades tratan de mantener un control sobre las nuevas edificaciones en estas áreas y podrían regular los colores de pintura de los exteriores de los hogares (caso de Cuitzeo, en Michoacán) al igual que los adornos en el exterior de esos hogares. El desarrollo urbano triunfante es un factor dentro de la herencia o cultura de la región al igual que en los aspectos como los peligros naturales.

\section{Seguridad}

Los desarrolladores urbanos tienen que considerar la seguridad de los residentes y visitantes al desarrollar un poblado o ciudad. Las condiciones de un clima extremoso, como los huracanes o inundaciones, demandan de planeación para rutas de emergencia y características de seguridad, como las paredes de retención en los cuerpos de agua o albergues.

\section{Edificios deteriorados}

Existen muchas ciudades las cuales batallan con el qué hacer con edificios abandonados y deteriorados, así como con el control de hierba y escombros. Esto tiene un impacto de manera importante en el desarrollo urbano ya que para el impedir el deterioro se cree es una parte central para advertir el deterioro de toda la ciudad, especialmente en áreas de crimen, drogas y otros aspectos sociales. El desarrollo urbano tiene que atender cómo evitar el deterioro, barrios bajos y pobres o descuido.

\section{Transporte}

El transporte es un problema clave en muchas de las áreas urbanas y presenta un problema único para un desarrollador. El desarrollo urbano precisa de atender el tránsito que incrementa o disminuye, áreas de estacionamiento, los patrones del tránsito, y métodos alternativos de transporte, como camiones, trenes o trolebuses.

\section{Reconstrucción y renovación}

Otro de los factores involucrados en el desarrollo urbano es el de la reconstrucción y renovación, que se hace evidente en áreas que han sido destruidas por desastres naturales o causados por humanos. Un plan de construcción para una comunidad que experimenta la renovación debe considerar los recursos existentes, como la cultura y los negocios, así como considerar las metas de largo plazo de la ciudad al crear el diseño.

\section{Desarrollo urbano sustentable}

\section{Concepciones de desarrollo urbano}

Para poder abordar el tema, se hace necesario aproximarse a las concepciones en vigencia sobre desarrollo urbano. 


\section{Modernización material centralista}

El desarrollo urbano según esta definición es la construcción de centros comerciales, grandes edificios, modernas pistas, obras físicas que privilegian atractivos de turismo y de recreación. El encargado de construirlas en las grandes urbes es el sector privado, y en parte el Estado a través del municipio. Este modelo concentra su enfoque en construir obras y edificios que satisfagan la demanda inmediata y generen ingresos económicos; no toma en cuenta una visión de futuro; solamente una visión de corto plazo; no prevé por ejemplo los peligros que implica construir edificios enormes en zonas sísmicas; sin servicios de agua y colectores para drenaje suficientes (Torres, 2008).

El desarrollo material derriba casonas coloniales para construir edificios nuevos en inmuebles que originalmente alojaban a 7 personas, para albergar a más de 200 en módulos verticales, generando sobre densidad y múltiples problemas.

Por otro parte, fruto de la falta de regulación y el afán de conseguir recursos económicos a cualquier costa, se deforesta gran parte de la campiña y zonas naturales que pertenecen a los aires al mar, y al campo.

El proceso de urbanización acelerada es intenso y sin algún control práctico. Extensas zonas agrícolas y forestales pronto se convierten en urbanizaciones de asfalto y cemento; siendo esto un grave error de fatales consecuencias, porque es afectado el campo agrícola que es necesario para la producción de alimentos y el equilibrio en el ecosistema.

La vegetación tiene que ser parte integrante de la ciudad; en caso contrario se afecta la calidad de vida, ahí radica el establecer un equilibrio que permita el desarrollo urbano sin afectar a la naturaleza. El desarrollo material centralizado provoca desorden urbano, sobre masificación, contaminación ambiental, inseguridad ciudadana, escasez y encarecimiento de servicios.

Al modelo material centralista, no le interesan los problemas de grave contaminación ambiental, carencia de servicios y condiciones de vida de las personas en las zonas urbanas y urbanas marginales; para ellos su interés principal es ver si los ciudadanos pueden comprar y pagar pequeñas viviendas en altos edificios.

Respecto a la planificación, esta concepción considera que no es de ninguna manera posible orientar el desarrollo urbano; que es necesario dejar a la iniciativa privada que construya de acuerdo con criterios de oferta y demanda, de las empresas tanto constructoras como financieras. Asimismo, que la ciudad debe ser dejada al libre albedrío de las leyes del mercado; por lo que el rol del estado y municipio es solo facilitar la actividad a la iniciativa privada.

Todo ello aparentemente es atractivo y fuente de inversiones económicas; más, sin embargo, genera profundos contrastes y realidades que se oponen; se tienen miles de edificios y enormes centros comerciales, pero a la vez excesivo centralismo y barrios de pobreza extrema.

La ciudad en su conjunto lentamente se convierte en un centro sobre saturado de personas y vehículos; inseguridad urbana y de contaminación. Si a esto se le añade la posibilidad de sufrir movimientos telúricos, escasez de agua, o como algunos lugares ya se puede observar erupción de volcanes y desastres de la naturaleza por el calentamiento global, los peligros que se corre por falta de previsión y planificación y fundamentalmente por sobredimensionar, las expectativas económicas, son inmensos.

Por ello es irresponsable, dejar el desarrollo y el crecimiento de la ciudad al libre albedrío de las fuerzas del mercado, o sea a los grandes intereses económicos de empresas constructoras y financieras, esto es que el gobierno debe de planear y planificar el desarrollo de los grandes núcleos de población.

El desarrollo material, sin planificación produce nuevas y masivas invasiones de migrantes del interior del país hacia los centros urbanos, que con justicia buscan algo de bienestar y progreso porque sus pueblos y ciudades, no hay el desarrollo urbano que ellos encuentran en la ciudad están abandonados por el Estado y el sector privado. 
En síntesis, la visión centralista de desarrollo material no tiene un basamento sustentable por los siguientes motivos:

La ciudad se densifica y masifica, mucho más de lo que realmente ella puede soportar ocasionando falta de servicios públicos básicos, por híper centralismo.

- $\quad$ Existe un riesgo de desabasto de alimentos, falta de servicios esenciales y posibilidad de no poder hacerle frente a los desastres naturales; debido a la excesiva masificación de personas.

- El parque automotor aumenta a niveles que llegan a hacer colapsar las vías; aumentando los riesgos de circulación, las horas pico por el exceso de tráfico, los accidentes y la contaminación ambiental (Torres, 2008).

\section{Desarrollo urbano sustentable otra definición}

El desarrollo urbano en que se basa este modelo es la posibilidad de una población determinada, de satisfacer las necesidades elementales: Alimentación, educación, salud, vivienda, trabajo, cultura. Es formar un hábitat en un ambiente armónico, en el que se respete los derechos humanos de las personas; niños abandonados, no exista masificación, mendigos, delincuencia, ni contaminación, o éstas sean mínimas; lo que quiere decir un lugar racional y equilibrado en el que se respete la dignidad del ser humano; la seguridad y bienestar social y ecología. Según esta concepción, no importan tanto indudablemente los grandes edificios y las bellas pistas; como el desarrollo humano en un ambiente equilibrado y preservando el ambiente natural (Torres, 2008).

Ello es posible lograrlo en base a una planificación estratégica armonizando tanto el interés público como el interés privado. A ello se le denomina desarrollo urbano sustentable con formulación y realización de planes urbanos sustentados en el ambiente ecológico, a corto, mediano y largo plazo; desempeñando principios de equidad, descentralismo, previsión de servicios básicos en todo el país, generación de fuentes de empleo y concertación con los actores sociales para el desarrollo.

La clave para este modelo es la descentralización, el desarrollo equilibrado y racional de todas las ciudades de manera armónica, tratando de evitar la excesiva concentración de personas en ciudades, a la fecha sobre pobladas, y que crean cinturones de miseria, caso de Lima, Ciudad de México, Bogotá.

Para ello es trascendental la elaboración y ejecución de políticas públicas de descentralización urbana, por parte del gobierno municipal, estatal y federal. De la misma manera, gestión dirigida por el gobierno local, con la participación tanto del estado como de la sociedad civil.

El planificador en este caso no impone, hace propuestas, convoca, coordina con las instituciones públicas y privadas. El Estado estimula el desarrollo racional de todas las ciudades y pueblos. El desarrollo urbano es determinado en términos de carácter social, cívico, ecológico, cultural y económico.

Haciendo referencia a los factores urbanos (población, servicios viviendas), es obligatorio hacer uso de programas de informática, nombrados sistemas de información urbanística y geográfica, que sitúan la densidad racional de una ciudad, la capacidad de servicios, trabajo, transporte.

En la actualidad es posible con sistemas de modelística, ayudar a planificar y simular el desarrollo urbano de o con formulación de costos y beneficios, desde un ordenador. Los sistemas de multimedia, o realidad virtual, son herramientas muy valiosas, para realizar una planificación integral.

Es así como el desarrollo urbano se puede orientar en estudios y pruebas realizadas en laboratorios de urbanismo e informática, con los propósitos de descentralizar la ciudad, construir ciudades - campiñas autónomas en las provincias y distritos; diseñar edificios, vías, áreas de educación, recreación, salud, turismo y servicios, en forma racional y armónica a lo largo y ancho del país, no solamente en los centros urbanos, guiados por intereses económicos. 
La tecnología digital, para el desarrollo sustentable ${ }^{10}$, en la actualidad es un instrumento indispensable. El desarrollo sustentable, se debe orientar por políticas de descentralización racional y protección del medio ambiente tanto en la ciudad como en el campo, a lo largo y ancho de toda la república. La autoridad urbana, ya sea el estado o el municipio, tiene que planificar, prever, dirigir, coordinar esfuerzos, en suma, gobernar; en concordancia con la actividad privada (Torres, 2008).

\section{Guía básica para un desarrollo sustentable}

Para llevar a cabo un crecimiento urbano, armónico, ordenado y con respeto y armonía con el medio ambiente se hace necesario tomar en cuenta los siguientes requisitos.

- $\quad$ Crecimiento Urbano Ordenado y Planificado.

- $\quad$ Uso de la tecnología más adecuada.

- $\quad$ Tener cuidado del patrimonio monumental.

El gobernante local para ello debe hilar intereses y voluntades; que se convierta en un director de orquesta, que logre sintonizar las motivaciones, expectativas, necesidades del grupo social, conforme a un plan urbano, que debe de ser una real constitución respetada y cumplida por todos.

\section{Crecimiento urbano ordenado}

Una de las razones del caos urbano, es que tanto las autoridades, como la mayoría de los ciudadanos no respetan los planes urbanos.

El Derecho Urbano, es un elemento fundamental de la planificación. Hasta la fecha existe un enorme número de normas que orientan el desarrollo local, más, sin embargo, no se cumplen ni las acatan a cabalidad. El derecho como parte de la superestructura, ha demostrado que puede ser una herramienta de cambio y renovación. No es por la anarquía, la posesión de grandes capitales, ni por la improvisación, que se va a alcanzar un crecimiento urbano ordenado, más bien en base a la planificación, la participación de los ciudadanos, el respeto a ley, el uso de la tecnología adecuada, y el buen manejo de los recursos disponibles (Torres, 2008).

De la misma manera, la solución racional de variables que afectan al desarrollo, como la constante migración, la falta de empleo, el centralismo, y lo que es más grave la escasez del recurso vital para la vida como lo es el agua.

\section{Uso racional del suelo}

La política urbana de los municipios, así como en general a nivel nacional, ha sido hasta el día de hoy solo expansionista; como si no existieran los barrios o como si no hubiera necesidad de inversiones y de habilitación progresiva de lo que ya existe. Una alternativa para no crecer de manera desproporcionada reside en reestablecer áreas deterioradas internas; des tugurizar, reanimar o completar lo que la sociedad en su conjunto se ha esforzado en desarrollar y edificar (Torres, 2008).

No es nada recomendable que la ciudad siga creciendo bastante en el plano horizontal ni a mayores alturas, porque se dificulta la dotación de servicios básicos y equipamiento.

Es indispensable que el desarrollo se promueva en las ciudades y pueblos del interior del país en forma armónica, equitativa y descentralizada. Que se oriente el desarrollo, a la construcción de viviendas productivas y la construcción del segundo y tercer piso de los bienes inmuebles, en las urbanizaciones consolidadas; que se estimule la creación de fuentes de empleo, educación y oportunidades en las zonas de más baja densidad poblacional.

\footnotetext{
${ }^{10}$ El concepto desarrollo sustentable es el resultado de una acción concertada de las naciones para impulsar un modelo de desarrollo económico mundial compatible con la conservación del medio ambiente y con la equidad social.
} 
Los municipios pudieran usar como política de ocupación de espacio urbano, por citar un ejemplo, la promoción del derecho de superficie, la edificación de casas prefabricadas, las construcciones en el subsuelo y sobresuelo, la construcción de viviendas económicas en base a contratación jurídica no tradicional, como las figuras del joint venture, y otras.

Para ello se demanda:

- $\quad$ Prevención y control del desperfecto del suelo urbano.

- $\quad$ Recuperación y rehabilitación de las áreas urbanas afectadas por el deterioro.

Recuperación y protección de los centros históricos de las ciudades.

Rehabilitación de predios en situación del alto riesgo (inundaciones, huracanes, temblores etc.).

Eliminación progresiva de tugurios y bares de mala muerte.

En algunas ciudades supuestamente sobra espacio; más, sin embargo, ese espacio sin la posibilidad de recursos hídricos, ni servicios básicos, tiene muy poco valor. Lo más importante es la ampliación de la zona agrícola. No es posible pensar en continuar construyendo viviendas, a base de destruir zonas agrícolas. La producción de alimentos, la ecología y los recursos naturales deben necesariamente ser preservados y cuidados.

Es indispensable planificar la construcción de edificios de un máximo de 12 niveles, en las ciudades del interior del país que estén ubicados en una zona altamente sísmica; incentivar el derecho de superficie, la construcción vertical moderada, guardando espacios para los biohuertos. La construcción de viviendas no puede ni debe seguir destruyendo la vegetación; por una planta destruida, si se pretende preservar la vida se deben de sembrar dos.

\section{La investigación científica}

La vía fundamental para que la ciencia logre su objetivo es el proceso de investigación científica, el cual, como elemento integrante de las ciencias alcanza también el carácter de institución social, a cuya actividad las empresas y los estados de los distintos países, dedican gran atención por su incidencia en la competitividad y en el desarrollo de las diferentes esferas de la vida social, proyectando estrategias para la realización de dichas investigaciones.

\section{Identificación de factores y variables}

En una primera fase el análisis muestra las variables que conforman o afectan la organización. La mirada tanto al sistema como a su ambiente han de ser una mirada espacial y temporal a la vez, en el reconocimiento que la situación actual ha sido inducida por hechos y variables de efectos preliminares, y que el desempeño futuro va a depender de las circunstancias que las tendencias y el futuro ofrezcan espacios posibles probables y deseables deberán ser considerados (Scribd, 2018).

Una variable es una forma de manifestar las peculiaridades o atributos que tienen en común los actores que participan en una investigación o experimentación y pueden se pueden presentar en modalidades desiguales o por grados. Por ejemplo, el peso de una persona, su estatura, el número de aciertos de un examen, el género, etcétera.

Cuando estas particularidades o atributos son maniobrados o controlados por el investigador se les llama variable independiente. Por ejemplo, si se quisiera saber si hay diferencias por sexo en las calificaciones conseguidas en una escuela primaria, la variable independiente sería el sexo, ya que este no se puede cambiar, pero el experimentador puede controlar en su estudio la cantidad de sujetos por sexo, para que sean igual número de niños que de niñas.

La variable independiente por lo general siempre se presenta antes que la variable dependiente y causa efectos en la variable dependiente, debido a eso recibe ese nombre, ya que va a responder a los cambios que se hagan en la variable independiente. 
Toda investigación requiere tener muy claro cuáles son las variables de estudio, esto es, cuáles son las variables independiente y dependiente. Esto permitirá saber al investigador qué es lo que va a manipular (variable independiente) y cuáles son los efectos producidos (variable dependiente) con los cambios provocados.

Para la presente investigación, se optó por usar el modelo de competitividad creado por el ITM en el ICTEM 2012 y que no es únicamente una lista de factores comparativos y competitivos sino también toma en cuenta la relación y desempeño entre los diferentes factores a manera de crear un modelo sistémico de competitividad del destino turístico. En este sentido, el modelo de competitividad usado en el ICTEM 2012 está compuesto de cuatro elementos:

1. Medio ambiente.

2. Recursos clave y atractivos.

3. Administración del destino.

4. Condiciones situacionales.

\section{Metodología}

El método propuesto consiste en una revisión de diversos factores agrupados en cuatro fases o etapas, cada una de las cuales tiene una ponderación, de acuerdo con ella, en cada fase las distintas variables estudiadas van incrementando en mayor o menor medida su prioridad.

A cada fase se le ha otorgado una ponderación subjetiva (explicada enseguida), tomando para ello las siguientes consideraciones:

$\mathrm{Pr}=\mathrm{aMM}+\mathrm{bEE}+\mathrm{cFV}+\mathrm{dMA}$

Donde:

$\operatorname{Pr}=$ Prioridad de la variable.

MM=Mapa Mental.

EE=Entrevista a Expertos.

FV=Frecuencia de Variables.

MA=Modelos Aplicados.

$a+b+c+d=1$ (factores de ponderación).

Mapa Mental: ponderación a $=0.1$. Esta fase es la inicial para un problema de investigación, aquí se apuntan las variables independientes que el investigador supone tienen intervención con la variable dependiente. La ponderación es baja debido a que solo es el punto de vista del investigador basado en su experiencia.

Entrevista a Expertos: ponderación $b=0.2$. En esta actividad se realizan entrevistas a expertos en el tema estudiado, pueden ser investigadores, estudiosos del tema, docentes, figuras públicas, empresarios, clientes, especialistas de algún área, etc., con la intención de conocer cuáles son las variables independientes más importantes que a su punto de vista afecten a la dependiente. Por esa razón la ponderación es el doble que la anterior fase. 
Frecuencia de Variables: ponderación c=0.3. En varios estudios, una forma de elegir a las variables independientes es construir una matriz de frecuencia de variables, revisando revistas, artículos, libros, modelos, tesis y otros trabajos de investigación, como por sí solo este método permite elegir de manera expedita las variables independientes, se les otorga una ponderación mayor a las otras dos fases anteriores.

Modelos Aplicados: ponderación d=0.4. Esta última actividad lleva el peso más fuerte en el método, la razón es porque se utilizan los resultados de modelos ya aplicados en problemas iguales o similares, por lo tanto, al ya existir una medición; su impacto es de más grande relevancia.

Como es lógico suponer el número de variables incorporadas al mapa mental, irá creciendo conforme se avance en las etapas del método y la cantidad de expertos a entrevistar, la cantidad, literatura revisada y los modelos aplicados serán a consideración del investigador. Se recomiendan las siguientes cifras: mapa mental. 10-15 variables, entrevistas a expertos: 10-20 entrevistados, frecuencia de variables: 20-40 fuentes de información y modelos aplicados: 2-5 con resultados explícitos.

\section{Flexibilidad del método}

El método es flexible tanto en la ponderación de cada fase, así como en el número de ellas, va a depender del tema de investigación y del acceso a la información que se vaya presentando, las fases se pueden eliminar y el peso correspondiente de la fase eliminada puede distribuirse entre las fases que aun persistan, tomando en consideración la tabla 5 de proporciones entre las ponderaciones:

Tabla 5 Proporciones sugeridas del método

\begin{tabular}{|l|r|r|r|r|}
\hline \multicolumn{1}{|c|}{ Fase } & Mapa mental & \multicolumn{1}{c|}{ Entrevista expertos } & \multicolumn{1}{c|}{ Frecuencia de variables } & Modelos aplicados \\
\hline Mapa mental & $1: 1$ & $1: 2$ & $1: 3$ & $1: 4$ \\
\hline Entrevista a expertos & $2: 1$ & $1: 1$ & $1: 2$ & $1: 3$ \\
\hline Frecuencia de variables & $3: 1$ & $2: 1$ & $1: 1$ & $1: 2$ \\
\hline Modelos aplicados & $4: 1$ & $3: 1$ & $2: 1$ & $1: 1$ \\
\hline
\end{tabular}

Fuente: Propia en base a las ponderaciones del método MORO

Si el investigador no tiene la menor idea del tema que quiere investigar, no habría mapa mental, el $10 \%$ correspondiente se repartiría entre las otras 3 fases, respetando la proporción y así quedarían:

Entrevista a Expertos=22\%, Frecuencia de Variables=33\% y Modelos Aplicados=45\%. y quedan:

En otro caso, que no fuera posible entrevistar a expertos, entonces las ponderaciones se mueven

Mapa Mental=13\%, Frecuencia de Variables=35\% y Modelos Aplicados=52\%.

En caso de que no se encontraran modelos aplicados en el tema de investigación, las ponderaciones se establecerían:

Mapa Mental=17\%, Entrevista a Expertos=33\% y Frecuencia de Variables $=50 \%$.

\section{Resultados del método de investigación aplicado}

Los resultados generales del método aplicado a la planeación estratégica territorial en la zona conurbada Moroleón-Uriangato de Guanajuato, se muestran en la tabla 6. 
Tabla 6 Resultados generales del método de investigación aplicado

\begin{tabular}{|c|c|c|c|c|c|c|c|c|}
\hline No. & Dimensión & $\begin{array}{r}\mathrm{M} \\
\text { ment }\end{array}$ & $\begin{array}{l}17 \% \\
a\end{array}$ & $\begin{array}{l}\text { Ent } \\
\text { expe }\end{array}$ & $\begin{array}{l}\text { ta a } \\
33 \%\end{array}$ & $\begin{array}{l}\text { Frecu } \\
\text { varial }\end{array}$ & $\begin{array}{l}\mathrm{ade} \\
50 \%\end{array}$ & Total \\
\hline 1 & Infraestructura & 6 & 10.2 & 6 & 19.8 & 6 & 30.0 & 60.00 \\
\hline 2 & Desorden comercial & 3 & 5.1 & 2 & 6.6 & 5 & 25 & 36.70 \\
\hline 3 & Servicios & 4 & 6.8 & 3 & 9.9 & 4 & 20 & 36.70 \\
\hline 4 & Transporte publico deficiente & 4 & 6.8 & 3 & 9.9 & 4 & 20 & 36.70 \\
\hline 5 & Políticas publicas & 6 & 10.2 & 3 & 9.9 & 6 & 30 & 50.10 \\
\hline 6 & Modernización comercial & 2 & 3.4 & 2 & 6.6 & 3 & 15 & 25.00 \\
\hline 7 & Utilización del agua & 6 & 10.2 & 3 & 9.9 & 6 & 30 & 50.10 \\
\hline 8 & Crecimiento urbano & 6 & 10.2 & 3 & 9.9 & 6 & 30 & 50.10 \\
\hline 9 & Asentamientos humanos irregulares & 1 & 1.7 & 2 & 6.6 & 1 & 5 & 13.30 \\
\hline 10 & Impunidad & 1 & 1.7 & 1 & 3.3 & 1 & 5 & 10.00 \\
\hline 11 & Mal gobierno & 1 & 1.7 & 1 & 3.3 & 2 & 10 & 15.00 \\
\hline 12 & Zona de conflicto & 2 & 3.4 & 1 & 3.3 & 1 & 5 & 11.70 \\
\hline 13 & Legislación no adecuada & 1 & 1.7 & 1 & 3.3 & 1 & 5 & 10.00 \\
\hline 14 & Problemas ejidales & 1 & 1.7 & 1 & 3.3 & 1 & 5 & 10.00 \\
\hline 15 & Desaprovechamiento suelo urbano & 1 & 1.7 & 1 & 3.3 & 1 & 5 & 10.00 \\
\hline 16 & Seguridad publica & 1 & 1.7 & 1 & 3.3 & 1 & 5 & 10.00 \\
\hline 17 & Corrupción & 3 & 5.1 & 2 & 6.6 & 1 & 5 & 16.70 \\
\hline 18 & Competencia desleal & 5 & 8.5 & 2 & 6.6 & 1 & 5 & 20.10 \\
\hline 19 & Anarquía & 1 & 1.7 & 0 & 0 & 6 & 30 & 31.70 \\
\hline 20 & Motos sin control & 4 & 6.8 & 0 & 0 & 5 & 25 & 31.80 \\
\hline 21 & Mala imagen urbana & 4 & 6.8 & 0 & 0 & 4 & 20 & 26.80 \\
\hline 22 & Mal gobierno & 2 & 3.4 & 0 & 0 & 2 & 10 & 13.40 \\
\hline 23 & Zona de conflicto & 4 & 6.8 & 0 & 0 & 1 & 5 & 11.80 \\
\hline
\end{tabular}

Fuente: Elaboración propia con datos colectados para cada una de la etapa del modelo

Resultados de la aplicación del método para determinar la prioridad en variables independientes.

Tabla 7 Resultados finales ordenados del método de investigación aplicado

\begin{tabular}{|r|l|r|r|r|r|r|}
\hline \multicolumn{2}{|c|}{ No Dimensión } & \multicolumn{2}{c}{$\begin{array}{c}\text { Mapa } \\
\text { mental 17\% }\end{array}$} & \multicolumn{2}{c|}{$\begin{array}{c}\text { Entrevista a } \\
\text { expertos 33\% }\end{array}$} & $\begin{array}{c}\text { Frecuencia de } \\
\text { variables 50\% }\end{array}$ \\
\hline 1 & Infraestructura & 6 & 10.20 & 6 & 19.80 & 6 \\
\hline 2 & Políticas públicas & 6 & 10.20 & 3 & 9.90 & 6 \\
\hline 3 & $\begin{array}{l}\text { Utilización del } \\
\text { agua }\end{array}$ & 6 & 10.20 & 3 & 9.90 & 6 \\
\hline 4 & Crecimiento urbano & 6 & 10.20 & 3 & 9.90 & 6 \\
\hline
\end{tabular}

Fuente: Elaboración propia con datos colectados para cada una de la etapa del modelo

\section{Operacionalización de las variables}

Una definición operacional la constituyen una serie de procedimientos o indicadores para poder realizar la medición de una variable definida conceptualmente (Kerlinger, 1979).

Es un proceso metodológico el cual consiste en descomponer deductivamente las variables que componen el problema de investigación, a partir de lo más general a lo más específico; lo que quiere decir que estas variables se dividen (si son complejas) en áreas, dimensiones, indicadores, aspectos, índices, subíndices, ítems; mientras si son concretas solamente en indicadores, índices e ítems.

Ahora bien, una variable es operacionalizada con el objetivo de convertir un concepto abstracto en uno empírico, susceptible de ser medido por medio de la aplicación de un instrumento. Este proceso tiene su importancia en la eventualidad que un investigador poco experimentado pueda tener la seguridad de no perderse o cometer errores que son frecuentes en un proceso de investigación, cuando no existe relación entre la variable y la manera en que se optó por medirla, perdiendo así la validez, dicho de otra manera (grado en que la medición empírica representa la medición conceptual). 
En consecuencia, la operacionalización de las variables es el proceso a través del cual el investigador explica en detalle la definición que adoptará de las categorías y/o variables de estudio, tipos de valores (cuanti o cualitativos) que pudieran asumir las mismas y los cálculos que se tendrían que realizar para lograr obtener los valores de las variables cuantitativas. La operacionalización es un proceso que variará de acuerdo con el tipo de investigación y de diseño. Sin embargo, las variables tienen que estar claramente definidas y convenientemente operacionalizadas. Se consideran incompletos aquellos protocolos cuyo nivel de operacionalización es muy vago (Carrasco, 2009).

Tabla 8 Operacionalización de variables tanto independientes como dependientes para la planificación estratégica en la zona conurbada Moroleón-Uriangato

\begin{tabular}{|c|c|c|c|}
\hline Variables & Definición conceptual & Dimensiones & Indicadores \\
\hline $\begin{array}{l}\text { V.I. } \\
\text { Infraestructura. }\end{array}$ & $\begin{array}{l}\text { Mayor o menor tiempo en acceder } \\
\text { al municipio y una vez ahí ver los } \\
\text { servicios que se ofrecen a los } \\
\text { visitantes y compradores. }\end{array}$ & $\begin{array}{l}\text { Accesibilidad geográfica } \quad \text { y } \\
\text { servicios. }\end{array}$ & $\begin{array}{l}\text { Tiempo en que tarda en } \\
\text { llegar al lugar de compras y } \\
\text { facilidad para encontrar } \\
\text { servicios, escasez de } \\
\text { servicios, calles en mal } \\
\text { estado, calles angostas. }\end{array}$ \\
\hline $\begin{array}{l}\text { V.I. } \\
\text { Crecimiento } \\
\text { urbano. }\end{array}$ & $\begin{array}{l}\text { En la mayoría de los países } \\
\text { desarrollados, la urbanización está } \\
\text { trayendo consigo grandes cambios } \\
\text { en la distribución espacial de } \\
\text { personas, recursos, así como en el } \\
\text { uso y consumo de suelo. Aunque } \\
\text { un proceso de tales características } \\
\text { está fuertemente vinculado al } \\
\text { desarrollo social y económico, } \\
\text { muchos países carecen de } \\
\text { políticas y de marcos de apoyo } \\
\text { que puedan impulsar el proceso } \\
\text { para incrementar los beneficios } \\
\text { del desarrollo y guiarlo hacia } \\
\text { patrones más sostenibles. }\end{array}$ & $\begin{array}{l}\text { Creación de fraccionamientos } \\
\text { clandestinos. Invasión a derechos } \\
\text { de vía. Uso de suelo no } \\
\text { planificado. }\end{array}$ & $\begin{array}{lr}\text { Creación de barrios pobres y } \\
\text { marginales, } & \text { mayor } \\
\text { contaminación } & \text { y } \\
\text { criminalidad } & \text { (Banco } \\
\text { mundial, 2013). } & \end{array}$ \\
\hline $\begin{array}{l}\text { V.I. Políticas } \\
\text { Publicas }\end{array}$ & $\begin{array}{l}\text { Instrumento diseñado para } \\
\text { responder a las problemáticas de } \\
\text { la sociedad, planificar su } \\
\text { crecimiento y otras. }\end{array}$ & $\begin{array}{l}\text { Diseño de planes de desarrollo } \\
\text { urbano. Aplicación de planes de } \\
\text { desarrollo urbano }\end{array}$ & $\begin{array}{l}\text { Expedición de permisos de } \\
\text { construcción en zonas no } \\
\text { compatibles con el uso del } \\
\text { suelo } \\
\text { Otorgación de licencias en } \\
\text { lugares no adecuados a } \\
\text { familiares, o cambio de } \\
\text { dinero } \\
\text { La falta de vigilancia del } \\
\text { municipio para suspender } \\
\text { obras en construcción donde } \\
\text { no se debe construir }\end{array}$ \\
\hline $\begin{array}{l}\text { V.I. Utilización } \\
\text { del agua }\end{array}$ & $\begin{array}{l}\text { La escasez de agua se puede } \\
\text { definir como una falta de agua } \\
\text { suficiente, o no tener acceso a } \\
\text { suministros de agua seguros. }\end{array}$ & $\begin{array}{l}\text { Las principales fuentes de agua } \\
\text { para consumo humano como ríos, } \\
\text { lagos, la humedad del suelo y las } \\
\text { cuencas de aguas subterráneas a } \\
\text { poca profundidad se distribuyen de } \\
\text { manera irregular y, por lo general, } \\
\text { están lejos de las zonas urbanas. } \\
\text { Alrededor del } 36 \% \text { de la población } \\
\text { mundial, ó } 2.4 \text { billones de } \\
\text { personas, viven en regiones donde } \\
\text { falta el agua y el 52\% va a } \\
\text { experimentar una severa escasez de } \\
\text { agua hacia el año } 2050 \text {. El acceso } \\
\text { al abastecimiento de agua en las } \\
\text { ciudades es limitado. (Onu hábitat, } \\
\text { 2018). }\end{array}$ & $\begin{array}{l}\text { Sequia de pozos. } \\
\text { Racionalidad en varias } \\
\text { colonias. } \\
\text { Negación de factibilidad para } \\
\text { dotación en nuevas colonias. }\end{array}$ \\
\hline
\end{tabular}




\begin{tabular}{|c|c|c|c|}
\hline $\begin{array}{l}\text { V.D. Planeación } \\
\text { estratégica } \\
\text { territorial. }\end{array}$ & $\begin{array}{l}\text { Constituye la aplicación del } \\
\text { modelo de gobernanza local a las } \\
\text { políticas públicas para impulsar el } \\
\text { desarrollo socioeconómico en las } \\
\text { ciudades. Los principios } \\
\text { elementales de esta nueva } \\
\text { modalidad de planificación son } \\
\text { los del modelo de gobernanza } \\
\text { para la elaboración e } \\
\text { implementación del PP, lo quiere } \\
\text { decir, la participación ciudadana y } \\
\text { la cooperación público-privada } \\
\text { entre actores de la ciudad como } \\
\text { método de adaptarse a las nuevas } \\
\text { exigencias y demandas que el } \\
\text { actual contexto de complejidad } \\
\text { impone a la mejora de la calidad } \\
\text { de vida en las ciudades. }\end{array}$ & $\begin{array}{l}\text { - Infraestructura local de buena } \\
\text { calidad. } \\
\text { - Políticas y reglamentos que } \\
\text { incrementen la eficiencia de las } \\
\text { empresas (van desde la } \\
\text { capacitación laboral hasta la } \\
\text { regulación de los recursos } \\
\text { naturales, va incluido el } \\
\text { funcionamiento de los } \\
\text { mercados inmobiliarios). } \\
\text { El fomento de servicios } \\
\text { importantes para el desarrollo } \\
\text { en la economía local } \\
\text { (mantenimiento, contabilidad, } \\
\text { informática). }\end{array}$ & $\begin{array}{l}\text { Alta debilidad y muy poca } \\
\text { convicción en el Gobierno } \\
\text { Central sobre el papel de la } \\
\text { planificación estratégica. } \\
\text { - Autoridades locales con una } \\
\text { débil percepción de la } \\
\text { necesidad de crear en } \\
\text { consenso una visión de } \\
\text { futuro. } \\
\text { - Sectores productivos } \\
\text { desvinculados de } \\
\text { verdaderas oportunidades } \\
\text { de desarrollo y del } \\
\text { consenso local. } \\
\text { - Líderes sectoriales con una } \\
\text { visión a corto plazo y } \\
\text { demasiada dependencia } \\
\text { del nivel central. } \\
\text { Miedo de abrir espacios de } \\
\text { debate por posiciones } \\
\text { políticas, autoridades con } \\
\text { una visión del desarrollo y } \\
\text { estilo de gestión } \\
\text { tradicionales. }\end{array}$ \\
\hline
\end{tabular}

Fuente: Elaboración propia, con base en el Marco Teórico desarrollado

\section{Obtención de información para las variables independientes}

\section{Diseño del instrumento}

El instrumento elegido fue el cuestionario, el cual se diseñó con el propósito de medir los indicadores que integran las variables de la presente investigación:

- Variable infraestructura: con sus indicadores falta de servicios y calles en mal estado los cuales miden la percepción que tiene la gente, sobre las vías de acceso a la ciudad, así como los servicios que ofrece la zona a personas externas e internas.

- Variable crecimiento urbano: con sus indicadores creación de barrios pobres y peligrosos y falta de espacios públicos ambos miden la opinión de la población, sobre el crecimiento desmedido y sin control, ocasionado por la creación de asentamientos humanos irregulares y construcción en zonas no aptas para ello.

- Variables políticas públicas: con sus indicadores corrupción y falta de vigilancia municipal, éstas pretenden medir la percepción entre la población sobre la creación de PPy que sean bien aplicadas para planificación estratégica territorial, de esta región.

- Variable utilización del agua: con sus indicadores mala cultura del agua y sequia de pozos con estos se abordará un tema grave a nivel mundial como lo es la falta de agua, y lo que impacta en el crecimiento urbano. 
Tabla 9 Indicadores de las variables independientes

\begin{tabular}{|c|c|}
\hline Variables independientes & Indicadores \\
\hline \multirow[t]{6}{*}{ Infraestructura } & Dificultad para acceder a la ciudad \\
\hline & Calles en mal estado \\
\hline & Calles angostas \\
\hline & Falta de estacionamientos \\
\hline & Falta de servicios \\
\hline & Carencia de lugares de descanso \\
\hline \multirow[t]{6}{*}{ Crecimiento urbano } & Creación de barrios pobres y peligrosos \\
\hline & Afectación a derecho de vías \\
\hline & Falta de espacios públicos \\
\hline & Falta de espacios educativos \\
\hline & Fraccionamientos irregulares sin servicios \\
\hline & Mala traza urbanística, creando conflictos vehiculares \\
\hline \multirow[t]{6}{*}{ Políticas publicas } & Corrupción \\
\hline & Otorgamiento de licencias no factibles \\
\hline & Falta de vigilancia municipal \\
\hline & No aplicación de la Ley de Fraccionamientos \\
\hline & Beneficio a familiares o amigos \\
\hline & Incapacidad administrativa \\
\hline \multirow[t]{6}{*}{ Utilización del agua } & Sequia de pozos \\
\hline & Racionalidad de agua \\
\hline & Negación de dotación de agua en colonias nuevas \\
\hline & Mala cultura del agua \\
\hline & Años con pocas lluvias \\
\hline & Pozos contaminados \\
\hline
\end{tabular}

Fuente: Elaboración propia, con base en el Marco Teórico desarrollado

Para manejar las variables en forma correcta se requiere conocer el nivel de medición en que pueden ser manipuladas. Los niveles de medición son cuatro: 1) nominal o clasificatorio, 2) ordinal, 3) intervalo y 4), razón (Rojas, 1997) cada una de ellas representa un tipo diferente de regla de asignación de número o "escala" de medición. Al pasar del tipo más débil (nominal) al más fuerte (razón) ocurren dos cosas: primero, las exigencias numéricas de la pertenencia a una escala se tornan más rigurosas; segundo, los modos permisibles de la expresión y análisis de datos van liberalizándose, esto es, se admiten más variedades de operaciones estadísticas.

La escala nominal es el tipo más primitivo de los cuatro y su debilidad matemática es tal que ni siquiera es una escala de medición en absoluto. En lo fundamental la escala consta de categorías que son colectivamente exhaustivas (cada individuo u objeto ha de pertenecer a una de ellas) y mutuamente excluyentes (las categorías no se sobreponen). En la medida en que los números se asignan a individuos o fenómenos; su objetivo consiste tan sólo en identificar la categoría a que pertenece cada uno de ellos. Los números carecen de valor matemático y no son indispensables en la escala nominal de medición (Weiers, 1986).

La escala de intervalo es definida como una escala de medición cuantitativa en la que se evalúa la diferencia entre dos variables. Dicho de otra manera, las variables se miden en valores reales y no de forma relativa, en donde la presencia de cero es arbitraria. Esto significa que la diferencia entre dos variables en una escala es una distancia verdadera o igual. No es difícil recordar el propósito de esta escala ya que "intervalo" equivale a la distancia entre dos variables. Otra manera fácil de recordar lo que es una escala de intervalo es considerar que esta es la resta que se define entre dos variables. Esto es diferente a la escala de radio, donde la división se define entre dos variables (Questionpro, 2020).

La escala de razón es la forma de medición que utiliza valores cero absolutos y que permite establecer diferencias entre cualquier par de objetos a un máximo de precisión. Este tipo de escalas cae fuera del ámbito de las ciencias sociales, porque constituye la medición de longitudes, pesos y masas. En general, los datos procedentes de una escala de nivel superior (intervalo) permiten utilizar métodos más potentes de análisis estadísticos (análisis de frecuencias, de correlaciones, de conglomerados, de varianzas y discriminatorio) los cuáles, a su vez, permiten un tamaño menor de la muestra en la fase de obtención de datos. Además, el uso de estas técnicas posibilita extraer conclusiones y recomendaciones más concluyentes al finalizar el análisis de datos (Medina, 2011). 
Desde el punto de vista estadístico, no es eficiente reunir datos de un nivel superior (escala de intervalo) y luego proceder a analizarlos mediante un método que tiene una escala de orden inferior (nominal u ordinal) como límite de aplicabilidad; hacerlo significa que estamos perdiendo información muy valiosa que podría aprovecharse mejor.

Para lograr una precisión científica y no caer en especulaciones abstractas, es necesario "medir" de alguna forma los hechos y fenómenos que se producen. Con el fin de aclarar este concepto y examinar su funcionalidad en la investigación social. El término actitud, designa un estado de disposición psicológica adquirida y organizada a través de la propia experiencia, que incita al individuo a reaccionar de una manera característica frente a determinadas personas, objetos o situaciones (Egg, 1994).

Dado lo anterior, en la presente investigación se aplicará la escala de medición intervalar para conocer la actitud que tienen las personas hacia la planeación estratégica en la región. La medición de la actitud puede realizarse con diferentes escalas:

- $\quad$ Escala de Stoufer.

- $\quad$ Escala tipo Likert.

- $\quad$ Escala de Thurstone.

- Escalograma de Guttman.

- $\quad$ Método de comparación por pares.

- $\quad$ Escalas de Osgood.

\section{Escalas de distancia social de Bogardus}

En esta investigación se utiliza la escala tipo Likert. La escala presenta un número de enunciados negativos y positivos acerca de un objeto de actitud. Al responder los individuos a los puntos de esta escala, indican su reacción asignándole un número a cada una:

- $\quad$ Totalmente de acuerdo $\quad 5$

- $\quad$ De acuerdo en general 4

- $\quad$ Ni de acuerdo ni en desacuerdo $\quad 3$

- $\quad$ En desacuerdo en general $\quad 2$

- $\quad$ Totalmente en desacuerdo 1

La escala tipo Likert, de acuerdo con Kerlinger, es un conjunto de elementos de actitudes consideradas aproximadamente de igual "valor de actitud", y cada una de las cuáles, los sujetos responden con diversos grados de acuerdo o desacuerdo. Los puntajes de los reactivos son sumados para proporcionar el puntaje a las actitudes de un individuo. La escala original se ha extendido a la aplicación en preguntas y observaciones. A veces se acorta o incrementa el número de categorías en este tipo de escala, pero el número de categorías debe ser siempre el mismo para todos los ítems y en cada escala se considera que los ítems tienen igual peso (Hernández, (Lara, 2009). La escala de medición se integra con los siguientes valores asignados de 5,4,3,2, 1, que corresponden a:

- $\quad$ Muy de acuerdo, excelente o siempre.

- De acuerdo en general, buena o con frecuencia.

- Regular o regularmente, no interesa, en ocasiones o en algunas veces.

- $\quad$ En desacuerdo en general, regular o a veces.

- Muy en desacuerdo, mala o nunca, nada. 


\section{Diseño del cuestionario}

En esta investigación se aplicará el diseño tipo Likert. La escala de Likert es una de las herramientas más utilizadas por los investigadores de mercado cuando desean evaluar las opiniones y actitudes de una persona. Existen varios tipos de escalas de medición enfocadas directamente a medir las actitudes de las personas, entre ellas, una de las más utilizadas es de la que se hablara a continuación (Questionpro, 2018).

El cuestionario es un tipo de herramienta de captación de datos que presenta preguntas y/o enunciados dirigidos a los informantes, para obtener datos específicos acerca de las variables que serán objeto de captación y posteriormente de ser analizadas (INEGI, 2010).

En el diseño del cuestionario, los temas y las categorías son tomados en cuenta para marcar las diversas secciones en la distribución de las preguntas.

- Variable: concepto que permite diversos valores para la caracterización o clasificación de un componente o un conjunto. En el diseño del cuestionario, las variables se traducen normalmente en preguntas que son aplicadas a cada elemento de una categoría específica.

Clasificación: es el ordenamiento de todas las modalidades nominales o intervalos numéricos que son admitidos por una variable (SNIEG s.f.).

El cuestionario tiene que reflejar puntualmente los contenidos del marco conceptual y debe tener presente los esquemas para la presentación de resultados (que responden a las necesidades de información), debe considerar cruces de variables e indicadores, de tal forma que el cuestionario no prescinda de la pregunta de algún concepto necesario, o se interrogue por algunos que no estén contemplados en él. La amplitud del marco conceptual y naturaleza de sus conceptos, van a influir en el grado de dificultad para captar los datos, problema que debe ser atendido, en la medida de lo posible, debido al diseño del cuestionario. Así, a un mayor número de preguntas se incrementan los problemas de pases o saltos, proceso para hacer la entrevista fluida, la colaboración del informante para proporcionar los datos solicitados, etc., por lo que se debe buscar un equilibrio entre las necesidades de información a que responde y la operatividad y simplicidad del cuestionario (INEGI, 2010).

\section{Requisitos generales}

- Debe corresponder con el marco conceptual. Tiene que cubrir la totalidad de conceptos del marco conceptual y establecer de una forma clara la relación existente las preguntas y las variables.

- $\quad$ Sencillez. El formato debe simplificar su llenado en el operativo de captación y hacer ágil las actividades de procesamiento de los datos.

- Fluidez. Tiene que incluir preguntas o comentarios para guiar con sutileza al consultado de una sección a otra. Es necesario que exista vinculación entre las diferentes secciones y estás seguir un orden lógico que le hagan de una manera más sencilla la facilidad al informante de proporcionar los datos que se le solicitan.

Autosuficiencia. Es necesario cuidar que el cuestionario contenga a todos los elementos para su aplicación. Se debe considerar la inclusión de notas o instrucciones de atención que alerten al informante acerca de aspectos que debe tener presentes al proporcionar los datos requeridos. Además, tiene que considerar rubros para el control y referencia geográfica de cada cuestionario.

\section{Marco referencial}

En el estado de Guanajuato durante el censo 2015 intercensal de INEGI se contabilizaron 5853677 habitantes. El municipio de Moroleón, Guanajuato, cuenta con 49,364 habitantes (INEGI, 2015) lo que representa el $0.84 \%$ de la población total del estado y el municipio de Uriangato, Guanajuato, tiene 62,761 habitantes lo que es el $1.07 \%$ del total estatal, entre los dos municipios representan el $1.91 \%$ del total del estado (INEGI, 2015). 
Para el diseño de la investigación se estudiará la zona en donde convergen los dos municipios, que es la Zona Centro, de ambos municipios, por considerarse la más trascendente en todos los asuntos más importantes de estas dos localidades y que además es la zona donde se encuentra el eje transversal de la economía de ambos municipios, es donde se encuentra la zona comercial y ahí se realiza la actividad económica más importante de estos municipios como es el comercio a través de la venta de prendas de vestir, y demás enseres relacionados con los productos textiles. Además de encontrarse ahí la mayoría de los talleres donde se elaboran las prendas de vestir, y que va desde pequeños, medianos y grandes talleres, en donde laboran gran parte de la población de estos municipios.

\section{Zona de estudio}

La zona de estudio en Moroleón comprenderá las siguientes calles: Calle Colon, Manuel Doblado, Hidalgo, Morelos como eje transversal y calles aledañas a este eje como Cuauhtémoc, Pípila, José López Bermúdez, Obreros Libres, González Ortega, Colegio Militar, Comercio, Abasolo, Ocampo Jaime Nunó, Jesús Garibay, Isabel La Católica, Vicente Guerrero, 16 de Septiembre, América, Guadalupe Victoria, 19 de Diciembre, Madero, Bartolomé de las Casas, Vasco de Quiroga, Juárez, 5 de Mayo, Escobedo, Lázaro Cárdenas, Plan Sexenal, Santos Degollado, Constitución y Violeta.

En Uriangato las calles serán: Como eje transversal calle 16 de Septiembre, Victoria, Obregón, Leovino Zavala y las calle aledañas Morita, Colon, Bravo, Madero, Urrutia, Morelos, 5 de Mayo, Ocampo, Juárez, San Miguel, Abasolo, Guerrero, Lerdo, Guadalupe, Cuauhtémoc, Violeta Aztecas, Pedraza, Libertad, Del Prado, Aurelio López, Josefa Ortiz de Domínguez, Tomasa Estévez, Margarita Maza de Juárez, y Eva Sámano. Al no haber información sobre el total de la población, ésta se obtuvo mediante la herramienta de INEGI, DENUE, lo que arrojó un total de la población de este sector de ambas ciudades de 10409 personas.

Con base, en el Method for Employing Sampling Thecniques, se obtuvo la muestra de ambas ciudades; siendo 385 personas a investigar. 


\section{Capítulo V Resultados de la investigación}

En este capítulo se analizarán los resultados de las herramientas aplicadas en la investigación en este caso son las encuestas, con el programa de estadística SPSS, para determinar la correlación que existe entre las variables independientes y la variable dependiente, así como la estadística descriptiva, donde se indica el género, lugar, la edad y más datos de las encuestas aplicadas.

\section{Medición de la validez y confiabilidad}

Cronbach en 1971 señala que la validación es el mecanismo por medio del cual el investigador que desarrolla cuestionarios obtiene evidencia para sostener sus deducciones. Este proceso de validación requiere un estudio empírico dirigido a recolectar la evidencia requerida.

La validez representa una evaluación de cuán apropiadas y adecuadas son las interpretaciones y los usos que se hacen de los resultados del cuestionario.

En la evaluación de la validez de un cuestionario se busca que las interpretaciones de los resultados sean basadas en evidencia de que el cuestionario mide lo que realmente se pretende que mida, que los resultados no se vean alterados por variables o factores no trascendentes a lo que se pretende medir. Dicho de otra manera, la evaluación de la validez de un cuestionario importa los resultados y las consecuencias de las decisiones que se eligen con esos resultados.

Por otro lado, y a partir de la base de que una condición necesaria, aunque no suficiente, para aprobar una medida es su confiabilidad, se ha procedido a su determinación para cada uno de los constructos y dimensiones. De acuerdo a George y Mallery (1995), la fiabilidad se relaciona con el hecho de que 1 instrumento de medición ocasione los mismos resultados cada vez que sea administrado a la misma persona y en las iguales circunstancias. Así, por lo general las herramientas empleadas en las ciencias sociales se pueden considerar fiables si: al margen de quién los administre y de la forma en que se haga, se obtienen resultados similares. Un instrumento de medición debe cumplir con el requisito de confiabilidad de manera que se pueda comprobar que el instrumento que se está evaluando recopila información defectuosa y por tanto llevaría a conclusiones equivocadas o si se trata de un instrumento fiable que hace mediciones estables y consistentes (Lara, 2009).

\section{Cuestionario social}

Se realizaron los cuestionarios sociales tanto en Moroleón, como en Uriangato, en todos los estratos de la población, aplicándose en varias zonas de afluencia de la población de ambos municipios, lo mismo en talleres de fabricación de ropa, talleres de herrería, talleres mecánicos, unas en las presidencias municipales de cada uno de los ayuntamientos, en algunas escuelas de nivel superior como el Instituto Tecnológico de Educación Superior del Estado de Guanajuato, ubicado en Uriangato, y la Universidad de León, campus Moroleón, y en general se aplicaron también en las plazas públicas, realizándose a todos los sectores de esta zona.

\section{Resultados de la prueba piloto}

Durante el proceso de elaboración de la prueba piloto se observó que algunas preguntas de la encuesta debían de modificarse, lo cual se hizo de manera que las personas encuestadas pudieran entenderlas con mayor facilidad, y se dotó de un lenguaje más sencillo a dichas interrogaciones.

Con ayuda del (SPSS), se realizó la prueba de fiabilidad, obteniendo los siguientes resultados:

Tabla 10 Estadísticas de fiabilidad

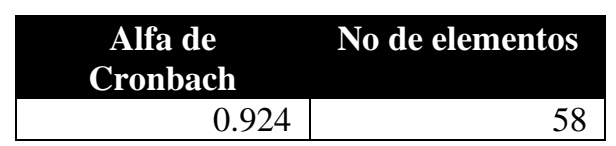

Fuente: Datos de campo procesados con SPSS (2019) 
Se obtuvo un $92.40 \%$ de fiabilidad en la prueba piloto.

Tabla 11 Genero

\begin{tabular}{|l|r|r|r|}
\hline \multicolumn{1}{|c|}{ Genero } & Frecuencia & Porcentaje & Porcentaje válido \\
\hline Mujer & 254 & 66.0 & 66.0 \\
\hline Uriangato & 131 & 34.0 & 34.0 \\
\hline Otros & 385 & 100.0 & 100.0 \\
\hline
\end{tabular}

Fuente: Datos de campo procesados con SPSS

Tabla 12 Lugar

\begin{tabular}{|c|c|c|c|}
\hline Municipios & Frecuencia & Porcentaje & $\begin{array}{l}\text { Porcentaje } \\
\text { valido }\end{array}$ \\
\hline Moroleón & 146 & 37.90 & 37.90 \\
\hline Uriangato & 139 & 36.10 & 36.10 \\
\hline Otros & 100 & 26.00 & 26.00 \\
\hline & 100.00 & 100.00 & 100.00 \\
\hline
\end{tabular}

Fuente: Datos de campo procesados con SPSS

\section{Interpretación de los resultados para correlación}

Su dimensión indica el nivel de asociación entre las variables. Cuando es menor a cero $(\mathrm{r}<0) \mathrm{Se}$ concluye que hay correlación negativa: Las variables se correlacionan en un sentido inverso.

$r_{x y}=\frac{\sum Z_{X} Z_{Y}}{N}$

A valores altos en una de las variables, por lo general le suelen corresponder valores bajos en la otra variable y viceversa. Cuánto el valor esté más próximo a -1 dicho coeficiente de correlación más evidente será la covariación extrema.

Si $\mathrm{r}=-1$ se habla de correlación negativa perfecta, en la que supone una determinación absoluta entre las dos variables, en sentido directo coexiste una relación lineal perfecta de pendiente negativa.

Cuando es mayor a cero $(r>0)$ Se menciona que hay correlación positiva: Ambas variables se correlacionan en un sentido directo.

A valores altos en una de las dos variables, le corresponden valores altos en la otra variable y asimismo en una situación inversa sucede con los valores bajos. Cuánto más próximo a +1 se encuentre el coeficiente de correlación más indudable será la covariación.

Si $r=1$ Se habla de correlación positiva perfecta, la cual supone una determinación absoluta entre las dos variables, en sentido directo coexiste una relación lineal perfecta de pendiente positiva).

Cuando es igual a cero $(r=0)$ Se menciona que las variables están incorrectamente relacionadas, no se puede hacer posible establecer algún sentido de covariación.

No existe relación lineal, pero esto no implica necesariamente que las variables sean independientes, pudiendo existir relaciones no lineales entre las variables.

Cuando ambas variables son independientes se afirma que no están correlacionadas, aunque el resultado de reciprocidad no es precisamente cierto.

Para concluir se puede afirmar que se ve más complejo de lo que realmente resulta ser, sobre todo si se dispone de tecnología avanzada, pues hoy día existen múltiples programas que facilitan esta labor de cálculo e interpretación del coeficiente de Pearson.

Para examinar la relación lineal entre las variables (Pearson) (Minitab, 2019). 


\section{Fuerza}

El valor del coeficiente de correlación puede variar de $-1 \mathrm{a}+1$. Mientras más grande sea el valor absoluto del coeficiente, más fuerte será la relación entre las variables (Minitab, 2019). Para la correlación de Pearson, un valor absoluto de 1 indica una relación lineal perfecta. Una correlación cercana a 0 indica que no existe relación lineal entre ambas variables.

\section{Dirección}

El signo del coeficiente muestra la dirección de la relación. Si las dos variables tienden ya sea a disminuir o aumentar al mismo tiempo, el coeficiente es positivo y la línea que representa la correlación forma una pendiente hacia arriba. Si una variable tiende a incrementarse mientras la otra disminuye, el coeficiente es negativo y la línea que representa la correlación forma una pendiente hacia abajo.

Para determinar si la correlación entre las variables es significativa, se compara el valor $\mathrm{p}$ con su nivel de significancia. Por lo general, un nivel de significancia (denotado como $\alpha$ o alfa) de 0.05 funciona adecuadamente. Un $\alpha$ de 0.05 indica que el riesgo de concluir que existe una correlación, cuando en realidad no es así, es 5\%. El valor p indica si el coeficiente de correlación es significativamente diferente de 0 . (Un coeficiente de 0 indica que no existe una relación lineal) (Riquelme, 2019).

Este es el resultado obtenido de la relación entre las variables:

Tabla 13 Correlaciones de Pearson

\begin{tabular}{|c|c|c|c|c|}
\hline Variables & I & II & III & IV \\
\hline I. Infraestructura & & & & \\
\hline II. Crecimiento urbano & $0.545^{\text {*** }}$ & & & \\
\hline III.Política publica & $0.493^{\text {** }}$ & $0.600^{* * *}$ & & \\
\hline IV.Uso del agua & $0.420^{\text {*** }}$ & $0.522^{* * *}$ & $0.668^{* * *}$ & \\
\hline V. Planeación estratégica & $0.464^{* * *}$ & $0.549^{* * *}$ & $\mathbf{0 . 7 3 3}^{* * *}$ & $0.612 * *$ \\
\hline
\end{tabular}

Fuente: Datos de campo procesados con SPSS (2019)

\section{Infraestructura}

Este indicador se construyó tratando de medir la percepción que tiene la población de la importancia que le significa la infraestructura, y presentó un valor de 0.464 , lo que indica que solo existe una relación lineal débil moderada entre las variables.

\section{Crecimiento urbano}

Este indicador se construyó tratando de medir la percepción que tiene la población de la importancia que le significa el crecimiento urbano, y presentó un valor de $0.549^{* *}$, lo que indica que solo existe una correlación lineal media entre las variables.

\section{Políticas públicas}

Este indicador se construyó tratando de medir la percepción que tiene la población de la importancia que le significan las políticas públicas, y presentó un valor de $0.733^{* *}$, lo que indica que existe una relación lineal fuerte entre las variables. La relación es positiva porque a medida que una variable aumenta, la otra variable también aumenta.

\section{Uso del agua}

Este indicador se construyó tratando de medir la percepción que tiene la población de la importancia que le significa el uso del agua, y presentó un valor de $0.612^{* *}$, lo que indica que existe una correlación positiva moderada lineal media entre las variables. 


$\begin{array}{lll}\text { Intervalo de } & \text { 0 a } 2 & \text { muy baja. } \\ \text { Intervalo de } & 2 \text { a } 4 & \text { baja. } \\ \text { Intervalo de } & 4 \text { a } 6 & \text { regular } \\ \text { Intervalo de } & \text { 6 a } 8 & \text { alta. } \\ \text { Intervalo de } & 8 \text { a } 10 & \text { muy alta. }\end{array}$

El indicador compuesto se estudia bajo un análisis de correlación, con la finalidad de identificar cuáles son las variables independientes que inciden sobre la variable dependiente de manera positiva o negativa, finalmente, se efectúa la prueba de hipótesis para determinar qué factores tienen mayor influencia en el fenómeno observado, es decir, cuáles de las variables independientes inciden sobre la variable dependiente, comprobando la bondad del modelo planteado (Lara, 2009).

\section{$\mathrm{Y}=\mathrm{B} 1 \mathrm{X} 1+\mathrm{B} 2 \mathrm{X} 2+\mathrm{B} 3 \mathrm{X} 3+\mathrm{B} 4 \mathrm{X} 4$}

Donde:

Y = Planeación estratégica.

$\mathrm{X} 1=$ Infraestructura.

$\mathrm{X} 2=$ Crecimiento urbano.

$\mathrm{X} 3=$ Políticas publicas.

$\mathrm{X} 4=$ Uso del agua.

\section{Función de la ANOVA}

Medir o evaluar el efecto de dos o más variables independientes sobre una variable dependiente. ANOVA de un factor (también conocida como anova unifactorial o one-way anova en inglés) es una técnica estadística que muestra si dos variables (una independiente y otra dependiente) están relacionadas en base a si las medias de la variable dependiente son diferentes en las categorías o grupos de la variable independiente. Esto quiere decir que, señala si las medias entre dos o más grupos son similares o diferentes (Sampieri, 2010).

Tabla 14 ANOVA

\begin{tabular}{|c|c|c|c|c|c|}
\hline Modelo & Suma de cuadrados & g.l. & Media cuadrática & $\mathbf{F}$ & Sig. \\
\hline Regresión & 5591.714 & 4 & 1397.929 & 130.818 & $.000^{\mathrm{b}}$ \\
\hline Residual & 4060.701 & 380 & 10.686 & & \\
\hline Total & 9652.416 & 384 & & & \\
\hline
\end{tabular}

Fuente: Datos de campo procesados con SPSS (2019)

El valor de F es 130.818 y la significación es 0,000 . Al ser la significación menor de 0,05 es que las diferencias de media de variables son significativas. Aunque aparentemente se pueda pensar que las diferencias no son exageradas, la decisión de si las diferencias son significativas no depende de algún criterio, sino de la significación de F. Este es el propósito de aplicar ANOVA de un factor: valorar estadísticamente si las diferencias de medias son significativas o no.

Cuanto más alto sea el valor de F, más diferencias de medias habrá y por lo tanto más fuerte es la relación entre las variables. 
Tabla 15 Resumen del modelo

\begin{tabular}{|r|c|c|c|r|}
\hline Modelo & $\mathbf{R}$ & $\mathbf{R}^{\mathbf{2}}$ & $\mathbf{R}^{\mathbf{2}}$ corregida & Error tipo de la estimación \\
\hline 1 & $.761^{\mathrm{a}}$ & .579 & .575 & 3.26895 \\
\hline \multicolumn{5}{|c|}{ a. Variables predictoras: (Constante), Agua, Infraestructura, Crecimiento, Política } \\
\hline
\end{tabular}

Fuente: Datos de investigación de campo procesados con SPSS (2019)

La correlación estadística es medida por lo que se denomina coeficiente de correlación (r). Su valor numérico varía de 1,0 a $-1,0$. Indica la fuerza de la relación. Aquí, $r=1,0$ describe una correlación positiva perfecta y $\mathrm{r}=-1,0$ describe una correlación negativa perfecta, por tanto, en el caso de este modelo $\mathrm{R}$ describe $0.761^{* *}$, lo que indica que existe una relación lineal fuerte entre las variables. La relación es positiva porque a medida que una variable aumenta, la otra variable también aumenta.

El $\mathrm{R}^{2}$ es el porcentaje de variación de la variable de respuesta que explica su relación con una o más variables predictoras. Por lo general, mientras mayor sea el $\mathrm{R}^{2}$, mejor será el ajuste del modelo a sus datos. El $\mathrm{R}^{2}$ siempre se encuentra entre 0 y $100 \%$. El R-cuadrado también se conoce como el coeficiente de determinación o determinación múltiple (en la regresión lineal múltiple).

El $\mathrm{R}^{2}$ corregido es el porcentaje de variación en la variable de respuesta que es explicado por su relación con una o más variables predictoras, ajustado para el número de predictores en el modelo.

Es decir, a medida que se incluyan más variables en el modelo, el $\mathrm{R}$ cuadrado aumentará por lo que puede hacer pensar que el modelo es mejor porque incluye más variables. El error tipo de la estimación se llama residuo. La varianza residual es la varianza de estos residuos. 


\section{Conclusiones}

Es evidente el papel y la importancia que ha tenido la planificación estratégica territorial en el país, así como en la región estudiada, donde gran parte de la economía regional depende de una buena planificación, asimismo, la problemática que experimenta esta región a nivel nacional y regional, donde la caída de ventas de los productos locales han ido perdiendo terreno e interés entre los compradores que habitualmente venían a la región a realizar sus compras, permite validar la importancia y vigencia de la presente investigación, como un aporte para explicar el fenómeno que experimenta la planeación en la región.

Verificándose la relación entre las teorías de la planificación estratégica y el DR, cuyos conceptos y su evolución teórica han dado origen a la planificación estratégica, destacando la importancia cada vez mayor, en los aspectos territoriales dentro de la economía y el desarrollo de los países. Asimismo, es posible identificar la creciente importancia de este concepto, el cual, ha venido desagregándose a niveles territoriales cada vez más específicos, destacándose la importancia que tiene la planificación estratégica territorial en espacios locales como estados, ciudades, municipios y microrregiones.

Esto fue posible investigar la parte teórica de las variables independiente, permitiendo con ello la validación de las hipótesis planteadas, así como la obtención de las dimensiones e indicadores que permitieron el estudio de campo. Al respecto, es importante señalar que no hay mucha información sobre el tema en la zona de estudio y que la falta de información estadística a nivel municipal, representó una de las limitantes más importantes a la presente investigación, esto se resolvió con ayuda de la herramienta Denue del portal de información del INEGI, que permitió conocer la población del área a estudiar.

A diferencia de los índices y trabajos revisados, la aplicación de la metodología empleada para la evaluación de la planificación a diferentes ámbitos (países, estados, ciudades, empresas), tuvo como elemento central de análisis, la vocación productiva de la región, también llamada en las teorías analizadas, como el sistema productivo local o clúster, el cual fue plenamente definido e identificado mediante los índices de concentración regional, destacando la importancia de la industria textil y de la confección en la región zona conurbada Moroleón-Uriangato.

La importancia que tiene y ha tenido esta industria a nivel regional, se ha visto impactada en últimos años experimentando una pérdida de clientela, que los ha llevado a ser desplazados del mercado local, regional y nacional.

Es posible concluir siguiendo el orden de relación fuerte a la no tan fuerte, que los principales factores son: las PP al presentar una fuerte relación con la variable dependiente denominada Planificación Estratégica Territorial, Uso del agua indica que existe una relación positiva moderada lineal media entre la variable dependiente, Crecimiento urbano indica que solo existe una relación lineal media entre las variables y por último la Infraestructura que indica que solo existe una relación lineal débil moderada entre las variable dependiente.

Las variables con mayor influencia como la política pública y el uso del agua, presentaron ambas una correlación sustancial sobre el crecimiento urbano y la infraestructura de 0.733 y 0.612 respectivamente (ver página 208, tabla 8); por lo que puede concluirse que el incremento en estas variables, traerá a la par una mejora en el nivel de la planeación urbana , lo que pone en evidencia la importancia de estas dos variables y la interrelación existente entre ellas, como variables explicativas de la planificación estratégica en la región.

Las variables restantes crecimiento urbano e infraestructura, no se consideran muy significativas al no existir una relación fuerte entre la variable planificación estratégica territorial, al tener 0.549 y 0.464 respectivamente. 
Se concluye que la hipótesis general no puede ser rechazada, dado que no existe evidencia estadística, lo cual se verificó mediante la prueba Pearson y ahí se observa la correlación entre las variables independientes con la dependiente por lo que es posible afirmar que las políticas públicas y la utilización del agua son las variables de mayor influencia en la planificación estratégica territorial en la zona conurbada Moroleón Uriangato ubicadas en el sur del estado de Guanajuato.

A nivel local, el municipio de Uriangato presentó un nivel más bajo de planeación estratégica debido a que mucho de su territorio es actualmente zona ejidal y que al ser estas tierras destinadas para cultivos y uso agropecuario, ahí no se puede establecer una planeación estratégica, y todavía se realizan asambleas ejidales, para otorgar ciertas facultades a los ejidatarios como el uso del dominio pleno, o realizar un cambio de destino con el Registro Agrario Nacional y la Procuraduría Agraria.

Moroleón en cambio, aunque todavía existen zonas ejidales, éstas se manifiestan solo en las zonas rurales, que no son muchas únicamente cuenta con 16 comunidades, sin embargo, la estrategia de crecimiento está muy limitada por el uso del agua, y porque cuando originalmente se planeó crecer hacia el sur, los dueños de grandes terrenos que podrían ofrecer una venta a la población, aumentaron los precios de forma exagerada y aun hoy en día los precios por metro cuadrado son en verdad elevados, sobrevaluados.

Es posible establecer que si bien la planeación estratégica territorial en la región, experimenta la problemática de un desarrollo urbano no, es posible implementar una planeación estratégica de alto nivel en la región.

A partir de una estrategia de buen gobierno principalmente, y que ambos municipios trabajen juntos, que se articulen entre ambos, para que las instituciones, organismos y dependencias, establezcan los lineamientos, acciones y el marco legal, que facilite y propicie el llevar a cabo la planificación estratégica territorial y el desarrollo urbano ordenado y sustentable en los dos municipios y las instituciones presentes, así como procurando el desarrollo de un entorno propicio para la especialización, intercambio, asociación y desarrollo de la industria.

Con respecto a la pregunta de investigación se establece que las variables políticas públicas y utilización del agua son las que más han influido en la planeación estratégica territorial en ambos municipios, al presentar una mayor correlación entre las variables independientes y la dependiente, mientras que las variables infraestructura y crecimiento urbano presentaron una menor correlación. Los objetivos se cumplieron porque se lograron determinar y establecer las principales variables que han influido en la planeación estratégica territorial mediante un modelo y su influencia en la actividad comercial.

Este trabajo de investigación debe ser el principio, para tratar de resolver la problemática que aún persiste en esta zona, y que dada su complejidad y el tiempo que paso sin que ninguna entidad tratara de resolver esta situación derivo en el agravamiento de la situación. Se deben de hacer más investigaciones sobre el tema para tratar de solventar las irregularidades que aún existen en la zona por lo que:

\section{Recomendaciones}

1. El modelo propuesto para la medición de la planificación estratégica territorial en esta investigación, tuvo como base el análisis de los diferentes factores que integran los índices de planeación más utilizados a nivel nacional e internacional, validando con ello, las variables utilizadas como explicativas del fenómeno de la planeación, sin embargo, no se descarta que existan otras variables que afecten la planificación estratégica de la región y de su industria textil, pero se debe aclarar que a nivel municipal (local), existe una carencia de información que limita el poder cuantificarlas; sin embargo, la presente investigación, representa un esfuerzo y un primer acercamiento a la medición de la planificación a niveles más desagregados, tomando como base los modelos existentes. Al respecto, también es importante aclarar que no hay elementos teóricosmetodológicos, que permitan ordenar jerárquicamente los factores que explican la planificación ya que dependen del nivel de análisis y del objeto de estudio; por lo que se recomienda en las investigaciones posteriores se consideren variables de las cuáles sea factible cuantificar a partir de la información existente a nivel local y municipal. 
2. Se constataron los diferentes esfuerzos que se llevan a cabo en torno a esta planificación estratégica en la región, los cuales existen desde instancias internacionales, nacionales, estatales y municipales; sin embargo, también fue posible constatar la debilidad y en ocasiones rivalidad que existe a nivel municipal y estatal, para la integración de la región y de la industria a fin de generar sinergias, en torno a un proyecto regional en beneficio de la planificación estratégica por lo que se recomienda establecer líneas de comunicación interestatal e intermunicipal que permitan la integración de un proyecto regional para la industria.

3. Fue posible constatar que estos esfuerzos para impulsar y apoyar la planificación estratégica, carecen de un plan o proyecto común, y que este es el motivo por el cual ambos municipios han crecido y siguen creciendo sin mucha planeación ni orden llegando a formar asentamientos humanos que son cinturones de miseria en la periferia de ambos municipios, dejando manifiesta una débil autoridad que no ha podido frenar este crecimiento desordenado y sin planificación en toda la región; por lo que se recomienda que se apliquen las leyes de desarrollo urbano y que se pongan en marcha los, programas y proyectos en apoyo a la planeación de ambos municipios.

4. Al respecto, actualmente existe una iniciativa impulsada por el gobierno del estado de Guanajuato para las zonas metropolitanas el estado, y éstas cuentan con un recurso que es específico y exclusivo para los estudios, planes, evaluaciones, programas, proyectos, acciones, obras de infraestructura y su equipamiento financiados con el Fondo Metropolitano, por lo que se recomienda que esta inversión se aplique en este sector de la planificación estratégica territorial, pero que sea en conjunto, donde participen los dos municipios

5. De igual forma, es recomendable que esta iniciativa se blinde de los cambios en la dirección de los organismos de representación, de las instituciones y de las dependencias públicas, así como de los cambios de alcaldes en los gobiernos locales, ya que existe evidencia de desmantelamiento de este tipo de iniciativas, por agentes que desconocen o no están interesados en respaldarlas, cuando se presentan relevos en la dirección, por lo que es determinante el papel que jueguen las empresas y sus órganos de representación para darle continuidad y soporte en el mediano y largo plazo a este proyecto de integración y articulación.

6. También es recomendable establecer y guiar el crecimiento urbano de ambos municipios, crecer de forma compactada, evitando dejar zonas baldías sin desarrollo urbano es buena opción, también lo es homologar los costos catastrales en ambos municipios, ya que no puede ser posible que el costo por metro cuadrado cambie tan radical como lo hace solo porque está en Moroleón, y siendo que la ubicación es la misma no cambia solo la separa algunos metros de distancia.

7. En Uriangato abordando el tema del ejido, aun este municipio cuenta con superficie bajo esta modalidad, y existen parcelas dentro de la zona urbana que son ejidales, se recomienda que cualquier tipo de actividad de desarrollo urbano, al momento de dividir la parcela, para hacer una lotificación, esta sea realizada de acuerdo al Plan de Desarrollo Urbano de la región, para que no contraste con la zona donde la modalidad es pequeña propiedad, deben de cumplir ambos tipos de tenencia de la tierra con las leyes y disposiciones de la Ley de Desarrollo Urbano, para ya no generar más planeaciones deficientes.

8. Es también de digno de mencionar y de recomendar la falta de espacios públicos que no existen en esta zona, en ambos municipios la recomendación es comprar terrenos para ahí construir los espacios de recreación que servirán a la gente para la actividad destinada al aprovechamiento del tiempo libre para el esparcimiento físico y mental, tan necesario en estos tiempos de mucha tensión.

9. Debe existir un orden de gobierno a nivel conurbación (o metropolizacion, como aquí se le conoce) con autonomía propia, conformado por especialistas en la materia de planificación, y que no se manipule por los distintos gobiernos que sea imparcial en la toma de decisiones, buscando un mejor desarrollo urbano que sea el ideal para ambos municipios, este organismo será quien decida hacia donde se buscar el desarrollo urbano, como este debe de ser, procurando que no afecte ni, el medio ambiente, que propicie un mejor bienestar para toda la población y que no se beneficien solo algunos como ha sucedido en épocas anteriores. 


\section{Anexos}

\section{Anexo 1. Cuestionario con variables}

\begin{tabular}{|c|c|c|c|c|c|}
\hline $\begin{array}{c}\text { Variables } \\
\text { independientes }\end{array}$ & Dimensiones & Indicador & & Amplitud del índice & Escala \\
\hline \multirow{15}{*}{$\begin{array}{ll}\text { Datos del } \\
\text { encuestado }\end{array}$} & \multirow[t]{5}{*}{ Edad } & \multirow[t]{5}{*}{ Cuantos años tiene } & A & Entre 15 y 20 & $\mathrm{~S} / \mathrm{E}$ \\
\hline & & & \begin{tabular}{|l|}
$\mathrm{B}$ \\
\end{tabular} & Entre 20 y 30 & $\mathrm{~S} / \mathrm{E}$ \\
\hline & & & $\mathrm{C}$ & Entre 30 y 40 & $\mathrm{~S} / \mathrm{E}$ \\
\hline & & & $\mathrm{D}$ & Entre 40 y 50 & $\mathrm{~S} / \mathrm{E}$ \\
\hline & & & $\mathrm{E}$ & Entre $50 \mathrm{y}$ mas & $\mathrm{S} / \mathrm{E}$ \\
\hline & \multirow[t]{3}{*}{ Localización } & \multirow[t]{3}{*}{ Donde vive } & $\mathrm{A}$ & Moroleón & $\mathrm{S} / \mathrm{E}$ \\
\hline & & & $\mathrm{B}$ & Uriangato & $\mathrm{S} / \mathrm{E}$ \\
\hline & & & $\mathrm{C}$ & En ambas ciudades & $\mathrm{S} / \mathrm{E}$ \\
\hline & \multirow[t]{5}{*}{ Ocupación } & \multirow[t]{5}{*}{ A que se dedica } & A & Profesionista & $\mathrm{S} / \mathrm{E}$ \\
\hline & & & $\mathrm{B}$ & Comerciante & $\mathrm{S} / \mathrm{E}$ \\
\hline & & & $\mathrm{C}$ & Albañil & $\mathrm{S} / \mathrm{E}$ \\
\hline & & & $\mathrm{D}$ & Peón & $\mathrm{S} / \mathrm{E}$ \\
\hline & & & \begin{tabular}{|l|l|}
$\mathrm{E}$ \\
\end{tabular} & Funcionario púbico & $\mathrm{S} / \mathrm{E}$ \\
\hline & \multirow[t]{2}{*}{ Genero } & \multirow[t]{2}{*}{ Pregunta de genero } & $\mathrm{A}$ & Hombre & $\mathrm{S} / \mathrm{E}$ \\
\hline & & & $\mathrm{B}$ & Mujer & $\mathrm{S} / \mathrm{E}$ \\
\hline \multirow[t]{50}{*}{ Infraestructura } & \multirow{10}{*}{$\begin{array}{l}\text { Dificultad para acceder } \\
\text { a la ciudad }\end{array}$} & \multirow{5}{*}{$\begin{array}{l}\text { Como considera usted los accesos a las ciudades } \\
\text { de Moroleón y Uriangato? }\end{array}$} & $\mathrm{A}$ & Excelentes & 5 \\
\hline & & & $\mathrm{B}$ & Buenos & 4 \\
\hline & & & $\mathrm{C}$ & Regulares & 3 \\
\hline & & & $\mathrm{D}$ & Malos & 2 \\
\hline & & & \begin{tabular}{|l|l}
$\mathrm{E}$ \\
\end{tabular} & \begin{tabular}{|l|} 
Muy malos \\
\end{tabular} & 1 \\
\hline & & \multirow{5}{*}{$\begin{array}{l}\text { Como le parece el tiempo que se tarda alguien } \\
\text { para acceder a los dos centros de estas } \\
\text { ciudades? }\end{array}$} & A & Excelente & 5 \\
\hline & & & $\mathrm{B}$ & Bueno & 4 \\
\hline & & & $\mathrm{C}$ & Regular & 3 \\
\hline & & & \begin{tabular}{|l|l|}
$\mathrm{D}$ \\
\end{tabular} & Malo & 2 \\
\hline & & & $\mathrm{E}$ & Muy malo & 1 \\
\hline & Calles en mal estado & ¿El estado que guardan las calles de Moroleón y & A & Excelente & 5 \\
\hline & & Uriangato que tal le parece? & $\mathrm{B}$ & Bueno & 4 \\
\hline & & & $\mathrm{C}$ & Regular & 3 \\
\hline & & & $\mathrm{D}$ & Malo & 2 \\
\hline & & & $\mathrm{E}$ & Muy malo & 1 \\
\hline & & El estado que guardan las calles de Moroleón y & A & Nada & 5 \\
\hline & & Uriangato influye en el comercio, ¿qué tanto? & $\mathrm{B}$ & Muy poco & 4 \\
\hline & & & $\mathrm{C}$ & Poco & 3 \\
\hline & & & $\mathrm{D}$ & Mucho & 2 \\
\hline & & & $\mathrm{E}$ & Demasiado & 1 \\
\hline & Calles angostas & ¿Que tanto influyen las calles angostas en el & $\mathrm{A}$ & Nada & 5 \\
\hline & & desarrollo de Moroleón y Uriangato? & $\mathrm{B}$ & Muy poco & 4 \\
\hline & & & $\mathrm{C}$ & Poco & 3 \\
\hline & & & $\mathrm{D}$ & Mucho & 2 \\
\hline & & & $\mathrm{E}$ & Demasiado & 1 \\
\hline & & ¿Considera usted que las calles angostas de & $\mathrm{A}$ & Nada & 5 \\
\hline & & ambas ciudades afectan actividades & $\mathrm{B}$ & Muy poco & 4 \\
\hline & & comerciales? & \begin{tabular}{|l|l}
$\mathrm{C}$ \\
\end{tabular} & \begin{tabular}{|l|} 
Poco \\
\end{tabular} & 3 \\
\hline & & & $\mathrm{D}$ & Mucho & 2 \\
\hline & & & $\mathrm{E}$ & Demasiado & 1 \\
\hline & Falta de & ¿Le parece que los estacionamientos actuales de & A & Son suficientes & 5 \\
\hline & estacionamientos & esta zona son suficientes? & $\mathrm{B}$ & $\begin{array}{l}\text { Están adecuados para las } \\
\text { ciudades }\end{array}$ & 4 \\
\hline & & & $\mathrm{C}$ & Hacen falta & 3 \\
\hline & & & $\mathrm{D}$ & Son escasos & 2 \\
\hline & & & $\mathrm{E}$ & No hay & 1 \\
\hline & & \begin{tabular}{|cccccc} 
¿Como considera la ubicación de & los
\end{tabular} & $\mathrm{A}$ & Adecuada & 5 \\
\hline & & estacionamientos en Moroleón-Uriangato? & $\mathrm{B}$ & Buena & 4 \\
\hline & & & $\mathrm{C}$ & Regular & 3 \\
\hline & & & $\mathrm{D}$ & Mala & 2 \\
\hline & & & $\mathrm{E}$ & Muy mala & 1 \\
\hline & Falta de servicios & Los servicios en Moroleón-Uriangato para & $\mathrm{A}$ & Excelentes & 5 \\
\hline & & atender a la población local como foránea son: & $\mathrm{B}$ & Buenos & 4 \\
\hline & & & $\mathrm{C}$ & Regulares & 3 \\
\hline & & & $\mathrm{D}$ & Malos & 2 \\
\hline & & & $\mathrm{E}$ & Muy malos & 1 \\
\hline & & Esos servicios son: & A & Son suficientes & 5 \\
\hline & & & B & $\begin{array}{l}\text { Están adecuados para las } \\
\text { ciudades }\end{array}$ & 4 \\
\hline & & & $\mathrm{C}$ & Hacen falta & 3 \\
\hline & & & $\mathrm{D}$ & Escasos & 2 \\
\hline & & & $\mathrm{E}$ & Muy escasos & 1 \\
\hline
\end{tabular}




\begin{tabular}{|c|c|c|c|c|c|}
\hline \multirow[t]{10}{*}{ Infraestructura } & \multirow{10}{*}{$\begin{array}{l}\text { Carencia de lugares } \\
\text { de descanso }\end{array}$} & \multirow{5}{*}{$\begin{array}{l}\text { Existen en Moroleón - Uriangato suficientes } \\
\text { lugares de descanso }\end{array}$} & A & A) Son suficientes & 5 \\
\hline & & & $\mathrm{B}$ & B) Están adecuados para las ciudades & 4 \\
\hline & & & $\mathrm{C}$ & Regulares & 3 \\
\hline & & & $\mathrm{D}$ & Hacen falta & 2 \\
\hline & & & $\mathrm{E}$ & No hay & 1 \\
\hline & & \multirow{5}{*}{$\begin{array}{l}\text { En qué medida calificaría esos lugares de } \\
\text { descanso }\end{array}$} & $\mathrm{A}$ & Excelentes & 5 \\
\hline & & & $\mathrm{B}$ & Buenos & 4 \\
\hline & & & $\mathrm{C}$ & Regulares & 3 \\
\hline & & & $\mathrm{D}$ & Malos & 2 \\
\hline & & & $\mathrm{E}$ & Pésimos & 1 \\
\hline \multirow{60}{*}{$\begin{array}{l}\text { Crecimiento } \\
\text { urbano }\end{array}$} & \multirow{10}{*}{$\begin{array}{l}\text { Creación de barrios } \\
\text { pobres y peligrosos }\end{array}$} & \multirow{5}{*}{$\begin{array}{l}\text { Considera usted que los barrios pobres son } \\
\text { peligrosos }\end{array}$} & $\mathrm{A}$ & Sin peligro & 5 \\
\hline & & & $\mathrm{B}$ & Poco peligro & 4 \\
\hline & & & $\mathrm{C}$ & Regulares & 3 \\
\hline & & & $\mathrm{D}$ & Peligrosos & 2 \\
\hline & & & $\mathrm{E}$ & Muy peligrosos & 1 \\
\hline & & \multirow{5}{*}{$\begin{array}{l}\text { ¿Qué tanta pobreza existe en los barrios de } \\
\text { Moroleón - Uriangato? }\end{array}$} & $\mathrm{A}$ & No hay & 5 \\
\hline & & & $\mathrm{B}$ & Poca & 4 \\
\hline & & & $\mathrm{C}$ & Regular & 3 \\
\hline & & & $\mathrm{D}$ & Mucha & 2 \\
\hline & & & $\mathrm{E}$ & Demasiada & 1 \\
\hline & \multirow{10}{*}{$\begin{array}{ll}\text { Afectación } & \text { a } \\
\text { derechos de vía }\end{array}$} & \multirow{5}{*}{$\begin{array}{l}\text { ¿Existen afectaciones de vía en Moroleón- } \\
\text { Uriangato? }\end{array}$} & $\mathrm{A}$ & No hay & 5 \\
\hline & & & $\mathrm{B}$ & Poca & 4 \\
\hline & & & $\mathrm{C}$ & Regular & 3 \\
\hline & & & $\mathrm{D}$ & Mucha & 2 \\
\hline & & & $\mathrm{E}$ & Demasiada & 1 \\
\hline & & \multirow{5}{*}{$\begin{array}{l}\text { ¿Qué tanto considera que las afectaciones a los } \\
\text { derechos de vía influyen en el crecimiento de } \\
\text { ambas ciudades? }\end{array}$} & $\mathrm{A}$ & Nada & 5 \\
\hline & & & $\mathrm{B}$ & Muy poco & 4 \\
\hline & & & $\mathrm{C}$ & Poco & 3 \\
\hline & & & $\mathrm{D}$ & Mucho & 2 \\
\hline & & & $\mathrm{E}$ & Demasiado & 1 \\
\hline & $\begin{array}{|ll|}\text { Falta de espacios } \\
\end{array}$ & ¿Usted piensa que los espacios públicos son & $\mathrm{A}$ & Suficientes & 5 \\
\hline & públicos & suficientes en la zona? & $\mathrm{B}$ & Adecuados & 4 \\
\hline & & & $\mathrm{C}$ & Regulares & 3 \\
\hline & & & $\mathrm{D}$ & Faltan espacios & 2 \\
\hline & & & $\mathrm{E}$ & No hay espacios & 1 \\
\hline & & ¿Los espacios públicos cumplen con el objetivo & $\mathrm{A}$ & Cumplen bien & 5 \\
\hline & & de recreación de la ciudadanía? & $\mathrm{B}$ & Son apropiados & 4 \\
\hline & & & $\mathrm{C}$ & Regulares & 3 \\
\hline & & & $\mathrm{D}$ & No cumplen & 2 \\
\hline & & & $\mathrm{E}$ & Son pésimos & 1 \\
\hline & & & $\mathrm{A}$ & A) Son suficientes & 5 \\
\hline & & & $\mathrm{B}$ & B) Están adecuados para las ciudades & 4 \\
\hline & & & $\mathrm{C}$ & Regulares & 3 \\
\hline & & & $\mathrm{D}$ & C) Hacen falta & 2 \\
\hline & & & $\mathrm{E}$ & D) No hay & 1 \\
\hline & & & $\mathrm{A}$ & Falta de espacio & 5 \\
\hline & & & $\mathrm{B}$ & Falta de donaciones & 4 \\
\hline & & & $\mathrm{C}$ & Al gobierno & 3 \\
\hline & & & $\mathrm{D}$ & Mala planeación & 2 \\
\hline & & & $\mathrm{E}$ & Pésima planeación & 1 \\
\hline & & & $\mathrm{A}$ & Muy buenos & 5 \\
\hline & & & $\mathrm{B}$ & Buenos & 4 \\
\hline & & & $\mathrm{C}$ & Regulares & 3 \\
\hline & & & $\mathrm{D}$ & Malos & 2 \\
\hline & & & $\mathrm{E}$ & Muy malos & 1 \\
\hline & & & $\mathrm{A}$ & $\mathrm{Si}$ & 5 \\
\hline & & & $\mathrm{B}$ & Regular & 4 \\
\hline & & & $\mathrm{C}$ & No, es falta de capacidad & 3 \\
\hline & & & $\mathrm{D}$ & No, es muy malo. & 2 \\
\hline & & & $\mathrm{E}$ & No, es pésimo & 1 \\
\hline & & & $\mathrm{A}$ & Excelente & 5 \\
\hline & & & $\mathrm{B}$ & Buena & 4 \\
\hline & & & $\mathrm{C}$ & Regular & 3 \\
\hline & & & $\mathrm{D}$ & Mala & 2 \\
\hline & & & $\mathrm{E}$ & Muy mala & 1 \\
\hline & & & $\mathrm{A}$ & No & 5 \\
\hline & & & $\mathrm{B}$ & En parte & 4 \\
\hline & & & $\mathrm{C}$ & Poco & 3 \\
\hline & & & $\mathrm{D}$ & Si influye & 2 \\
\hline & & & $\mathrm{E}$ & Totalmente & 1 \\
\hline
\end{tabular}




\begin{tabular}{|c|c|c|c|c|c|}
\hline \multirow{60}{*}{$\begin{array}{l}\text { Políticas } \\
\text { publicas }\end{array}$} & \multirow[t]{10}{*}{ Corrupción } & \multirow[t]{5}{*}{ ¿Qué tan grave para usted es el problema de la corrupción? } & A & Nada grave & 5 \\
\hline & & & $\mathrm{B}$ & Poco grave & 4 \\
\hline & & & $\mathrm{C}$ & Regular & 3 \\
\hline & & & $\mathrm{D}$ & Grave & 2 \\
\hline & & & $\mathrm{E}$ & Muy grave & 1 \\
\hline & & \multirow{5}{*}{$\begin{array}{l}\text { ¿Qué tan corruptos considera que son los gobiernos de } \\
\text { Moroleón-Uriangato? }\end{array}$} & $\mathrm{A}$ & Sin corrupción & 5 \\
\hline & & & $\mathrm{B}$ & Poco corruptos & 4 \\
\hline & & & $\mathrm{C}$ & Regulares & 3 \\
\hline & & & $\mathrm{D}$ & Corruptos & 2 \\
\hline & & & $\mathrm{E}$ & Muy corruptos & 1 \\
\hline & \multirow{10}{*}{$\begin{array}{l}\text { Otorgamiento de licencias } \\
\text { no factibles }\end{array}$} & \multirow{5}{*}{$\begin{array}{l}\text { ¿En Moroleón-Uriangato, con qué frecuencia cree usted } \\
\text { que se otorguen permisos que no son factibles? }\end{array}$} & A & Nunca & 5 \\
\hline & & & $\mathrm{B}$ & A veces & 4 \\
\hline & & & $\mathrm{C}$ & Poca frecuencia & 3 \\
\hline & & & $\mathrm{D}$ & Frecuentemente & 2 \\
\hline & & & $\mathrm{E}$ & Siempre & 1 \\
\hline & & \multirow{5}{*}{$\begin{array}{l}\text { Esos otorgamientos, que tanto afectan la planeación en } \\
\text { Moroleón-Uriangato }\end{array}$} & A & Nada & 5 \\
\hline & & & $\mathrm{B}$ & Muy poco & 4 \\
\hline & & & $\mathrm{C}$ & Poco & 3 \\
\hline & & & $\mathrm{D}$ & Mucho & 2 \\
\hline & & & $\mathrm{E}$ & Demasiado & 1 \\
\hline & \multirow{10}{*}{$\begin{array}{l}\text { Falta de vigilancia } \\
\text { municipal }\end{array}$} & \multirow{5}{*}{$\begin{array}{l}\text { ¿Como considera usted la vigilancia por parte del } \\
\text { municipio para vigilar la ciudad y evitar que se construya } \\
\text { donde no se debe? }\end{array}$} & A & Excelente & 5 \\
\hline & & & $\mathrm{B}$ & Buena & 4 \\
\hline & & & $\mathrm{C}$ & Regular & 3 \\
\hline & & & $\mathrm{D}$ & Mala & 2 \\
\hline & & & $\mathrm{E}$ & Muy mala & 1 \\
\hline & & \multirow{5}{*}{$\begin{array}{l}\text { ¿Cree usted que, si se detecta una obra en construcción, en } \\
\text { donde no se debe, se sancione adecuadamente? }\end{array}$} & A & Se sanciona & 5 \\
\hline & & & $\mathrm{B}$ & Se aplica la ley & 4 \\
\hline & & & $\mathrm{C}$ & Se aplica la ley a medias & 3 \\
\hline & & & $\mathrm{D}$ & No se aplica la ley & 2 \\
\hline & & & $\mathrm{E}$ & La autoridad se corrompe & 1 \\
\hline & \multirow{10}{*}{$\begin{array}{l}\text { No aplicación de la Ley de } \\
\text { Fraccionamientos }\end{array}$} & \multirow{5}{*}{$\begin{array}{l}\text { ¿Como cree usted que las leyes se aplican bien en } \\
\text { Moroleón - Uriangato? }\end{array}$} & A & Muy bien & 5 \\
\hline & & & $\mathrm{B}$ & Bien & 4 \\
\hline & & & $\mathrm{C}$ & Regular & 3 \\
\hline & & & $\mathrm{D}$ & Mal & 2 \\
\hline & & & $\mathrm{E}$ & Muy mal & 1 \\
\hline & & \multirow{5}{*}{$\begin{array}{l}\text { ¿Considera que la Ley de Fraccionamientos que regula el } \\
\text { crecimiento urbano está bien aplicada? }\end{array}$} & $\mathrm{A}$ & Bien aplicada & 5 \\
\hline & & & $\mathrm{B}$ & Aplicada & 4 \\
\hline & & & $\mathrm{C}$ & Regular & 3 \\
\hline & & & $\mathrm{D}$ & Mal aplicada & 2 \\
\hline & & & $\mathrm{E}$ & Muy mal aplicada & 1 \\
\hline & \multirow{10}{*}{$\begin{array}{l}\text { Beneficio a familiares } \mathrm{o} \\
\text { amigos }\end{array}$} & \multirow{5}{*}{$\begin{array}{l}\text { Que tanto se beneficia desde el interior del gobierno a } \\
\text { familiares y amigos en Moroleón-Uriangato }\end{array}$} & A & Muy poco & 5 \\
\hline & & & $\mathrm{B}$ & Poco & 4 \\
\hline & & & $\mathrm{C}$ & Regular & 3 \\
\hline & & & $\mathrm{D}$ & Mucho & 2 \\
\hline & & & $\mathrm{E}$ & Demasiado & 1 \\
\hline & & \multirow{5}{*}{$\begin{array}{l}\text { Cuanto considera usted que afecte el beneficio a familiares } \\
\text { y amigos a la planeación }\end{array}$} & A & Muy poco & 5 \\
\hline & & & $\mathrm{B}$ & Poco & 4 \\
\hline & & & $\mathrm{C}$ & Regular & 3 \\
\hline & & & $\mathrm{D}$ & Mucho & 2 \\
\hline & & & $\mathrm{E}$ & Demasiado & 1 \\
\hline & Incapacidad administrativa & ¿Qué tan capaces son los gobiernos de Moroleón- & $\mathrm{A}$ & Muy capaces & 5 \\
\hline & & Uriangato, para dirigir los destinos de estos municipios? & $\mathrm{B}$ & Capaces & 4 \\
\hline & & & $\mathrm{C}$ & Regular & 3 \\
\hline & & & $\mathrm{D}$ & Incapaces & 2 \\
\hline & & & $\mathrm{E}$ & Incapaces y malos & 1 \\
\hline & & ¿Cree usted que el gobierno pone a personas capaces en & A & Pone personas capaces & 5 \\
\hline & & puestos administrativos, o a familiares $y$ amigos, sin & $\mathrm{B}$ & Pone personas regulares & 4 \\
\hline & & capacidad? & $\mathrm{C}$ & Pone a familiares & 3 \\
\hline & & & $\mathrm{D}$ & Pone a sus amigos & 2 \\
\hline & & & $\mathrm{E}$ & Venden puestos & 1 \\
\hline
\end{tabular}




\begin{tabular}{|c|c|c|c|c|c|}
\hline \multirow{30}{*}{$\begin{array}{l}\text { Utilización del } \\
\text { agua }\end{array}$} & \multirow[t]{10}{*}{ Sequia de pozos } & \multirow{5}{*}{$\begin{array}{l}\text { ¿Que tanto afecta la falta de agua en Moroleón- } \\
\text { Uriangato, a la planeación urbana? }\end{array}$} & $\mathrm{A}$ & Nada & 5 \\
\hline & & & $\mathrm{B}$ & Poco & 4 \\
\hline & & & $\mathrm{C}$ & Regular & 3 \\
\hline & & & $\mathrm{D}$ & Mucho & 2 \\
\hline & & & $\mathrm{E}$ & Demasiado & 1 \\
\hline & & \multirow[t]{5}{*}{ ¿La sequía de pozos como afecta a la población? } & $\mathrm{A}$ & Nada & 5 \\
\hline & & & $\mathrm{B}$ & Poco & 4 \\
\hline & & & $\mathrm{C}$ & Regular & 3 \\
\hline & & & $\mathrm{D}$ & Mucho & 2 \\
\hline & & & $\mathrm{E}$ & Demasiado & 1 \\
\hline & \multirow[t]{10}{*}{ Racionalidad del agua } & \multirow{5}{*}{$\begin{array}{l}\text { Como considera la dotación de agua que los Sistemas de } \\
\text { Agua Potable de Moroleón-Uriangato, hacen a ambos } \\
\text { municipios? }\end{array}$} & $\mathrm{A}$ & Excelente & 5 \\
\hline & & & $\mathrm{B}$ & Buena & 4 \\
\hline & & & $\mathrm{C}$ & Regular & 3 \\
\hline & & & $\mathrm{D}$ & Mala & 2 \\
\hline & & & $\mathrm{E}$ & No hay agua & 1 \\
\hline & & \multirow{5}{*}{$\begin{array}{l}\text { Como consideras la alternativa de racionalidad del agua } \\
\text { para afrontar el problema del agua en Moroleón- } \\
\text { Uriangato? }\end{array}$} & $\mathrm{A}$ & Muy buena & 5 \\
\hline & & & $\mathrm{B}$ & Buena & 4 \\
\hline & & & $\mathrm{C}$ & Regular & 3 \\
\hline & & & $\mathrm{D}$ & Mala & 2 \\
\hline & & & $\mathrm{E}$ & Pésima & 1 \\
\hline & \multirow{10}{*}{$\begin{array}{l}\text { Negación de dotación de } \\
\text { agua en colonias nuevas }\end{array}$} & \multirow{5}{*}{$\begin{array}{l}\text { ¿Considera que la negación de dotación de agua en } \\
\text { zonas de crecimiento es adecuada? }\end{array}$} & $\mathrm{A}$ & Muy adecuada & 5 \\
\hline & & & $\mathrm{B}$ & Adecuada & 4 \\
\hline & & & $\mathrm{C}$ & Regular & 3 \\
\hline & & & $\mathrm{D}$ & Mala & 2 \\
\hline & & & $\mathrm{E}$ & Pésima & 1 \\
\hline & & \multirow{5}{*}{$\begin{array}{l}\text { ¿Porque cree usted que se llegó a implementar esta } \\
\text { acción por parte del gobierno? }\end{array}$} & $\mathrm{A}$ & Buen cuidado del agua & 5 \\
\hline & & & $\mathrm{B}$ & Regular cuidado del agua & 4 \\
\hline & & & $\mathrm{C}$ & Mal cuidado del agua & 3 \\
\hline & & & $\mathrm{D}$ & Pésimo cuidado del agua & 2 \\
\hline & & & $\mathrm{E}$ & No hay cultura del agua & 1 \\
\hline
\end{tabular}

\begin{tabular}{|c|c|c|c|c|c|}
\hline \multirow{30}{*}{$\begin{array}{l}\text { Utilización del } \\
\text { agua }\end{array}$} & \multirow{10}{*}{$\begin{array}{l}\text { Mala cultura del } \\
\text { agua }\end{array}$} & \multirow{5}{*}{$\begin{array}{l}\text { ¿En qué medida los sistemas de agua potable de Moroleón- } \\
\text { Uriangato, promocionan la cultura del agua? }\end{array}$} & $\mathrm{A}$ & Promoción adecuada & 5 \\
\hline & & & $\mathrm{B}$ & Promoción & 4 \\
\hline & & & $\mathrm{C}$ & No hacen promoción & 3 \\
\hline & & & $\mathrm{D}$ & Pésima promoción & 2 \\
\hline & & & $\mathrm{E}$ & No hacen promoción & 1 \\
\hline & & \multirow[t]{5}{*}{ ¿En Moroleón-Uriangato, la gente como hace uso del agua? } & $\mathrm{A}$ & Muy buen uso & 5 \\
\hline & & & $\mathrm{B}$ & Uso adecuado & 4 \\
\hline & & & $\mathrm{C}$ & Uso regular & 3 \\
\hline & & & $\mathrm{D}$ & Desperdicia agua & 2 \\
\hline & & & $\mathrm{E}$ & Desperdicia mucha agua & 1 \\
\hline & \multirow{10}{*}{$\begin{array}{l}\text { Contaminación de } \\
\text { pozos }\end{array}$} & \multirow{5}{*}{$\begin{array}{l}\text { Como afecta a la planeación la contaminación de pozos, en } \\
\text { Moroleón-Uriangato }\end{array}$} & $\mathrm{A}$ & Nada & 5 \\
\hline & & & $\mathrm{B}$ & Poco & 4 \\
\hline & & & $\mathrm{C}$ & Regular & 3 \\
\hline & & & $\mathrm{D}$ & Mucho & 2 \\
\hline & & & $\mathrm{E}$ & Demasiado & 1 \\
\hline & & \multirow{5}{*}{$\begin{array}{l}\text { ¿Como considera el problema de la contaminación de pozos en } \\
\text { la zona? }\end{array}$} & $\mathrm{A}$ & Nada serio & 5 \\
\hline & & & $\mathrm{B}$ & Poco importante & 4 \\
\hline & & & $\mathrm{C}$ & Regular & 3 \\
\hline & & & $\mathrm{D}$ & Grave & 2 \\
\hline & & & $\mathrm{E}$ & Muy grave & 1 \\
\hline & \multirow{10}{*}{$\begin{array}{l}\text { Años con pocas } \\
\text { lluvias }\end{array}$} & \multirow[t]{5}{*}{ ¿Cuanto llueve en Moroleón-Uriangato? } & $\mathrm{A}$ & Mucho & 5 \\
\hline & & & $\mathrm{B}$ & Suficiente & 4 \\
\hline & & & $\mathrm{C}$ & Regular & 3 \\
\hline & & & $\mathrm{D}$ & Muy poco & 2 \\
\hline & & & $\mathrm{E}$ & No llueve & 1 \\
\hline & & \multirow{5}{*}{$\begin{array}{l}\text { ¿En qué medida afectan los años con pocas lluvias a la } \\
\text { población en Moroleón-Uriangato? }\end{array}$} & A & Muy poco & 5 \\
\hline & & & $\mathrm{B}$ & Poco & 4 \\
\hline & & & $\mathrm{C}$ & Regular & 3 \\
\hline & & & $\mathrm{D}$ & Mucho & 2 \\
\hline & & & $\mathrm{E}$ & Demasiado & 1 \\
\hline
\end{tabular}




\begin{tabular}{|c|c|c|c|c|c|c|}
\hline \multirow{35}{*}{$\begin{array}{l}\text { Planificación } \\
\text { territorial en } \\
\text { Uriangato }\end{array}$} & \multirow{35}{*}{$\begin{array}{l}\text { estratégica } \\
\text { Moroleón - }\end{array}$} & \multirow{35}{*}{$\begin{array}{l}\text { Planificación } \\
\text { estratégica territorial }\end{array}$} & \multirow{5}{*}{$\begin{array}{l}\text { ¿Como considera la planificación urbana en } \\
\text { Moroleón- Uriangato? }\end{array}$} & A & Excelente & 5 \\
\hline & & & & $\mathrm{B}$ & Buena & 4 \\
\hline & & & & $\mathrm{C}$ & Regular & 3 \\
\hline & & & & $\mathrm{D}$ & Mala & 2 \\
\hline & & & & $\mathrm{E}$ & Pésima & 1 \\
\hline & & & \multirow{5}{*}{$\begin{array}{l}\text { ¿En qué medida considera que el gobierno } \\
\text { municipal está planeando el desarrollo urbano? }\end{array}$} & $\mathrm{A}$ & Excelente & 5 \\
\hline & & & & $\mathrm{B}$ & Bueno & 4 \\
\hline & & & & $\mathrm{C}$ & Regular & 3 \\
\hline & & & & $\mathrm{D}$ & Malo & 2 \\
\hline & & & & $E$ & Pésimo & 1 \\
\hline & & & \multirow{5}{*}{$\begin{array}{l}\text { Que tanto incide la planificación urbana en el } \\
\text { desarrollo de Moroleón Uriangato }\end{array}$} & $\mathrm{A}$ & Demasiado & 5 \\
\hline & & & & $\mathrm{B}$ & Mucho & 4 \\
\hline & & & & $\mathrm{C}$ & Regular & 3 \\
\hline & & & & $\mathrm{D}$ & Poco & 2 \\
\hline & & & & $\mathrm{E}$ & Nada & 1 \\
\hline & & & \multirow{5}{*}{$\begin{array}{l}\text { ¿Qué tan buen lugar para vivir es Moroleón- } \\
\text { Uriangato? }\end{array}$} & $\mathrm{A}$ & Excelente & 5 \\
\hline & & & & $\mathrm{B}$ & Bueno & 4 \\
\hline & & & & $\mathrm{C}$ & Regular & 3 \\
\hline & & & & $\mathrm{D}$ & Poco & 2 \\
\hline & & & & $\mathrm{E}$ & Nada & 1 \\
\hline & & & \multirow{5}{*}{$\begin{array}{l}\text { Cuanto le gusta la traza urbana de Moroleón } \\
\text { Uriangato }\end{array}$} & $\mathrm{A}$ & Me encanta & 5 \\
\hline & & & & $\mathrm{B}$ & Mucho & 4 \\
\hline & & & & $\mathrm{C}$ & Regular & 3 \\
\hline & & & & $\mathrm{D}$ & Poco & 2 \\
\hline & & & & $\mathrm{E}$ & Nada & 1 \\
\hline & & & \multirow{5}{*}{$\begin{array}{l}\text { ¿En qué medida considera que Moroleón- } \\
\text { Uriangato, está planificado urbanísticamente? }\end{array}$} & $\mathrm{A}$ & Muy bien planeado & 5 \\
\hline & & & & $\mathrm{B}$ & Bien planeado & 4 \\
\hline & & & & $\mathrm{C}$ & Regular & 3 \\
\hline & & & & $\mathrm{D}$ & Poco & 2 \\
\hline & & & & $\mathrm{E}$ & Nada & 1 \\
\hline & & & \multirow{5}{*}{$\begin{array}{l}\text { Cuanta planeación urbana hace falta en } \\
\text { Moroleón-Uriangato }\end{array}$} & A & Demasiada & 5 \\
\hline & & & & $\mathrm{B}$ & Mucha & 4 \\
\hline & & & & $\mathrm{C}$ & Regular & 3 \\
\hline & & & & $\mathrm{D}$ & Poca & 2 \\
\hline & & & & $E$ & Nada & 1 \\
\hline
\end{tabular}

\begin{tabular}{|c|c|c|c|c|c|}
\hline \multirow{15}{*}{$\begin{array}{l}\text { Planificación estratégica territorial en } \\
\text { Moroleón - Uriangato }\end{array}$} & \multirow{15}{*}{$\begin{array}{l}\text { Planificación } \\
\text { territorial }\end{array}$} & \multirow{5}{*}{$\begin{array}{l}\text { Que tanto ha afectado la falta de planeación urbana } \\
\text { a Moroleón-Uriangato }\end{array}$} & $\mathrm{A}$ & Demasiado & 5 \\
\hline & & & $\mathrm{B}$ & Mucho & 4 \\
\hline & & & $\mathrm{C}$ & Regular & 3 \\
\hline & & & $\mathrm{D}$ & Poco & 2 \\
\hline & & & $E$ & Nada & 1 \\
\hline & & \multirow{5}{*}{$\begin{array}{l}\text { Como considera la traza urbanística de Moroleón } \\
\text { Uriangato }\end{array}$} & $\mathrm{A}$ & Muy buena & 5 \\
\hline & & & $\mathrm{B}$ & Buena & 4 \\
\hline & & & $\mathrm{C}$ & Regular & 3 \\
\hline & & & $\mathrm{D}$ & Mala & 2 \\
\hline & & & $\mathrm{E}$ & Muy mala & 1 \\
\hline & & \multirow{5}{*}{$\begin{array}{l}\text { Cuanto afecta la traza urbana a las actividades } \\
\text { económicas de Moroleón-Uriangato }\end{array}$} & $\mathrm{A}$ & Demasiado & 5 \\
\hline & & & $\mathrm{B}$ & Mucho & 4 \\
\hline & & & $\mathrm{C}$ & Regular & 3 \\
\hline & & & $\mathrm{D}$ & Poco & 2 \\
\hline & & & $E$ & Nada & 1 \\
\hline
\end{tabular}




\section{Anexo 2. Encuesta Aplicada}

\section{Nombre del entrevistador: Martin Mora Zizumbo}

\section{Programa:}

Nombre del proyecto:

Criterios de evaluación:

\section{Doctorado en Ciencias del Desarrollo Regional}

Planificación estratégica territorial en la zona conurbada

Moroleón - Uriangato, Guanajuato.

Identifica e integra los elementos de su contexto que le permiten redimensionar

su proyecto de desarrollo.

Vivencia su proyecto de desarrollo en el marco del desarrollo humano según competencias ciudadanas.

\begin{tabular}{|c|c|c|c|c|c|c|}
\hline 1 & $\begin{array}{l}\text { Como califica usted las entradas a las } \\
\text { ciudades de Moroleón y Uriangato? }\end{array}$ & Muy malos & Malos & Regulares & Buenos & Muy buenos \\
\hline 2 & $\begin{array}{l}\text { Como le parece el tiempo que se tarda } \\
\text { alguien para acceder a los dos centros } \\
\text { de estas ciudades? }\end{array}$ & Muy malo & Malo & Regular & Bueno & Muy bueno \\
\hline 3 & $\begin{array}{l}\text { Como califica el estado que guardan las } \\
\text { calles de Moroleón y Uriangato? }\end{array}$ & Muy malo & Malo & Regular & Bueno & Muy bueno \\
\hline 4 & \begin{tabular}{|l} 
El estado que guardan las calles de \\
Moroleón y Uriangato afecta al \\
comercio, en qué medida?
\end{tabular} & Demasiado & Mucho & Poco & Muy poco & Nada \\
\hline 5 & $\begin{array}{l}\text { Que tanto influyen las calles angostas en } \\
\text { el desarrollo de Moroleón y Uriangato? }\end{array}$ & Demasiado & Mucho & Poco & Muy poco & Nada \\
\hline 6 & $\begin{array}{l}\text { Considera usted que las calles angostas } \\
\text { de ambas ciudades afectan actividades } \\
\text { comerciales? }\end{array}$ & Demasiado & Mucho & Poco & Muy poco & Nada \\
\hline 7 & $\begin{array}{l}\text { Le parece que los estacionamientos } \\
\text { actuales de esta zona son suficientes? }\end{array}$ & No hay & Son escasos & Hacen falta & $\begin{array}{l}\text { Están } \\
\text { adecuados para } \\
\text { las ciudades }\end{array}$ & $\begin{array}{l}\text { Son } \\
\text { suficientes }\end{array}$ \\
\hline 8 & $\begin{array}{|ll|}\text { Como considera la ubicación de los } \\
\text { estacionamientos } & \text { en Moroleón- } \\
\text { Uriangato? } & \end{array}$ & Muy mala & Mala & Regular & Adecuada & $\begin{array}{l}\text { Muy } \\
\text { adecuada }\end{array}$ \\
\hline 9 & $\begin{array}{l}\text { Los servicios de comida, descanso, } \\
\text { sanitarios etc. en Moroleón-Uriangato } \\
\text { para atender a la población tanto local } \\
\text { como foránea son: }\end{array}$ & Muy malos & Malos & Regulares & Buenos & Muy buenos \\
\hline 10 & Estos servicios son: & Son escasos & Hacen falta & Regulares & $\begin{array}{l}\text { Están } \\
\text { adecuados para } \\
\text { las ciudades }\end{array}$ & $\begin{array}{l}\text { Son } \\
\text { suficientes }\end{array}$ \\
\hline 11 & \begin{tabular}{|l|} 
Existen en Moroleón - Uriangato \\
suficientes lugares de descanso para \\
visitantes y compradores
\end{tabular} & No hay & Hacen falta & Regulares & $\begin{array}{l}\text { Están } \\
\text { adecuados para } \\
\text { las ciudades } \\
\end{array}$ & $\begin{array}{l}\text { Son } \\
\text { suficientes }\end{array}$ \\
\hline 12 & $\begin{array}{l}\text { En qué medida calificaría esos lugares } \\
\text { de descanso }\end{array}$ & Pésimos & Malos & Regulares & Buenos & Excelentes \\
\hline 13 & $\begin{array}{l}\text { Considera usted que los barrios pobres } \\
\text { son peligrosos }\end{array}$ & Muy peligrosos & Peligrosos & Regulares & Poco peligrosos & Son seguros \\
\hline 14 & $\begin{array}{l}\text { Que tanta pobreza existe en los barrios } \\
\text { de Moroleón - Uriangato }\end{array}$ & Demasiada & Mucha & Regular & Poca & No existe \\
\hline 15 & $\begin{array}{|lcr|}\text { Existen afectaciones } & \text { de vía } & \text { en } \\
\text { Moroleón-Uriangato } & \text { (invasión } & \text { a } \\
\text { canales, a ductos de PEMEX, etc.? } & \\
\end{array}$ & Demasiadas & Muchas & Regular & Pocas & No hay \\
\hline 16 & $\begin{array}{l}\text { Que tanto considera que las afectaciones } \\
\text { a los derechos de vía afecten a la } \\
\text { población en emergencias? }\end{array}$ & Demasiado & Mucho & Poco & Muy poco & Nada \\
\hline 17 & $\begin{array}{l}\text { Usted piensa que los espacios públicos } \\
\text { son suficientes en la zona? }\end{array}$ & No hay espacios & Faltan espacios & Regulares & Adecuados & Suficientes \\
\hline 18 & $\begin{array}{l}\text { Los espacios públicos existentes } \\
\text { cumplen con el objetivo de recreación } \\
\text { de la ciudadanía? }\end{array}$ & Son pésimos & No cumplen & Regulares & Son apropiados & Cumplen bien \\
\hline 19 & \begin{tabular}{|l|} 
Considera usted que son suficientes los \\
espacios educativos en Moroleón- \\
Uriangato?
\end{tabular} & No hay & Hacen falta & Regulares & $\begin{array}{l}\text { Están } \\
\text { adecuados para } \\
\text { las ciudades }\end{array}$ & $\begin{array}{l}\text { Son } \\
\text { suficientes }\end{array}$ \\
\hline 20 & $\begin{array}{l}\text { A que le atribuye usted la falta de } \\
\text { espacios educativos (escuelas)? }\end{array}$ & $\begin{array}{l}\text { Pésima } \\
\text { planeación }\end{array}$ & Mala planeación & Al gobierno & $\begin{array}{ll}\begin{array}{l}\text { Falta } \\
\text { donaciones }\end{array} & \text { de } \\
\end{array}$ & \begin{tabular}{|ll}
$\begin{array}{l}\text { Falta } \\
\text { espacio }\end{array}$ & de \\
\end{tabular} \\
\hline 21 & $\begin{array}{l}\text { Los fraccionamientos irregulares que } \\
\text { existen son buenos para el desarrollo } \\
\text { urbano en Moroleón-Uriangato? }\end{array}$ & Muy malos & Malos & Regulares & Buenos & Muy buenos \\
\hline 22 & $\begin{array}{l}\text { ¿Permitir fraccionamientos irregulares } \\
\text { en estas dos ciudades es bueno? }\end{array}$ & No, es pésimo & No, es muy malo. & Regular & Bueno & Muy bueno \\
\hline 23 & $\begin{array}{l}\text { La traza urbana de Moroleón-Uriangato } \\
\text { como la considera? }\end{array}$ & Muy mala & Mala & Regular & Buena & Excelente \\
\hline
\end{tabular}




\begin{tabular}{|c|c|c|c|c|c|c|}
\hline 24 & $\begin{array}{l}\text { Cree usted que los embotellamientos } \\
\text { que se dan sobre todo al final del año se } \\
\text { deban a la traza urbana? }\end{array}$ & Totalmente & Si influye & Poco & En parte & No \\
\hline 25 & $\begin{array}{l}\text { Que tan grave para usted es el problema } \\
\text { de la corrupcion? }\end{array}$ & Muy grave & Grave & Regular & Poco grave & Nada grave \\
\hline 26 & $\begin{array}{l}\text { Que tan corruptos considera que son los } \\
\text { gobiernos de Moroleón-Uriangato? }\end{array}$ & Muy corruptos & Corruptos & Regulares & Poco corruptos & $\begin{array}{l}\text { Sin } \\
\text { corrupcion }\end{array}$ \\
\hline 27 & $\begin{array}{l}\text { En Moroleón-Uriangato, con qué } \\
\text { frecuencia cree usted que se otorguen } \\
\text { permisos para construir donde no existe } \\
\text { factibilidad? }\end{array}$ & Siempre & Frecuentemente & $\begin{array}{l}\text { Poca } \\
\text { frecuencia }\end{array}$ & A veces & Nunca \\
\hline 28 & \begin{tabular}{|l|}
$\begin{array}{l}\text { Esos otorgamientos, que tanto afectan la } \\
\text { planeación en Moroleón-Uriangato }\end{array}$ \\
\end{tabular} & Demasiado & Mucho & Poco & Muy poco & Nada \\
\hline 29 & $\begin{array}{l}\text { Como considera usted la vigilancia por } \\
\text { parte del municipio para vigilar la } \\
\text { ciudad y evitar que se construya donde } \\
\text { no se debe? }\end{array}$ & Muy mala & Mala & Regular & Buena & Excelente \\
\hline 30 & $\begin{array}{l}\text { Cree usted que si se detecta una obra en } \\
\text { construcción, irregular, se sancione } \\
\text { adecuadamente? }\end{array}$ & $\begin{array}{l}\text { La autoridad se } \\
\text { corrompe }\end{array}$ & $\begin{array}{l}\text { No } \text { se aplica la } \\
\text { ley }\end{array}$ & $\begin{array}{l}\text { Se aplica la } \\
\text { ley a medias }\end{array}$ & Se sanciona & $\begin{array}{l}\text { Se aplica la } \\
\text { ley }\end{array}$ \\
\hline 31 & $\begin{array}{l}\text { Como cree usted que las leyes se aplican } \\
\text { en Moroleón - Uriangato? }\end{array}$ & Muy mal & Mal & Regular & Bien & Muy bien \\
\hline 32 & $\begin{array}{l}\text { En qué medida Considera que el } \\
\text { gobierno municipal, ha cumplido con el } \\
\text { desarrollo urbano en la zona? }\end{array}$ & Muy mal & Mal & Regular & Bien & Muy bien \\
\hline 33 & $\begin{array}{l}\text { Que tanto se beneficia desde el interior } \\
\text { del gobierno a familiares y amigos en } \\
\text { Moroleón-Uriangato }\end{array}$ & \begin{tabular}{|l|} 
Demasiado \\
\end{tabular} & Mucho & Regular & Poco & Muy poco \\
\hline 34 & $\begin{array}{l}\text { Que tanto considera usted que afecten } \\
\text { los favores especiales del gobierno, a } \\
\text { familiares y amigos a la planeación } \\
\text { urbana? }\end{array}$ & Demasiado & Mucho & Regular & Poco & Muy poco \\
\hline 35 & $\begin{array}{l}\text { Que tan capaces son los gobiernos de } \\
\text { Moroleón-Uriangato, para dirigir los } \\
\text { destinos de estos municipios? }\end{array}$ & Corruptos & Inoperantes & Regular & capaces & Muy capaces \\
\hline 36 & $\begin{array}{l}\text { Cree usted que el gobierno pone a } \\
\text { personas capaces en puestos } \\
\text { administrativos, o a familiares y amigos, } \\
\text { sin capacidad? }\end{array}$ & $\begin{array}{l}\text { Pone personas } \\
\text { incapaces } \quad y \\
\text { corruptas }\end{array}$ & $\begin{array}{l}\text { Pone personas } \\
\text { incapaces }\end{array}$ & $\begin{array}{l}\text { Pone } \\
\text { regulares } \\
\text { personas }\end{array}$ & $\begin{array}{l}\text { Pone personas } \\
\text { capaces }\end{array}$ & $\begin{array}{l}\text { Pone personas } \\
\text { muy capaces }\end{array}$ \\
\hline 37 & $\begin{array}{l}\text { Que tanto afecta la falta de agua en } \\
\text { Moroleón-Uriangato, a la planeación } \\
\text { urbana? }\end{array}$ & Demasiado & Mucho & Regular & Poco & Muy poco \\
\hline 38 & $\begin{array}{l}\text { La contaminación y sequia de pozos } \\
\text { cuanto afecta a la población? }\end{array}$ & Demasiado & Mucho & Regular & Poco & Muy poco \\
\hline 39 & $\begin{array}{l}\text { Como considera la dotación de agua que } \\
\text { los Sistemas de Agua Potable de } \\
\text { Moroleón-Uriangato, hacen a ambos } \\
\text { municipios? }\end{array}$ & Muy mala & Mala & Regular & Buena & Muy buena \\
\hline 40 & \begin{tabular}{|l} 
Como considera la \\
racionalidad del agua para afrontar el \\
problema del agua en Moroleón- \\
Uriangato?
\end{tabular} & Muy mala & Mala & Regular & Buena & Muy buena \\
\hline 41 & $\begin{array}{l}\text { Considera que el manejo del cuidado del } \\
\text { agua de los sistemas es bueno }\end{array}$ & Muy mala & Mala & Regular & Buena & Muy buena \\
\hline 42 & $\begin{array}{l}\text { Porque cree usted que se llegó a } \\
\text { implementar esta acción por parte del } \\
\text { gobierno? }\end{array}$ & $\begin{array}{l}\text { Muy mal } \\
\text { cuidado del agua }\end{array}$ & $\begin{array}{l}\text { Mal cuidado del } \\
\text { agua }\end{array}$ & $\begin{array}{l}\text { Regular } \\
\text { cuidado del } \\
\text { agua }\end{array}$ & $\begin{array}{l}\text { Buen cuidado } \\
\text { del agua }\end{array}$ & 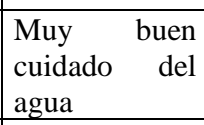 \\
\hline 43 & $\begin{array}{l}\text { En qué medida los sistemas de agua } \\
\text { potable de Moroleón-Uriangato, } \\
\text { promocionan la cultura del agua? }\end{array}$ & $\begin{array}{l}\text { Promoción muy } \\
\text { mala }\end{array}$ & Promoción mala & $\begin{array}{l}\text { Promoción } \\
\text { regular }\end{array}$ & $\begin{array}{l}\text { Promoción } \\
\text { buena }\end{array}$ & $\begin{array}{l}\text { Promoción } \\
\text { muy buena }\end{array}$ \\
\hline 44 & $\begin{array}{l}\text { En Moroleón-Uriangato, la gente como } \\
\text { usa el agua, la cuida, en qué medida? }\end{array}$ & La desperdicia & No la cuida & Regular & Mucho & Bastante \\
\hline 45 & $\begin{array}{l}\text { Como afecta a la planeación, la } \\
\text { contaminación de pozos, en Moroleón- } \\
\text { Uriangato }\end{array}$ & Demasiado & Mucho & Regular & Poco & Muy poco \\
\hline 46 & $\begin{array}{l}\text { Como considera el problema de la } \\
\text { contaminación de pozos en la zona? }\end{array}$ & Muy grave & Grave & Regular & Poco grave & Nada grave \\
\hline 47 & Cuanto llueve en Moroleón-Uriangato? & No llueve & Muy poco & Regular & Suficiente & Mucho \\
\hline 48 & \begin{tabular}{|l|} 
Como afectan los años con pocas lluvias \\
a la poblacion en Moroleón-Uriangato? \\
\end{tabular} & Demasiado & Mucho & Regular & Poco & Muy poco \\
\hline 49 & $\begin{array}{l}\text { Como considera la planificación urbana } \\
\text { en Moroleón- Uriangato? }\end{array}$ & Muy mala & Mala & Regular & Buena & Muy buena \\
\hline 50 & $\begin{array}{l}\text { En qué medida considera que el } \\
\text { gobierno municipal está planeando el } \\
\text { desarrollo urbano? }\end{array}$ & Muy mal & Mal & Regular & Bien & Muy bien \\
\hline 51 & $\begin{array}{l}\text { Que tanto incide la no planificación } \\
\text { urbana en el desarrollo de Moroleón } \\
\text { Uriangato }\end{array}$ & Demasiado & Mucho & Regular & Poco & Nada \\
\hline
\end{tabular}




\begin{tabular}{|c|c|c|c|c|c|c|}
\hline 52 & $\begin{array}{l}\text { Que tan buen lugar para vivir es } \\
\text { Moroleón- Uriangato? }\end{array}$ & Muy malo & Malo & Regular & Agradable & $\begin{array}{l}\text { Muy } \\
\text { agradable }\end{array}$ \\
\hline 53 & $\begin{array}{l}\text { En qué medida le agrada la traza urbana } \\
\text { de Moroleón Uriangato }\end{array}$ & No me gusta & Me gusta poco & Regular & Me agrada & $\begin{array}{l}\text { Me } \\
\text { mucho }\end{array}$ \\
\hline 54 & $\begin{array}{l}\text { En qué medida considera que Moroleón- } \\
\begin{array}{l}\text { Uriangato, está } \\
\text { correctamente? }\end{array}\end{array}$ & Es un caos & $\begin{array}{|lr|}\begin{array}{l}\text { No } \\
\text { planificación }\end{array} & \text { existe } \\
\end{array}$ & Regular & Planificado & $\begin{array}{l}\text { Muy } \\
\text { planificado }\end{array}$ \\
\hline 55 & $\begin{array}{l}\text { Cuanta planeación urbana hace falta en } \\
\text { Moroleón-Uriangato }\end{array}$ & \begin{tabular}{|l} 
Hace falta \\
mucha
\end{tabular} & Hace falta & Regular & Muy poca & No hace falta \\
\hline 56 & $\begin{array}{l}\text { Que tanto ha afectado la falta de } \\
\text { planeación urbana a } \\
\text { Uriangato }\end{array}$ & $\begin{array}{ll}\mathrm{Ha} & \text { afectado } \\
\text { mucho }\end{array}$ & Ha afectado & Regular & Poco & Muy poco \\
\hline 57 & $\begin{array}{l}\text { Como considera la traza urbanística de } \\
\text { Moroleón Uriangato }\end{array}$ & Muy mala & Mala & Regular & Buena & Muy buena \\
\hline 58 & $\begin{array}{l}\text { Cuanto afecta la traza urbana a las } \\
\text { actividades economicas de Moroleón- } \\
\text { Uriangato }\end{array}$ & Demasiado & Mucho & Regular & Poco & Muy poco \\
\hline
\end{tabular}


Anexo 3. Resultados obtenidos de la prueba piloto

\begin{tabular}{|c|c|c|c|c|}
\hline Número & $\begin{array}{c}\text { Media escala si el } \\
\text { elemento se ha } \\
\text { suprimido }\end{array}$ & $\begin{array}{l}\text { Varianza de escala } \\
\text { si el elemento se ha } \\
\text { suprimido }\end{array}$ & $\begin{array}{c}\text { Correlación total } \\
\text { de elementos } \\
\text { corregida }\end{array}$ & $\begin{array}{l}\text { Alfa de Cronbach } \\
\text { si el elemento se ha } \\
\text { suprimido }\end{array}$ \\
\hline $\mathrm{P} 1$ & 140.0000 & 429.526 & 0.416 & 0.923 \\
\hline $\mathrm{P} 2$ & 140.2564 & 429.564 & 0.428 & 0.923 \\
\hline P3 & 1406154 & 419.769 & 0.635 & 0.921 \\
\hline $\mathrm{P} 4$ & 140.5128 & 430.677 & 0.365 & 0.923 \\
\hline $\mathrm{P} 5$ & 140.8718 & 436.904 & 0.152 & 0.925 \\
\hline P6 & 140.8205 & 431.256 & 0.307 & 0.924 \\
\hline $\mathrm{P} 7$ & 140.5641 & 430.042 & 0.432 & 0.923 \\
\hline P8 & 140.3590 & 432.236 & 0.259 & 0.924 \\
\hline P9 & 140.4872 & 412.993 & 0.831 & 0.920 \\
\hline P10 & 140.9231 & 417.652 & 0.733 & 0.921 \\
\hline $\mathrm{P} 11$ & 141.1795 & 435.783 & 0.268 & 0.924 \\
\hline $\mathrm{P} 12$ & 140.5385 & 422.255 & 0.543 & 0.922 \\
\hline P13 & 140.4872 & 432.730 & 0.231 & 0.924 \\
\hline $\mathrm{P} 14$ & 140.5641 & 432.673 & 0.390 & 0.923 \\
\hline $\mathrm{P} 15$ & 140.3590 & 431.131 & 0.250 & 0.924 \\
\hline $\mathrm{P} 16$ & 140.8462 & 431.397 & 0.362 & 0.923 \\
\hline $\mathrm{P} 17$ & 140.9744 & 439.394 & 0.110 & 0.925 \\
\hline $\mathrm{P} 18$ & 140.3846 & 435.085 & 0.181 & 0.925 \\
\hline P19 & 140.8462 & 442.344 & -0.036 & 0.926 \\
\hline $\mathrm{P} 20$ & 140.6154 & 421.717 & 0.442 & 0.923 \\
\hline $\mathrm{P} 21$ & 140.5128 & 425.467 & 0.379 & 0.923 \\
\hline $\mathrm{P} 22$ & 140.6410 & 444.762 & -0.095 & 0.928 \\
\hline $\mathrm{P} 23$ & 140.6923 & 423.113 & 0.582 & 0.922 \\
\hline $\mathrm{P} 24$ & 141.0513 & 420.682 & 0.450 & 0.923 \\
\hline $\mathrm{P} 25$ & 141.6410 & 432.236 & 0.302 & 0.924 \\
\hline $\mathrm{P} 26$ & 140.8462 & 416.186 & 0.676 & 0.921 \\
\hline $\mathrm{P} 27$ & 140.5128 & 416.151 & 0.540 & 0.922 \\
\hline $\mathrm{P} 28$ & 141.1282 & 429.588 & 0.412 & 0.923 \\
\hline $\mathrm{P} 29$ & 140.8462 & 421.344 & 0.552 & 0.922 \\
\hline P30 & 140.4615 & 412.360 & 0.527 & 0.922 \\
\hline P31 & 140.6410 & 411.920 & 0.758 & 0.920 \\
\hline P32 & 140.4872 & 411.941 & 0.728 & 0.920 \\
\hline P33 & 140.7949 & 425.852 & 0.366 & 0.924 \\
\hline P34 & 140.9744 & 426.184 & 0.363 & 0.924 \\
\hline $\mathrm{P} 35$ & 140.1538 & 441.239 & -0.013 & 0.927 \\
\hline P36 & 140.7692 & 422.498 & 0.477 & 0.923 \\
\hline P37 & 141.2308 & 428.077 & 0.381 & 0.923 \\
\hline P38 & 141.3333 & 429.544 & 0.316 & 0.924 \\
\hline P39 & 140.1026 & 436.726 & 0.166 & 0.925 \\
\hline $\mathrm{P} 40$ & 140.1026 & 437.937 & 0.100 & 0.925 \\
\hline $\mathrm{P} 41$ & 140.5641 & 430.621 & 0.325 & 0.924 \\
\hline $\mathrm{P} 42$ & 140.4103 & 424.985 & 0.446 & 0.923 \\
\hline $\mathrm{P} 43$ & 140.2821 & 418.945 & 0.508 & 0.922 \\
\hline P44 & 140.6923 & 423.692 & 0.443 & 0.923 \\
\hline $\mathrm{P} 45$ & 141.1026 & 435.410 & .179 & .925 \\
\hline $\mathrm{P} 46$ & 141.1026 & 440.726 & .016 & .926 \\
\hline $\mathrm{P} 47$ & 140.5641 & 430.463 & .448 & .923 \\
\hline $\mathrm{P} 48$ & 141.1538 & 422.134 & .570 & .922 \\
\hline P49 & 140.8205 & 422.309 & .590 & .922 \\
\hline P50 & 140.6923 & 412.534 & .719 & .920 \\
\hline P51 & 141.0000 & 425.789 & .433 & .923 \\
\hline P52 & 139.5897 & 428.038 & .370 & .923 \\
\hline P53 & 140.5128 & 422.520 & .500 & .922 \\
\hline P54 & 140.8462 & 427.976 & .459 & .923 \\
\hline P55 & 141.5641 & 426.831 & .599 & .922 \\
\hline P56 & 141.4615 & 427.623 & .456 & .923 \\
\hline P57 & 140.6923 & 424.377 & .602 & .922 \\
\hline P58 & 141.0513 & 426.366 & .447 & .923 \\
\hline
\end{tabular}




\section{Referencias}

Abardía, A., \& Morales, F. (2008). Desarrollo regional Reflexiones para la gestión de los territorios. McEditores, 60-61.

Adame, C., Mohedano, A., \& Benavides, M. (2012). Tendencias actuales desde la perspectiva basada en los recursos. Nuevas Corrientes de Pensamiento Económicas, Marzo-Abril(865), 119-130.

Aguado, I., Echebarria, C., \& Barrutia, J. M. (2008). El desarrollo sostenible a lo largo de la historia del pensamiento económico. Revista de Economía Mundial(21), 87-110.

Aguilar, C. (2000). La necesidad de la planeación estratégica, Temas de ciencia y tecnología. Vol. 4 Núm., 19.

Avina, \& Korin. (2011). En busca de la sostenibilidad. El camino de la Responsabilidad Social Empresarial en América Latina y la contribución de la Fundación AVINA. Fundación Avina. Buenos Aires, Arg.

Ariana, C. (2012). Politicas públicas urbanas e instrumentos de regulación en la ciudad de Rosario. Centro Universitario Rosario de Investigaciones Urbanas y Regionales, FAPyD - UNR y FDyCP UAI. RIURB. Revista Iberoamericana de Urbanismo. N 7.

Barbosa, D., Piñeros, R., \& Noguera, Á. (2013). Retos actuales del gobierno corporativo en torno a la creación de valor. Criterio Libre, 11(19), 187-204.

Barrenechea, P., González, M., Pintos, F., Rado, C., Rodríguez, Miranda A., Troncoso, C., \& Zurbriggen, C. (2011). Planificación Estratégica Territorial en la Zona de Cuchilla de Haedo. Área de Políticas Territoriales OPP, documento de trabajo No. 18, Presidencia Oficina de Planeamiento y Presupuesto, Uruguay Integra.

Boisier, S. (1997). Ensayos sobre descentralización y desarrollo regional. CEPAL, Ilpes. Naciones Unidas, Santiago de Chile, 83.

Bourne, L. (2014). The six functions of governance. PM World Journal, 3(11), 1-6.

Cárdenas, N. (2002). El desarrollo local su conceptualización y procesos. Provincia, núm. 8. Universidad de los Andes Mérida, Venezuela. 55-58.

Carroll, A. B., \& Shabana, K. M. (2010). The business case for corporate social responsibility: a review of concepts, research and practice. International Journal of Management Reviews, 12(1), 85-105.

Carpinetti, B. (2013). Introducción al desarrollo sustentabl. Universidad Nacional Arturo Jauretche, Buenos Aires Argentina. 10.

Elizalde, A. (2003). Planificación estratégica territorial y políticas públicas para el desarrollo local. Cepal, Gestión Pública 29. Santiago de Chile.

Estrella, V. \& González, A. (2014). Desarrollo Sustentable un nuevo mañana. Grupo Editorial Patria. México D.F. Primera edición, 4-5.

FAO. (2014). La alimentación y la agricultura en América Latina y el Caribe. Anuario Estadístico de la FAO. Organización de las Naciones Unidas para la Agricultura y la Alimentación. Santiago, Chile. Recuperado el 8 de julio de 2015, de http://www.fao.org/3/a-i3592s.pdf

Gil Flores, J. (2005). Aplicación del método bootstrap al contraste de hipótesis en la investigación educativa. Revista de Educación( 336), 251-265.

Guzmán, A., \& Frausto, José. (2012). La Determinación de Polígonos de Pobreza: Análisis metodológico. Nova scientia, 4(7), 85-124. 
Guzmán, E., Hernández, J., García, J., Rebollar, S., De la Garza M., Hernández, D. (2008). Consumo de agua subterránea en Guanajuato, Agro ciencia. Colpos.

H. Ayuntamiento 2012-2015, (2014). Plan municipal de desarrollo León hacia el futuro Visión 2040. Implan.1, 2, 4, 5, 6, 8, 9, 10 y 11.

Hernández, R., Fernández, C., \& Baptista, M. (2010). Metodología de la investigación (Quinta ed.). México: McGraw-Hill.

Juárez, G. (2013). Revisión del concepto de desarrollo local desde una perspectiva territorial, Revista líder. Vol. 23. México.

Kerlinger, F. N., \& Lee, H. B. (2002). Investigación del comportamiento (Cuarta ed.). México: McGraw-Hill.

Lara, R. (2009). Competitividad regional de la industria textil y de la confección en Bajío Sur Guanajuato- Michoacán, UMSNH-ININEE.

Lozano, J. (2000). Institutions and economic theory. The contribution of the new institutional economics, de Eric Furubotn y Rudolf Richter. Revista de Economía Institucional(2), 165-169.

Padua, J., Ahman, I., Apezechea, H., \& Borsotti, C. (1996). Técnicas de investigación aplicada a las ciencias sociales. México: Fondo de Cultura Económica

Ortega, R. (2010). Planificación Estratégica del Territorio Inversión Pública y Bienestar. Ministerio de Planificación Federal Inversión Pública y Servicios, Universidad de Salamanca.

ONU, (2012). Hábitat por un mejor futuro urbano, Políticas nacionales urbanas. https://es.unhabitat.org/iniciativas-urbanas/iniciativas-programas/politicas-nacionales-urbanas/

Periódico Oficial del Gobierno del Estado de Guanajuato, 26 de agosto 2016.

Periódico oficial del Gobierno del Estado de Guanajuato No. 205, 12 de octubre de 2018.

PLAN Nacional de Desarrollo (2013-201 Gobierno de la Republica, 20 mayo 2013.

Programa municipal de gobierno municipal 2015-2018, Honorable ayuntamiento de Moroleón 20152018. 26 de agosto 2016.

Programa de Gobierno 2015-2018 Municipio de Uriangato Gto. 2016.

Ricart, J. E., \& Rodríguez, M. Á. (2002). Código de conducta de gobierno para la empresa sostenible. Guía para su implementación. Center for Business in Society, IESE, Universidad de Navarra, España.

Rojas, C. (2010). Valoración de Recursos Minerales bajo la teoría del desarrollo sostenible. Revista EIA(13), 65-75.

Rojas, R. (2013). Guía para realizar investigaciones sociales (Trigésima octava ed.). México: Plaza y Valdés.

Schuschny, A., \& Soto, H. (2009). Guía metodológica diseño de indicadores compuestos de desarrollo Sostenible. Documento de proyecto. Comisión Económica para América Latina y el Caribe. Naciones Unidas, Santiago de Chile.

Shaeffler, K. (2006). Pobreza y responsabilidad social del empresariado. Un modelo de gestión que agrega valor y crea capital social en beneficio de la comunidad. Revista Futuros, 4(13), 1-12.

Vargas, J. G. (2008). Perspectivas del Institucionalismo y Neoinstitucionalismo. Ciencia Administrativa(1), 47 - 58. 
Veitia, E. R., Montalván, A., \& Martínez, Y. (2014). Elección de indicadores sistémicos para la sostenibilidad ambiental del suelo. Ciencias Técnicas Agropecuarias, 23(4), 43-50.

Vázquez, A. (2009). Desarrollo Local una Estrategia para tiempos de crisis. Universitas Fórum, Vol. 1, No. 2.

Vázquez, A. (2007). Desarrollo endógeno. Teorías y políticas de desarrollo territorial Investigaciones Regionales, núm. 11,183-210.

Zapata, G. J., \& Hernández, A. (2014). Origen de los recursos y ventajas competitivas de las organizaciones: reflexiones teóricas. Revista Venezolana de Gerencia (RVG), Año 19(68), 735-759. 


\section{[Título de Libro en Times New Roman y Negritas No.14 en Español e Inglés]}

Apellidos (EN MAYUSCULAS), Nombre de $1^{\text {er }}$ Autor†*, Apellidos (EN MAYUSCULAS), Nombre de $2^{\text {do }}$ Autor, Apellidos (EN MAYUSCULAS), Nombre de $3^{\text {er }}$ Autor y Apellidos (EN

MAYUSCULAS), Nombre de $4^{\text {to }}$ Autor

Institutional Affiliation of Author including Dependency (No.10 Times New Roman and Italic)

$\underline{\text { International Identification of Science - Technology and Innovation }}$

ID $1^{\text {er }}$ Autor: (ORC ID - Researcher ID Thomson, arXiv Author ID - PubMed Autor ID - Open ID) y CVU $1^{\text {er }}$ autor: (Becario-PNPC o SNI-CONACYT) (No.10 Times New Roman)

ID $1^{\text {er }}$ Coautor: (ORC ID - Researcher ID Thomson, arXiv Author ID - PubMed Autor ID - Open ID) y CVU $2^{\text {do }}$ autor: (Becario-PNPC o SNI-CONACYT) (No.10 Times New Roman)

ID $2^{\text {do }}$ Coautor: (ORC ID - Researcher ID Thomson, arXiv Author ID - PubMed Autor ID - Open ID) y CVU $3^{\text {er }}$ autor: (Becario-PNPC o SNI-CONACYT) (No.10 Times New Roman)

ID $3^{\text {er }}$ Coautor: (ORC ID - Researcher ID Thomson, arXiv Author ID - PubMed Autor ID - Open ID) y CVU $4^{\text {to }}$ autor: (Becario-PNPC o SNI-CONACYT) (No.10 Times New Roman)

Institución de Afiliación del Autor incluyendo dependencia (en Times New Roman No.12)

Correo institucional (Times New Roman No.12)

\section{Resumen (En Español, 150-200 palabras)}

Objetivos

Metodología

Contribución

Indicar 3 palabras clave en Times New Roman y Negritas No. 12 (En Español)

Resumen (En Inglés, 150-200 palabras)

Objetivos

Metodología

Contribución

\section{Indicar 3 palabras clave en Times New Roman y Negritas No. 12 (En Inglés)}

Indica área de investigación (CONACYT) (Time New Roman No. 12)

Área:

Campo:

Disciplina:

Subdisciplina:

Indicación si corresponde a celebración de año conmemorativo o festejo institucional 


\section{Introducción}

Texto redactado en Times New Roman No.12, espacio sencillo.

Explicación del tema en general y explicar porque es importante.

¿Cuál es su valor agregado respecto de las demás técnicas?

Enfocar claramente cada una de sus características.

Explicar con claridad el problema a solucionar y la hipótesis central.

Explicación de las secciones del Capítulo.

Desarrollo de Secciones y Apartados del Capítulo con numeración subsecuente

[Título en Times New Roman No.12, espacio sencillo y Negrita]

Desarrollo de Capítulos en Times New Roman No.12, espacio sencillo.

\section{Inclusión de Gráficos, Figuras y Tablas-Editables}

En el contenido del Capítulo todo gráfico, tabla y figura debe ser editable en formatos que permitan modificar tamaño, tipo y número de letra, a efectos de edición, estas deberán estar en alta calidad, no pixeladas y deben ser notables aun reduciendo la imagen a escala.

[Indicando el título en la parte Superior con Times New Roman No.12 y Negrita, señalando la fuente en la parte Inferior centrada con Times New Roman No. 10]

Tabla 1.1 Título

\begin{tabular}{|l|l|r|}
\hline Variable & Descripción & Valor \\
\hline $\mathrm{P}_{1}$ & Partición 1 & 481.00 \\
\hline $\mathrm{P}_{2}$ & Partición 2 & 487.00 \\
\hline $\mathrm{P}_{3}$ & Partición 3 & 484.00 \\
\hline $\mathrm{P}_{4}$ & Partición 4 & 483.50 \\
\hline $\mathrm{P}_{5}$ & Partición 5 & 484.00 \\
\hline $\mathrm{P}_{6}$ & Partición 6 & 490.79 \\
\hline $\mathrm{P}_{7}$ & Partición 7 & 491.61 \\
\hline
\end{tabular}

Fuente de Consulta:

(No deberán ser imágenes, todo debe ser editable)

Figura 1.1 Título

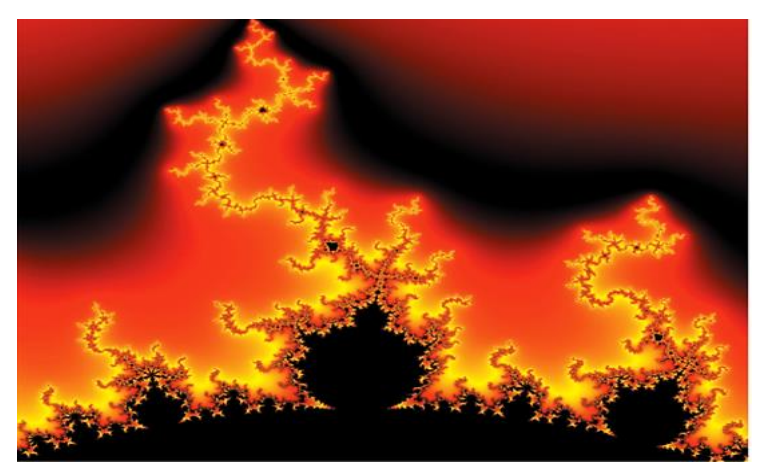

Fuente de Consulta:

(No deberán ser imágenes, todo debe ser editable) 
Gráfico 1.1 Título

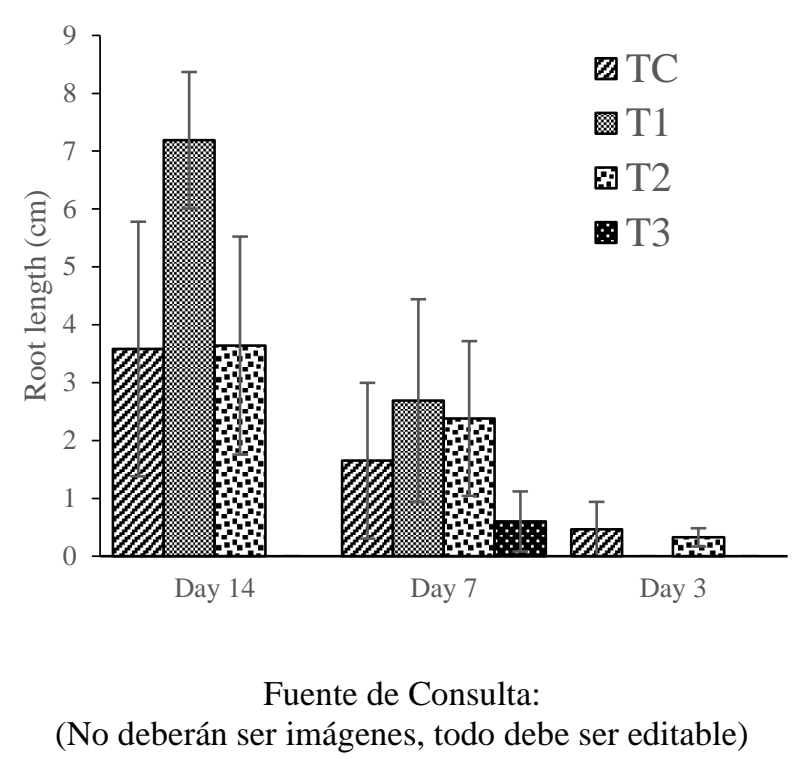

Cada Capítulo deberá presentar de manera separada en 3 Carpetas: a) Figuras, b) Gráficos y c) Tablas en formato .JPG, indicando el número en Negrita y el Titulo secuencial.

Para el uso de Ecuaciones, señalar de la siguiente forma:

$\int_{\lim ^{-1}}^{\lim ^{1}}=\int \frac{\lim ^{1}}{\lim ^{-1}}=\left[\frac{1(-1)}{\lim }\right]^{2}=\frac{(0)^{2}}{\lim }=\sqrt{\lim }=0=0 \rightarrow \propto$

Deberán ser editables y con numeración alineada en el extremo derecho.

\section{Metodología a desarrollar}

Dar el significado de las variables en redacción lineal y es importante la comparación de los criterios usados.

\section{Resultados}

Los resultados deberán ser por sección del Capítulo.

\section{Anexos}

Tablas y fuentes adecuadas.

\section{Agradecimiento}

Indicar si fueron financiados por alguna Institución, Universidad o Empresa.

\section{Conclusiones}

Explicar con claridad los resultados obtenidos y las posibilidades de mejora.

\section{Referencias}

Utilizar sistema APA. No deben estar numerados, tampoco con viñetas, sin embargo, en caso necesario de numerar será porque se hace referencia o mención en alguna parte del Capítulo. 


\section{Ficha Técnica}

Cada Capítulo deberá presentar en un documento Word (.docx):

Nombre del Books

Título del Capítulo

Abstract

Keywords

Secciones del Capítulo, por ejemplo:

1. Introducción

2. Descripción del método

3. Análisis a partir de la regresión por curva de demanda

4. Resultados

5. Agradecimiento

6. Conclusiones

7. Referencias

Nombre de Autor (es)

Correo Electrónico de Correspondencia al Autor

Referencias

Requerimientos de Propiedad Intelectual para su edición:

- Firma Autógrafa en Color Azul del Formato de Originalidad del Autor y Coautores

- Firma Autógrafa en Color Azul del Formato de Aceptación del Autor y Coautores 


\section{Reserva a la Política Editorial}

ECORFAN Books se reserva el derecho de hacer los cambios editoriales requeridos para adecuar la Obra Científica a la Política Editorial del ECORFAN Books. Una vez aceptada la Obra Científica en su versión final, el ECORFAN Books enviará al autor las pruebas para su revisión. ECORFAN® únicamente aceptará la corrección de erratas y errores u omisiones provenientes del proceso de edición de la revista reservándose en su totalidad los derechos de autor y difusión de contenido. No se aceptarán supresiones, sustituciones o añadidos que alteren la formación de la Obra Científica.

\section{Código de Ética - Buenas Prácticas y Declaratoria de Solución a Conflictos Editoriales}

Declaración de Originalidad y carácter inédito de la Obra Científica, de Autoría, sobre la obtención de datos e interpretación de resultados, Agradecimientos, Conflicto de intereses, Cesión de derechos y distribución.

La Dirección de ECORFAN-México, S.C reivindica a los Autores de la Obra Científica que su contenido debe ser original, inédito y de contenido Científico, Tecnológico y de Innovación para someterlo a evaluación.

Los Autores firmantes de la Obra Científica deben ser los mismos que han contribuido a su concepción, realización y desarrollo, así como a la obtención de los datos, la interpretación de los resultados, su redacción y revisión. El Autor de correspondencia de la Obra Científica propuesto requisitara el formulario que sigue a continuación.

Título de la Obra Científica:

- $\quad$ El envío de una Obra Científica a ECORFAN Books emana el compromiso del autor de no someterlo de manera simultánea a la consideración de otras publicaciones seriadas para ello deberá complementar el Formato de Originalidad para su Obra Científica, salvo que sea rechazado por el Comité de Arbitraje, podrá ser retirado.

- $\quad$ Ninguno de los datos presentados en esta Obra Científica ha sido plagiado y/o inventado. Los datos originales se distinguen claramente de los ya publicados. Y se tiene conocimiento del testeo en PLAGSCAN si se detecta un nivel de plagio Positivo no se procederá a arbitrar.

- Se citan las referencias en las que se basa la información contenida en la Obra Científica, así como las teorías y los datos procedentes de otras Obras Científicas previamente publicados.

Los autores firman el Formato de Autorización para que su Obra Científica se difunda por los medios que ECORFAN-México, S.C. en su Holding México considere pertinentes para divulgación y difusión de su Obra Científica cediendo sus Derechos de Obra Científica.

- Se ha obtenido el consentimiento de quienes han aportado datos no publicados obtenidos mediante comunicación verbal o escrita, y se identifican adecuadamente dicha comunicación y autoría.

El Autor y Co-Autores que firman este trabajo han participado en su planificación, diseño y ejecución, así como en la interpretación de los resultados. Asimismo, revisaron críticamente el trabajo, aprobaron su versión final y están de acuerdo con su publicación.

- $\quad$ No se ha omitido ninguna firma responsable del trabajo y se satisfacen los criterios de Autoría Científica.

Los resultados de esta Obra Científica se han interpretado objetivamente. Cualquier resultado contrario al punto de vista de quienes firman se expone y discute en la Obra Científica. 


\section{Copyright y Accesso}

La publicación de esta Obra Científica supone la cesión del copyright a ECORFAN-Mexico, S.C en su Holding México para su ECORFAN Books, que se reserva el derecho a distribuir en la Web la versión publicada de la Obra Científica y la puesta a disposición de la Obra Científica en este formato supone para sus Autores el cumplimiento de lo establecido en la Ley de Ciencia y Tecnología de los Estados Unidos Mexicanos, en lo relativo a la obligatoriedad de permitir el acceso a los resultados de Investigaciones Científicas.

Título de la Obra Científica:

\begin{tabular}{|l|l|}
\hline Nombre y apellidos del Autor de contacto y de los Coautores & Firma \\
\hline 1. & \\
\hline 2. & \\
\hline 3. & \\
\hline 4. & \\
\hline
\end{tabular}

\section{Principios de Ética y Declaratoria de Solución a Conflictos Editoriales}

\section{Responsabilidades del Editor}

El Editor se compromete a garantizar la confidencialidad del proceso de evaluación, no podrá revelar a los Árbitros la identidad de los Autores, tampoco podrá revelar la identidad de los Árbitros en ningún momento.

El Editor asume la responsabilidad de informar debidamente al Autor la fase del proceso editorial en que se encuentra el texto enviado, así como de las resoluciones del arbitraje a Doble Ciego.

El Editor debe evaluar los manuscritos y su contenido intelectual sin distinción de raza, género, orientación sexual, creencias religiosas, origen étnico, nacionalidad, o la filosofía política de los Autores.

El Editor y su equipo de edición de los Holdings de ECORFAN® no divulgarán ninguna información sobre la Obra Científica enviado a cualquier persona que no sea el Autor correspondiente.

El Editor debe tomar decisiones justas e imparciales y garantizar un proceso de arbitraje por pares justa.

\section{Responsabilidades del Consejo Editorial}

La descripción de los procesos de revisión por pares es dado a conocer por el Consejo Editorial con el fin de que los Autores conozcan cuáles son los criterios de evaluación y estará siempre dispuesto a justificar cualquier controversia en el proceso de evaluación. En caso de Detección de Plagio a la Obra Científica el Comité notifica a los Autores por Violación al Derecho de Autoría Científica, Tecnológica y de Innovación.

\section{Responsabilidades del Comité Arbitral}

Los Árbitros se comprometen a notificar sobre cualquier conducta no ética por parte de los Autores y señalar toda la información que pueda ser motivo para rechazar la publicación de la Obra Científica.

Además, deben comprometerse a mantener de manera confidencial la información relacionada con la Obra Científica que evalúan.

Cualquier manuscrito recibido para su arbitraje debe ser tratado como documento confidencial, no se debe mostrar o discutir con otros expertos, excepto con autorización del Editor.

Los Árbitros se deben conducir de manera objetiva, toda crítica personal al Autor es inapropiada. 
Los Árbitros deben expresar sus puntos de vista con claridad y con argumentos válidos que contribuyan al que hacer Científico, Tecnológica y de Innovación del Autor.

Los Árbitros no deben evaluar los manuscritos en los que tienen conflictos de intereses y que se hayan notificado al Editor antes de someter la Obra Científica a evaluación.

\section{Responsabilidades de los Autores}

Los Autores deben garantizar que sus Obras Científicas son producto de su trabajo original y que los datos han sido obtenidos de manera ética.

Los Autores deben garantizar no han sido previamente publicados o que no estén siendo considerados en otra publicación seriada.

Los Autores deben seguir estrictamente las normas para la publicación de Obra Científica definidas por el Consejo Editorial.

Los Autores deben considerar que el plagio en todas sus formas constituye una conducta no ética editorial y es inaceptable, en consecuencia, cualquier manuscrito que incurra en plagio será eliminado y no considerado para su publicación.

Los Autores deben citar las publicaciones que han sido influyentes en la naturaleza de la Obra Científica presentado a arbitraje.

\section{Servicios de Información}

\section{Indización - Bases y Repositorios}

- RESEARCH GATE (Alemania).

- MENDELEY (Gestor de Referencias bibliográficas).

- GOOGLE SCHOLAR (Índices de citaciones-Google).

- REDIB (Red Iberoamericana de Innovación y Conocimiento Científico-CSIC).

\section{Servicios Editoriales}

Identificación de Citación e Índice $\mathrm{H}$

Administración del Formato de Originalidad y Autorización

Testeo del T-Book con PLAGSCAN

Evaluación de Obra Científica

Emisión de Certificado de Arbitraje

Edición de Obra Científica

Maquetación Web

Indización y Repositorio

Publicación de Obra Científica

Certificado de Obra Científica

Facturación por Servicio de Edición

\section{Política Editorial y Administración}

143 - 50 Itzopan Calle. La Florida, Ecatepec Municipio México Estado, 55120 Código postal, MX. Tel: +52 $15520243918,+521556159$ 2296, +52 1554640 1298; Correo electrónico: contact@ecorfan.org www.ecorfan.org 


\section{ECORFAN®}

Editor en Jefe

VARGAS-DELGADO, Oscar. PhD

Directora Ejecutiva

RAMOS-ESCAMILLA, María. PhD

Director Editorial

PERALTA-CASTRO, Enrique. MsC

Diseñador Web

ESCAMILLA-BOUCHAN, Imelda. PhD

Diagramador Web

LUNA-SOTO, Vladimir. PhD

Asistente Editorial

TREJO-RAMOS, Iván. BsC

Traductor

DÍAZ-OCAMPO, Javier. BsC

Filóloga

RAMOS-ARANCIBIA, Alejandra. BsC

Editores Asociados

OLIVES-MALDONADO, Carlos. MsC

MIRANDA-GARCIA, Marta. PhD

CHIATCHOUA, Cesaire. PhD

SUYO-CRUZ, Gabriel. PhD

CENTENO-ROA, Ramona. MsC

ZAPATA-MONTES, Nery Javier. PhD

ALAS-SOLA, Gilberto Américo. PhD

MARTÍNEZ-HERRERA, Erick Obed. MsC

ILUNGA-MBUYAMBA, Elisée. MsC

IGLESIAS-SUAREZ, Fernando. MsC

FUENTES-RODRÍGUEZ, Germán. MsC

\section{Publicidad y Patrocinio}

(ECORFAN®- Mexico- Bolivia- Spain- Ecuador- Cameroon- Colombia- El Salvador- GuatemalaNicaragua- Peru- Paraguay- Democratic Republic of The Congo- Taiwan), sponsorships@ecorfan.org

\section{Licencias del Sitio}

03-2010-032610094200-01-Para material impreso, 03-2010-031613323600-01-Para material electrónico, 03-2010-032610105200-01-Para material fotográfico, 03-2010-032610115700-14-Para Compilación de Datos, 04 -2010-031613323600-01-Para su página Web, 19502-Para la Indización Iberoamericana y del Caribe, 20-281 HB9-Para la Indización en América Latina en Ciencias Sociales y Humanidades, 671-Para la Indización en Revistas Científicas Electrónicas España y América Latina, 7045008-Para su divulgación y edición en el Ministerio de Educación y Cultura-España, 25409-Para su repositorio en la Biblioteca Universitaria-Madrid, 16258-Para su indexación en Dialnet, 20589-Para Indización en el Directorio en los países de Iberoamérica y el Caribe, 15048-Para el registro internacional de Congresos y Coloquios. financingprograms@ecorfan.org 


\section{Oficinas de Gestión}

244 Itzopan, Ecatepec de Morelos-México.

21 Santa Lucía, CP-5220. Libertadores -Sucre-Bolivia.

38 Matacerquillas, CP-28411. Moralzarzal -Madrid-España.

18 Marcial Romero, CP-241550. Avenue, Salinas 1 - Santa Elena-Ecuador.

1047 La Raza Avenue -Santa Ana, Cusco-Peru.

Boulevard de la Liberté, Immeuble Kassap, CP-5963.Akwa- Douala-Cameroon.

Southwest Avenue, San Sebastian - León-Nicaragua.

6593 Kinshasa 31 - Republique Démocratique du Congo.

San Quentin Avenue, R 1-17 Miralvalle - San Salvador-El Salvador.

16 Kilometro, American Highway, House Terra Alta, D7 Mixco Zona 1-Guatemala.

105 Alberdi Rivarola Captain, CP-2060. Luque City- Paraguay.

Distrito YongHe, Zhongxin, calle 69. Taipei-Taiwán

Calle 43 \# 30 -90 B. El Triunfo CP.50001. Bogotá-Colombia. 


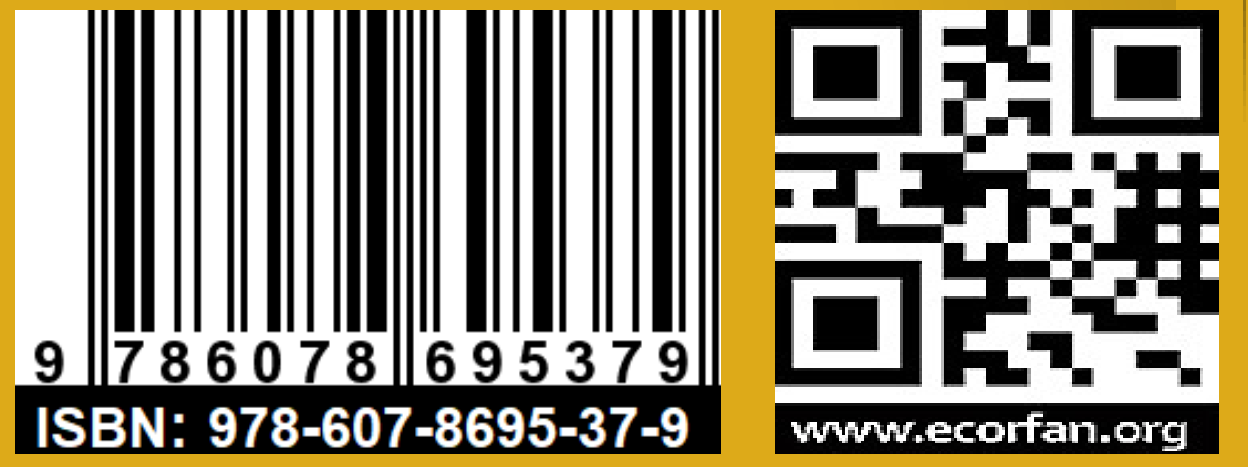

